\title{
Modelling DUne EVOLUTION AND DYNAMIC ROUGHNESS \\ IN RIVERS
}


Promotion committee:

prof. dr. F. Eising

prof. dr. S.J.M.H. Hulscher

University of Twente, chairman/secretary

dr. ir. C.M. Dohmen-Janssen

University of Twente, promotor

University of Twente, assistant-promotor

prof. dr. T. Hosoda

assoc. prof. S.E. Coleman

Kyoto University

University of Auckland

prof. dr. rer.-nat. S. Luding

University of Twente

prof. dr. ir. H.W.M. Hoeijmakers

University of Twente

prof. dr. ir. H.J. De Vriend

Delft University of Technology

dr. ir. J.M.T. Stam

Dutch Ministry of Public Works

This research is supported by:

The Technology Foundation STW, applied science division of NWO and the technology programme of the Ministry of Economic Affairs, the Netherlands (Project No. 06222).

Cover: Dunes during flood in the river IJssel, Deventer, the Netherlands. Design by Kim Brandwijk.

Typset in $\mathrm{H}_{\mathrm{A}} \mathrm{T} \mathrm{X}$

Copyright (c) 2008 by Andries Paarlberg, Enschede, the Netherlands

All rights reserved. No part of this publication may be reproduced, stored in a retrieval system, or transmitted, in any form or by any means, electronic, mechanical, photocopying, recording or otherwise, without written permission of the author.

Printed by Dratex, Lelystad, the Netherlands

ISBN 978-90-365-2674-6 


\title{
Modelling DUNE EVOLUTion AND DYNAMIC ROUGHNESS \\ IN RIVERS
}

\author{
PROEFSCHRIFT
}

ter verkrijging van

de graad van doctor aan de Universiteit Twente,

op gezag van de rector magnificus,

prof. dr. W.H.M. Zijm,

volgens besluit van het College voor Promoties

in het openbaar te verdedigen

op donderdag 28 augustus 2008 om 16:45 uur

door

Andries Jan Paarlberg

geboren op 7 maart 1980

te Alkmaar 
This thesis is approved by:

prof. dr. S.J.M.H. Hulscher promotor

dr. ir. C.M. Dohmen-Janssen assistant-promotor 


\section{Contents}

$\begin{array}{lr}\text { Preface } & 9\end{array}$

$\begin{array}{ll}\text { Summary } & 11\end{array}$

$\begin{array}{ll}\text { Samenvatting } & 13\end{array}$

1 Introduction $\quad 15$

1.1 Rivers and flood management . . . . . . . . . . . . . 15

1.2 River flow models and flow resistance . . . . . . . . . . . . 16

1.3 River dunes and associated flow resistance . . . . . . . . . . 17

1.3.1 River bed morphodynamics and river dunes characteristics 17

1.3.2 Form drag due to dunes . . . . . . . . . . . . . . . 19

1.3.3 Dynamic roughness due to dune evolution during floods . 21

1.4 Modelling dune evolution and dynamic roughness . . . . . . . 22

1.4.1 Existing approaches to model river dune evolution . . . . 22

1.4.2 Existing approaches to model (dynamic) roughness . . . . 25

1.5 Modelling dynamic roughness in rivers during floods . . . . . . 25

1.5.1 Problem formulation . . . . . . . . . . . . . . . 25

1.5.2 Research objective . . . . . . . . . . . . . . . 26

1.5.3 Research questions . . . . . . . . . . . . . . . . . 26

1.5.4 Research approach . . . . . . . . . . . . . . 26

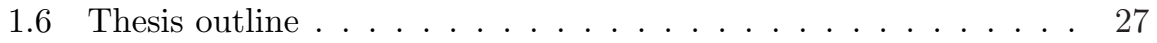

2 A parameterization of flow separation over subaqueous dunes 29

2.1 Introduction . . . . . . . . . . . . . . . . . . . . . 29

2.2 Flow separation . . . . . . . . . . . . . . . . . . . . 31

2.2 .1 Used data sets . . . . . . . . . . . . . . . . . . 31

2.2 .2 Shape of the flow separation zone . . . . . . . . . . 32

2.3 Parameterization of the separation streamline . . . . . . . 34

2.3.1 Determination of separation streamline . . . . . . . . 35

2.3.2 Determination of the flow reattachment point . . . . . . 36

2.3.3 Length of the flow separation zone . . . . . . . . . . . 37

2.3.4 Parameterization based on bedform properties . . . . . . 39

2.4 Discussion . . . . . . . . . . . . . . . . . . 42

2.4.1 Application of the parameterization in a 2-DV morpho-

dynamic model . . . . . . . . . . . . . . . . 42 
2.4.2 Application of the 2-DV parameterization to complex river dune configurations . . . . . . . . . . . . . 42

2.5 Conclusions . . . . . . . . . . . . . . . . . . . 44

3 Modelling river dune evolution using a parameterization of flow separation 45

3.1 Introduction . . . . . . . . . . . . . . . . . 45

3.2 Flow model . . . . . . . . . . . . . . . . . . . . . . . 48

3.2.1 Steady flow equations with hydrostatic pressure . . . . . 49

3.2.2 Boundary conditions . . . . . . . . . . . . . . 50

3.2.3 Flow separation criterion .............. 51

3.2.4 Parameterization of the separation streamline . . . . . . . 51

3.3 Sediment transport and bed evolution model . . . . . . . . . . 52

3.3.1 Bedload transport formula including bed-slope effects . . 52

3.3.2 Bed shear stress distribution in case of flow separation . . 54

3.3.3 Bed evolution . . . . . . . . . . . . . . 56

3.4 Parameter settings and calibration of the partial slip model . . . 57

3.5 Model results . . . . . . . . . . . . . . . . . 61

3.5.1 Flow field structure . . . . . . . . . . . . . 61

3.5.2 General model behaviour .............. . 61

3.5.3 Processes related to growth and saturation . . . . . . . 64

3.5.4 Comparison with various data sets . . . . . . . . . 68

3.5.5 Sensitivity analysis . . . . . . . . . . . . . . 69

3.6 Discussion . . . . . . . . . . . . . . . . . . . . . . . 72

3.7 Conclusions . . . . . . . . . . . . . . . . . . 74

Appendix A: Derivation of flow model . . . . . . . . . . . 76

4 Modelling dynamic roughness during floods 81

4.1 Introduction . . . . . . . . . . . . . . . . 81

4.2 Hydraulic model including dynamic roughness . . . . . . . . . . . . . 83

4.2.1 Hydraulic model Sobek . . . . . . . . . . . . . . . . 84

4.2 .2 Dune evolution model . . . . . . . . . . . . . . 85

4.2 .3 Roughness model . . . . . . . . . . . . . . . . 85

4.2.4 Method to determine dune length . . . . . . . . . . . 86

4.3 Model set-up and methodology for analysis . . . . . . . . . . . 88

4.3.1 Representative river Waal schematization . . . . . . . . 88

4.3.2 Flood wave scenario's . . . . . . . . . . . . 89

4.3.3 Comparison of Sobek models with different roughness formulations ......................... 89

4.4 Results of the extended Sobek model . . . . . . . . . . . . . . 93

4.4.1 Dune dynamics for sharp-peaked flood wave . . . . . . . . 93

4.4.2 Hysteresis effect in dune height . . . . . . . . . . . . . . . . 95

4.4.3 Effects of dune evolution on hydraulics . . . . . . . . . . . 97

4.5 Discussion . . . . . . . . . . . . . . . . . 100

4.6 Conclusions . . . . . . . . . . . . . . . 103 
5 Discussion $\mathbf{1 0 5}$

5.1 Justification of the modelling approach . . . . . . . . . . . . 105

5.1.1 Flow and sediment transport model . . . . . . . . . . . 105

5.1.2 Turbulence model and partial slip condition . . . . . . . . 106

5.1.3 Parameterization of flow separation . . . . . . . . . . 107

5.1.4 Dynamic roughness model . . . . . . . . . . . . 108

5.2 Model limitations for complex dune dynamics . . . . . . . . . . . 109

5.2.1 3-D flow and dune structures . . . . . . . . . . . . 109

5.2 .2 Non-uniform sediment dynamics . . . . . . . . . . . . 109

5.2 .3 Bedforms at different scales . . . . . . . . . . . . . 110

5.2.4 Dune initiation from flat bed and dune splitting . . . . . 111

5.3 Model application to natural river systems and other water systems 114

5.3.1 Deltaic low-land rivers with natural configurations . . . . 114

5.3 .2 Low flows . . . . . . . . . . . . . . . . 114

5.3.3 Offshore and estuarine systems . . . . . . . . . . 115

5.3.4 Opportunities to improve hydraulic simulation models . . 116

6 Conclusions and recommendations 117

6.1 Answers to the research questions . . . . . . . . . . . . . . . 117

6.2 Recommendations ................... 121

$\begin{array}{ll}\text { Bibliography } & 123\end{array}$

$\begin{array}{ll}\text { Nomenclature } & 137\end{array}$

$\begin{array}{lr}\text { List of publications } & 143\end{array}$

$\begin{array}{lr}\text { About the author } & 145\end{array}$ 



\section{Preface}

River dunes, that's what it's all about in this thesis. When I started this PhD research in November 2003, these bed patterns and their effects on the flow, were a puzzle to me. Unravelling the puzzle went with ups and downs, but I enjoyed the ride and I am happy with the final result. I could not have completed this thesis without the help of many people.

First of all my supervisors at the University of Twente: Suzanne Hulscher, Marjolein Dohmen-Janssen and Ralph Schielen. Sometimes I needed motivation... sometimes I needed to be slowed down. Suzanne always had a grip on the total picture, Marjolein was always able to motivate me and Ralph: your critical views from your experience on modelling alternating bars were always useful. HKV consultants provided me with a part-time working place and Paul Termes supervised me from HKV, providing many useful suggestions and knowledge from his past experiences with dunes.

This research has a strong link with the STW project 'Roughness modelling for managing natural shallow water systems' (Rough Water), for which Suzanne Hulscher received a VICI grant. Within this project, young researchers like me study or studied different aspects of roughness. Freek Huthoff just completed his research on vegetation resistance, Rolien van der Mark studies the effects of bedform stochastics upon bed roughness in rivers and seas, Daniëlle Noordam and later Jord Warmink study uncertainties in roughness modelling, Arjan Tuijnder investigates bedforms and morphological development in rivers, Mindert de Vries focusses on biogeomorphological aspects of bed roughness and Saskia Hommes' research is on the actual applicability of new river management techniques. Although I am not part of the Rough Water project, I was allowed to join the DRA(A)F meetings. I really enjoyed working closely with all of you!

I want to thank STW for funding the first four years of this research (project 06222). Also the financial contributions of HKV consultants are appreciated. The project was extended by six months, financed by STW and the Directorate Eastern Netherlands (DON) of the Dutch Ministry of Public Works. Although a period of six months does not seem very long, the extension was very fruitful, both for me and for the research; thanks Cor de Boer and Hendrik Havinga!

The STW user group was indispensable in this research. It's members were Cor de Boer, Hendrik Havinga, Erik Mosselman, Ralph Schielen, Arjan Sieben, Jean-Marie Stam, Paul Termes, Marijke Visser and Anne Wijbenga. Thank you for providing useful data and critically reviewing research results during the six-monthly user group meetings. I really enjoyed the meetings and they were very useful.

From October to December 2006, I was given the opportunity to visit two 
foreign research groups. Joost Lansink joined me on this experience within the framework of his final Master's project. First we went for a three day visit to the Urban Research group at the Kyoto University in Kyoto, Japan. Takashi Hosoda, Shinichiro Onda and the students, thanks for all your hospitality; we really enjoyed sharing not only research interests, but also the site-seeing and the times in bars and restaurants. Then we visited the Faculty of Engineering of the University of Auckland, New Zealand. Stephen Coleman and Heide Friedrich, we learned a lot from you guys and from the experimental work we did. One cannot simulate dune evolution without having seen dunes evolve in a flume. Thanks for the hospitality and for co-funding the experiments. Joost, thanks for your excellent help, enthusiasm, enjoying New Zealand while I was already on the way home and, of course, your fine graduation report.

The Water Engineering and Management (WEM) group of the University of Twente is a great group to do research. I have been given ample opportunities to improve my skills by following courses, giving lectures to students and attending conferences. Everyone was always available for advice and I want to thank you all for that. Special thanks to Arjan, Astrid, Bas, Blanca, Daniëlle, Denie, Fenneke, Freek, Jan Ribberink, Jebbe, Judith, Matthieu, Michiel, Pieter Roos, Pieter van Oel, René, Rolien and the secretaries Anke, Brigitte, Ellen, Hillie and Joke. From outside the group I want to thank Thijs Muizelaar for the help with $\mathrm{AT}_{\mathrm{E}} \mathrm{X}$, Joris van den Berg and Ruud van Damme for providing and helping to set-up the flow solver, and the IT support team. I want to thank all my HKV colleagues for showing interest in my research and helping me out with hydraulic or GIS issues.

I am grateful to the following people, either for providing data or having useful discussions: Steve McLean, Jim Best, Antoine Wilbers, Antoine Fourrière, Wim Uijttewaal, Orencio Durán, Attila Németh, Jeremy Venditti, Josh Wiebe, Gerrit Klaassen and Christian Winter. Mum, dad, thanks for supporting me during my study and these four and a half years. You were always available for advice. On my travels from Deventer to the University I was often accompanied by Dirk, Anne, Mark, Arjan and Rolien; it was often nice to have some company.

Pieter van Oel, you were on this journey with me right from the start, eventually even becoming roommates. It was quiet during the times you were in Brazil (fish don't speak that much... ) Jebbe van der Werf and Pieter van Oel, you will join me at the defence as my 'paranimfs', for which I am grateful.

Kim, the final words are for you, because only you deserve them. The past four and a half years went with ups and downs. It was you who pulled me through in completing this work. Slowly I realized that I should work to live, and not the other way around. We went living together in Deventer, together with Butchy and Milou, got married, and we are now living in Almere. Kim, thank you for your enduring patience. I hope to have you close to me for the rest of my life!

Andries Paarlberg

Almere, 20 Juli 2008. 


\section{Summary}

In sand-bed rivers, typically river dunes form due to interactions between the flow, the sediment transport and the bed morphology. Dune evolution during floods often shows a hysteresis, with different dune heights at the same discharge during the rising and falling stage of a flood wave. Flow resistance in the main channel of a river is mainly controlled by dune dimensions due to flow separation in the dune lee. Therefore, the hysteresis in dune height also appears in the behaviour of the roughness coefficients during floods, leading to a dynamic roughness. Due to limited knowledge on this dynamic roughness and computational limitations, the dynamic roughness behaviour is often not included in hydraulic simulation models. Instead, the roughness coefficient of the main channel is used as calibration parameter to match computed and observed water levels. Thus, hydraulic simulation models may yield incorrect water level predictions if they are applied to flood waves and discharges for which they were not calibrated.

The objective of this research is to develop a simulation model of dynamic roughness due to river dune evolution, which can be applied in hydraulic simulation models at flood wave time scales. The proposed dynamic roughness model consists of two parts: (1) a process-based river dune evolution model that requires limited computational effort, and (2) an empirical roughness predictor to translate computed dune dimensions into a resistance coefficient.

In this thesis a river dune evolution model is presented, which is able to predict important characteristics of river dune evolution, such as dune asymmetry, dune growth and saturation at a certain dune height. Dune dimensions, migration rates and times to equilibrium compare reasonably well with various flume data sets. The flow model solves the shallow water equations in a vertical plane (2-DV) using hydrostatic pressure conditions. As a basic turbulence closure, the eddy viscosity is taken constant over the water depth and a partial slip condition is used to correctly represent bed shear stresses. The sediment transport is modelled using a Meyer-Peter Müller type of formulation that includes gravitational bed-slope effects.

To avoid the necessity of modelling complex flow dynamics in the flow separation zone and enabling to treat the flow as hydrostatic, we include flow separation in a parameterized way. The separation streamline, which is the upper boundary of the flow separation zone, is parameterized as a third-order polynomial function using experimental data of turbulent flow over subaqueous bedforms. The coefficients of the polynomial are determined by the bedform height and bed slope at the flow separation point, and a fixed angle of the separation 
streamline at the flow reattachment point. In the dune evolution model, the separation streamline forms an artificial bed in the region of flow separation. The sediment transport in the flow separation zone is assumed to be zero and sediment passing the flow separation point is assumed to avalanche down the leeside of the dune. The shear stress distribution over the stoss-side of a dune is parameterized such that it increases from the critical stress at reattachment to a maximum value in the vicinity of the dune crest.

The dune evolution model is calibrated and verified using flume experiment data for migrating dunes. Model results show that bed-slope effects play a crucial role in the determination of the fastest growing wave length from a linear analysis. The fastest growing wave length is found to scale with the average water depth. Flow separation is shown to be crucial to take into account for modelling dune evolution: if flow separation is not included, dune shapes are incorrectly predicted and the dune height saturates at an early stage of bedform evolution, yielding an underprediction of dune height and time to equilibrium. The local bed slope at the dune crest, which is not necessarily zero in case of flow separation, also plays a crucial role to obtain saturation at an equilibrium dune height.

A dynamic roughness model is constructed based on the river dune evolution model and the roughness predictor of Van Rijn (1984). This dynamic roughness model can be coupled with hydraulic simulation models to simulate water levels in natural river settings, explicitly taking the time-evolution of river dunes into account. In this thesis, the dynamic roughness model is coupled with the 1-dimensional hydraulic simulation model SoBEK. Simulation results show a hysteresis in dune height, especially when the dune length significantly varies during a flood wave. The hysteresis effect is larger for broad-peaked flood waves than for sharp-peaked flood waves, since the relatively long period of high river discharge gives the dunes ample time to increase in height. The hysteresis effect in dune height clearly results in a hysteresis in flow resistance, with $5-10 \%$ lower Chézy coefficients (higher roughness) and larger flow depths during the falling stage of the flood wave than during the rising stage. This emphasizes the importance of the flood wave shape for dune evolution and thus roughness predictions. This aspect is not taken into account if roughness coefficients are calibrated as a function of discharge, as is done in current practice.

Dune dynamics and associated hysteresis effects can be excluded from calibrated roughness coefficients of hydraulic simulation models by using the dynamic roughness model of this thesis. In this way, the simulation models may better represent different flood wave shapes. Moreover, since the dune evolution model is process-based, it can be applied with more confidence to extreme discharges than a model using calibrated roughness coefficients. 


\section{Samenvatting}

Op zandige rivierbodems vormen zich bodempatronen, ofwel rivierduinen, als gevolg van interacties tussen stroming, sedimenttransport en morfologie. Deze rivierduinen beïnvloeden de stromingsweerstand, en dus waterstanden, van de rivier; hogere en langere duinen veroorzaken meer weerstand dan lagere en kortere duinen. Tijdens hoogwater vertoont de duinontwikkeling vaak een hysterese, met verschillende duinafmetingen bij dezelfde rivierafvoer tijdens de was en de val van het hoogwater. Dit hysterese effect beïnvloedt ook de stromingsweerstand, wat leidt tot een dynamische ruwheid. Omdat er relatief weinig kennis is over dynamische ruwheid en omdat het rekentechnisch moeilijk is te voorspellen, wordt dit gedrag vaak nog niet meegenomen in waterbewegingsmodellen. In plaats daarvan worden de ruwheidscoefficienten van de hoofdgeul vaak als parameter gebruikt om berekende en gemeten waterstanden aan elkaar te matchen. Dit betekent dat waterbewegingsmodellen verkeerde uitkomsten kunnen geven wanneer ze worden toegepast voor hoogwaters en afvoeren waarvoor ze niet zijn afgeregeld.

Het doel van dit onderzoek is om een rekenmodel voor dynamische ruwheid als gevolg van duinvorming te ontwikkelen, dat kan worden gebruikt in waterbewegingsmodellen op hoogwater tijdschalen (weken). Het voorgestelde dynamisch ruwheidsmodel bestaat uit twee delen: (1) een proces-gebaseerd duinontwikkelingsmodel dat relatief weinig rekentijd behoeft, en (2) een empirische relatie die voorspelde duindimensies in een ruwheidswaarde vertaald.

In dit proefschrift wordt een duinontwikkelingsmodel gepresenteerd dat in staat is om belangrijke karakteristieken van duinvorming te voorspellen, zoals duin asymmetrie, duingroei en saturatie op een bepaalde duinhoogte. Duindimensies, verplaatsingssnelheden en de tijd die het duurt voordat evenwichtsdimensies worden bereikt vergelijken redelijk goed met metingen in stroomgoten. Het stromingsmodel lost de ondiepwatervergelijkingen in een verticaal vlak (2-DV) op, gebruik makend van hydrostatische druk condities. De eddy viscositeit is constant genomen over de waterdiepte en er wordt een kleine snelheid aan de bodem toegestaan om bodemschuifspanningen correct te representeren. Het sedimenttransport wordt berekend met een Meyer-Peter Müller formulering waarin bodemhellingseffecten worden gemodelleerd.

Stromingsloslating achter steile duinen wordt geparameteriseerd om te voorkomen dat de complexe stromingsdynamica in de stromingsloslaatzone berekend moet worden. De separatie-stroomlijn, de bovengrens van de stromingsloslaatzone, wordt weergegeven met een derdegraads polynoom functie, welke is gebaseerd op experimentele data van turbulente stroming over rivierduinen. De 
coefficiënten van de polynoom worden bepaald door de duinhoogte en bodemhelling op het stromingsloslaatpunt en een vaste hoek van de separatie-stroomlijn op de locatie waar de stroming weer aanhecht. In het duinontwikkelingsmodel fungeert de separatie-stroomlijn als een artificiële bodem in het gebied van stromingsloslating. In het geval van stromingsloslating wordt het sedimenttransport in de loslaatzone gelijk aan nul verondersteld en wordt het sediment dat het loslaatpunt passeert gelijkmatig afgezet op de lijzijde van het duin. De bodemschuifspanningsverdeling over de loefzijde van een duin wordt zo geparameteriseerd dat de bodemschuifspanning toeneemt van de kritische waarde op het stromingsaanhechtpunt tot een maximum in de nabijheid van de duintop.

Het duinontwikkelingsmodel is gekalibreerd en geverifieerd met stroomgoot metingen voor migrerende duinen. Modelresultaten tonen aan dat bodemhellingseffecten een cruciale rol spelen bij de bepaling van de snelst-groeiende duinlengte in een lineaire stabiliteitsanalyse. De snelstgroeiende duinlengte schaalt met de gemiddelde waterdiepte. Stromingsloslating is cruciaal om te beschouwen wanneer de duin lijzijde een bepaalde steilheid overschrijdt. Wanneer stromingsloslating wordt genegeerd, wordt de duinvorm verkeerd voorspeld en satureert de duinhoogte in een te vroeg stadium, wat leidt tot een onderschatting van de duinhoogte en tijd tot evenwicht. De lokale bodemhelling bij de duintop, die niet noodzakelijk nul is in geval van stromingsloslating, speelt ook een belangrijke rol bij de voorspelling van een juiste evenwichtsduinhoogte.

In dit proefschrift is een dynamisch ruwheidsmodel ontwikkeld door het duinontwikkelingsmodel te koppelen met de ruwheidsvoorspeller van Van Rijn (1984). Het dynamisch ruwheidsmodel kan worden gekoppeld met waterbewegingsmodellen om waterstanden in rivieren te voorspellen, door de tijd ontwikkeling van duinen expliciet te beschouwen in de berekeningen. In dit proefschrift is het dynamisch ruwheidsmodel gekoppeld met het 1-dimensionale waterbewegingsmodel SoBeK. Resultaten laten zien dat het hysterese effect in duinhoogte vooral optreedt wanneer de duinlengte sterk varieert tijdens een hoogwater. Het hysterese effect is groter voor een hoogwater met een brede piek dan met een smalle piek, omdat de duinen ruim de tijd krijgen om hoger te worden tijdens de lange periode van hoge rivierafvoer. Er ontstaat ook een hysterese in ruwheidswaarden, met 5-10\% lagere Chézy coefficiënten (hogere ruwheid) en grotere waterdieptes tijdens de val van het hoogwater dan tijdens de was van het hoogwater. Dit benadrukt het belang van de vorm van het hoogwater voor duinontwikkeling en ruwheid. Dit aspect wordt niet beschouwd wanneer de ruwheidswaarden gekalibreerd worden als een directe functie van de rivierafvoer, zoals in de huidige praktijk wordt gedaan.

Duindynamica en gerelateerde hysterese effecten kunnen worden geëlimineerd uit gekalibreerde ruwheidswaarden van waterbewegingsmodellen, door het dynamisch ruwheidsmodel uit dit proefschrift te gebruiken. Op deze manier kan de waterbeweging als gevolg van verschillende vormen hoogwaters beter voorspeld worden. Bovendien kunnen de modellen dan met meer zekerheid voor extreme afvoeren worden toegepast dan een model met gekalibreerde ruwheden, omdat het duinontwikkelingsmodel proces-georiënteerd is. 


\section{Chapter 1}

\section{Introduction}

\subsection{Rivers and flood management}

A world without rivers is hard to imagine. They supply us with fresh drinking water, are used as navigation channels, and transport water, ice and sediments to seas or inland waters. Characteristics of rivers vary strongly from place to place. In mountain areas rivers have steep slopes and the river bed consists of coarse sediments. In relatively flat areas such as the Netherlands, we find typical lowland rivers characterized by mild slopes, high dikes, wide floodplains and the river bed consists of sand or fine gravel.

Because of their fertile soils due to frequent inundation of the surrounding lands of rivers, many people live close to them. Heavy rainfall or snow melt in the catchment area of a river can result in periods of high river discharge and may cause inundation of land (Fig. 1.1), resulting in damage to homes, businesses, live stock or other properties and possibly loss of life. To prevent rivers from flooding, for centuries, rivers are regulated with dikes to increase the safety for people and their properties. In 1926, severe floods occurred along the Dutch rivers, causing significant financial damage. More recently, critical water levels were reached in 1993, 1995 and 1998, leading to the evacuation of 250.000 people in one week in 1995 (Bezuyen et al., 1995). These recent events have led to a shift in flood management in the Netherlands. Next to strengthening dikes, the discharge capacity of rivers is increased by river restoration projects, such as widening and lowering of floodplains and the construction of flood channels.

In the Netherlands, it is established by law $^{1}$ that the expected water levels, corresponding to the design discharge, have to be determined every five years (Ministerie van Verkeer en Waterstaat, 2007). The design discharge of the river Rhine is a discharge with a probability of occurrence of $1 / 1250$ and serves as guideline to design flood protection measures. Currently, the design discharge of the river Rhine is determined as $16,000 \mathrm{~m}^{3} \mathrm{~s}^{-1}$, based on a statistical analysis of historical discharge data; for the river Meuse, the design discharge is 3,800 $\mathrm{m}^{3} \mathrm{~s}^{-1}$. In general practice (i.e. not established by law), changes in the river system are not allowed if they lead to a more than $1 \mathrm{~mm}$ water level increase at the design discharge.

To enable proper management of our river systems, river flow models are

${ }^{1}$ article 4 of the Dutch "Flood Protection Act" (Wet op de waterkering) 


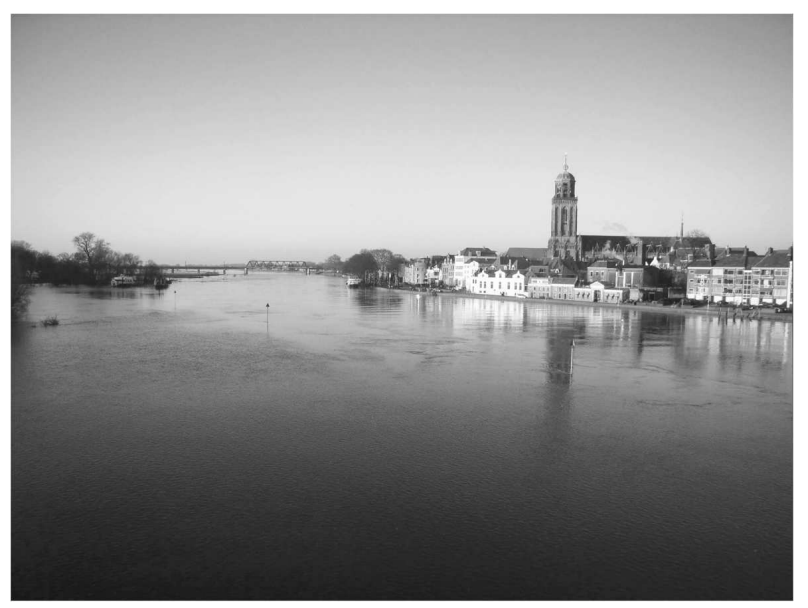

Figure 1.1: High discharge event in the river IJssel at Deventer on 16 december 2007 (discharge at Lobith was $4,500 \mathrm{~m}^{3} \mathrm{~s}^{-1}$ and the local water level was $5.45 \mathrm{~m}+\mathrm{NAP}$ ). The beacons on the picture are located on groynes which are currently below the water surface. At the right bank, the water level is almost at the level of the levees and the floodplain on the left is inundated.

required to provide water level predictions. In the Netherlands, the hydraulic simulation models WAQUA (developed by Rijkswaterstaat) and SoBEK (developed by Rijkswaterstaat and WL | Delft Hydraulics) are available for this purpose. These hydraulic simulation models are tools for water managers to verify if our flood defence system is adequate, by determining water levels at the design discharge (e.g. Van der Veen et al., 2002a,b; Udo et al., 2007). The simulation models are also useful to predict water levels during floods and to determine the effects of changes to the river system.

\subsection{River flow models and flow resistance}

River flows are influenced by the presence of elements protruding into the flow. These elements cause flow resistance by generating mixing patterns that feed on energy from the mean flow, effectively slowing it down and causing higher water levels at a certain discharge. Examples are grains and bedforms on the river bed, groynes, constructions or vegetation in the floodplains, and large-scale channel irregularities. A river flow model that takes all these flow resistance components directly into account, has to solve mixing patterns at all associated scales (i.e. from Kolmogorov time and spatial scales to complete river reaches). At present, this is not feasible at river-reach spatial scales and flood wave time scales, partly due to the required computational effort and partly due to insufficient knowledge on the processes involved. Therefore, practical hydraulic simulation models do not explicitly describe all flow resistance components.

There are several sources of uncertainties in hydraulic simulation models, 
ranging from e.g. river geometry and resistance coefficients, to the numerical model itself (Noordam, 2006; Warmink et al., 2007; Paarlberg, 2007). Outputs of hydraulic simulation models are especially sensitive to the resistance coefficients of the main channel and the floodplains (Van der Klis, 2003; Casas et al., 2006; Vidal et al., 2007). Therefore, resistance coefficients are often used as calibration parameters to match observed and computed water levels and discharges (e.g. Wijbenga et al., 1998; Udo et al., 2007). Effectively, this means that resistance coefficients in hydraulic models represent neglected energy losses and our lack of knowledge (Morvan et al., 2008); the calibrated resistance coefficients no longer have a strict physical meaning. Moreover, hydraulic models that use calibrated resistance coefficients could lead to inaccurate water level predictions, if they are applied to situations for which the model was not calibrated. This may lead to either unnecessary measures to the flood defence system or to flood damage.

Over the past decades, hydraulic modelling of river flows greatly improved, partly because of increasing computational power and measurement techniques and partly due to new insights into flow resistance. Examples are related to the characterization of floodplain vegetation and modelling its resistance (e.g. Van Velzen et al., 2003; Huthoff, 2007; Huthoff et al., 2007) or modelling groynes (e.g. Yossef, 2005).

According to Best (2005), dunes are present in nearly all fluvial channels and are vital in predicting flow resistance in rivers. In addition, several field studies revealed complex dune behaviour and associated flow resistance during floods (e.g. Julien et al., 2002; Wilbers \& Ten Brinke, 2003). At present, no suitable method is available to incorporate the effects of dunes and associated flow resistance due to floods in hydraulic simulation models. Developing such a method is the central theme in this thesis. Section 1.3 describes dune dynamics and associated flow resistance from a phenomenological point of view, while Section 1.4 focusses on existing approaches to model these aspects. The research objectives, the modelling framework that is applied in this thesis, and the research questions are formulated in Section 1.5.

\subsection{River dunes and associated flow resistance}

\subsubsection{River bed morphodynamics and river dunes characteristics}

In rivers, complex interactions between the turbulent flow, the sediment transport and the bed morphology give rise to various types of river bed configurations. According to the flow regime, the river bed can be either plane or covered by ripples, dunes, or anti-dunes. The distinction between ripples and dunes is that river dunes interact with the free-surface, with the water surface profile being out-of-phase with the bed profile. In many rivers, dunes wash out towards an upper-stage plane bed as the discharge and the bed shear stresses increase (e.g. Simons \& Richardson, 1966; Ashworth et al., 2000 and references therein; Prent \& Hickin, 2001). Upper-stage plane beds are associated with relatively large transport rates of both bed load and suspended load (Bennett et al., 1998) 


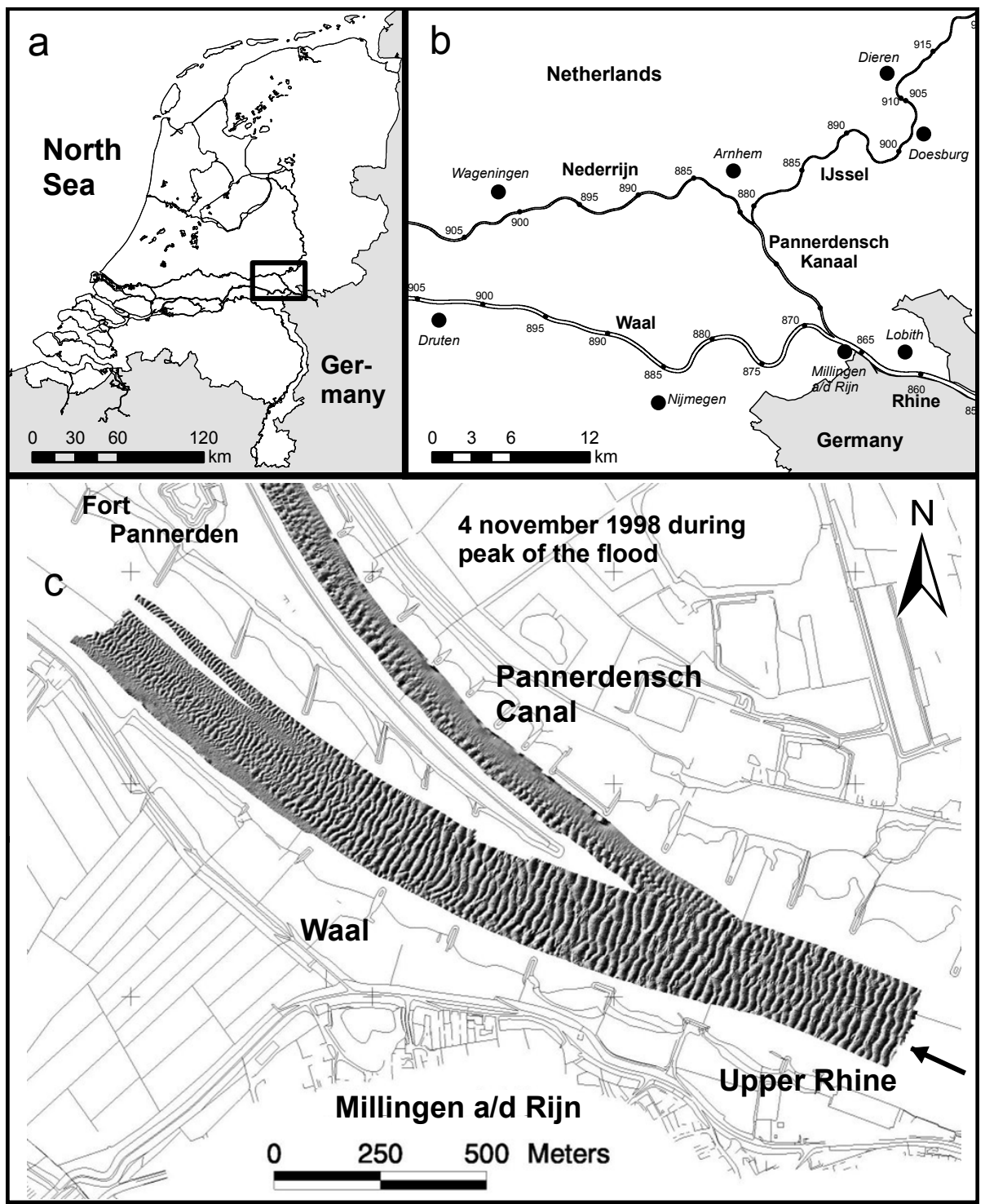

Figure 1.2: Measurements of dunes at the Pannerdensche Kop bifurcation in the river Rhine. (a) location in the Netherlands; (b) major river branches of the river Rhine; (c) detailed multibeam measurements during peak of the 1998 flood, with dune heights of 1-2 $\mathrm{m}$ and lengths of up to $50 \mathrm{~m}$ in an average flow depth of about $10 \mathrm{~m}$ (picture courtesy (c): Antoine Wilbers). 


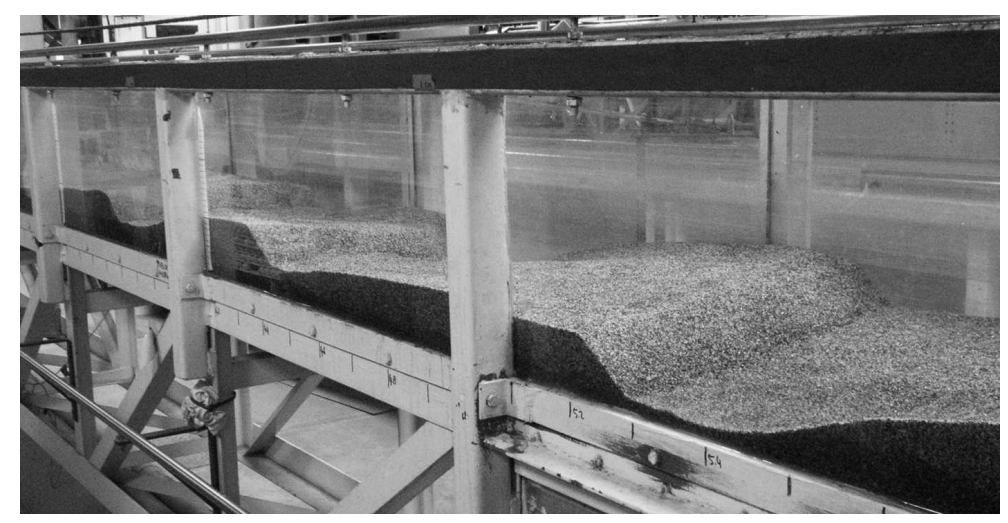

Figure 1.3: Dunes formed in a laboratory channel at the University of Auckland (Friedrich et al., 2007). Steady flow was from left to right. It was visually confirmed that there was flow separation present in the dune lees.

and do not necessarily require supercritical flow conditions.

In sandy or gravel-bed rivers, with subcritical turbulent flow, typically river dunes form (e.g. Simons \& Richardson, 1963; Allen, 1968a, Roden, 1998; Carling et al., 2000a; Wilbers \& Ten Brinke, 2003, see also Fig. 1.2; Best, 2005). Figure 1.3 gives an example of a train of dunes formed in a laboratory channel under steady flow conditions and Figure 1.4 illustrates their typical shape. The stoss-side of dunes is gentle, while avalanching at the leeside results in a dune with a brinkpoint and a slope at the angle of repose which is about $-30^{\circ}$ for sand in rivers. Dunes migrate in downstream direction because sediment is eroded at the stoss-side of the dune and deposited at the leeside of the dune.

Many field measurements and flume studies have shown that in steady flows, the dune height is about one-third of the water depth and the dune length about 6 times the water depth. For unsteady flow conditions, measurements in the river Rhine show heights of 10-30\% of the flow depth and lengths of 1-8 times the flow depth (Wilbers \& Ten Brinke, 2003). The migration rate of dunes depends on both dune dimensions and flow strength. Additionally, flume and field measurements have revealed that dune fields are often complex, where the equilibrium is actually dynamic with continuous splitting and merging of dunes at different spatial scales (e.g. Driegen, 1986; Julien et al., 2002; Wilbers \& Ten Brinke, 2003; Jerolmack \& Mohrig, 2005). Moreover, dune fields often show 3-dimensional (3-D) structures, such as amplitude variations or crestline curvature (e.g. Allen, 1968b; Best, 2005; Parsons et al., 2005).

\subsubsection{Form drag due to dunes}

Einstein (1950) and Einstein \& Barbarossa (1952) introduced the concept to split flow resistance caused by dunes into a skin friction and a from drag component, with the former often related to the grain size of the bed material and the latter to flow separation behind the dunes. If dunes are not present, the 


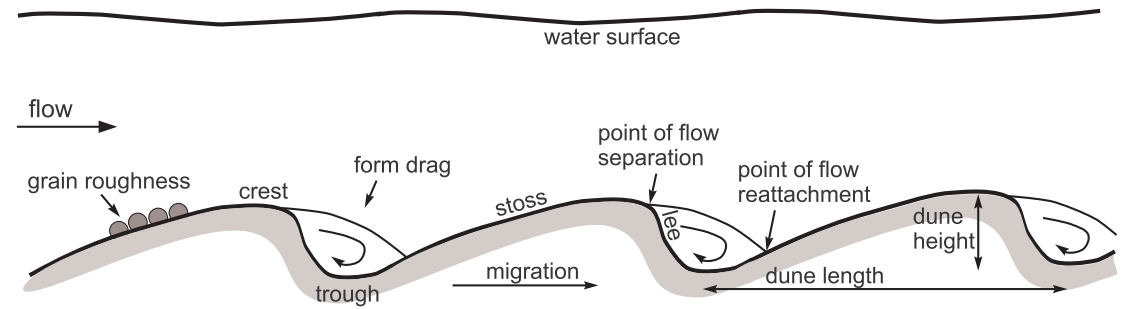

Figure 1.4: Sketch of a train of dunes with the water surface profile out-of-phase with the bed topography. Often used definitions for dune dimensions are indicated.

flow resistance of the main channel is almost fully determined by skin friction, while if dunes are present they introduce additional drag due to their typical shape (Fig. 1.4).

Due to the interaction between unidirectional flow in rivers and the sediment transport, sinusoidal bedforms develop into asymmetric dunes with gentle stosssides and steep leesides, as explained by Exner (see Leliavsky, 1955, p. 24-26). This means that due to the sudden expansion of the flow behind a dune, the static pressure increases in the direction of the flow (i.e. there exists an adverse pressure gradient). For a large enough pressure increase, the flow velocity near the boundary may become zero or even become reversed. Thus, eventually, if the leeside of a dune becomes so steep that the boundary layer encounters a sufficiently large adverse pressure gradient, it separates from the boundary under the formation of eddies or vortices (see e.g. Chang, 1970; Buckles et al., 1984).

Effectively, over well-developed dunes, a flow separation zone is formed with a recirculating eddy in the dune lee (Fig. 1.4). The turbulence (eddies) generated in the flow separation zone slows the flow down. This process is often referred to as form drag and can be regarded as an additional roughness due to dunes. The amount of turbulence (and thus roughness) caused by flow over dunes is expected to be related to general flow conditions and the shape and size of the flow separation zone. Thus, because of flow separation and associated energy dissipation, dunes significantly influence flow resistance (e.g. Vanoni \& Hwang, 1967; Ogink, 1988; Wijbenga, 1990; Julien et al., 2002).

Complex dune shapes influence the flow resistance of dunes. Allen (1968b) illustrated flow patterns over 3-D dunes revealing complex flow separation zone dynamics due to generated vorticity and convergence and divergence of flow. Venditti (2007) and Maddux et al. (2003a,b) showed that the flow field over simple regular 3-D dunes is significantly different from that over 2-D dunes. In addition, Fernandez et al. (2006) showed that bedform superimposition and amalgation of dunes significantly alters turbulence structures in the flow field and thus flow resistance. 

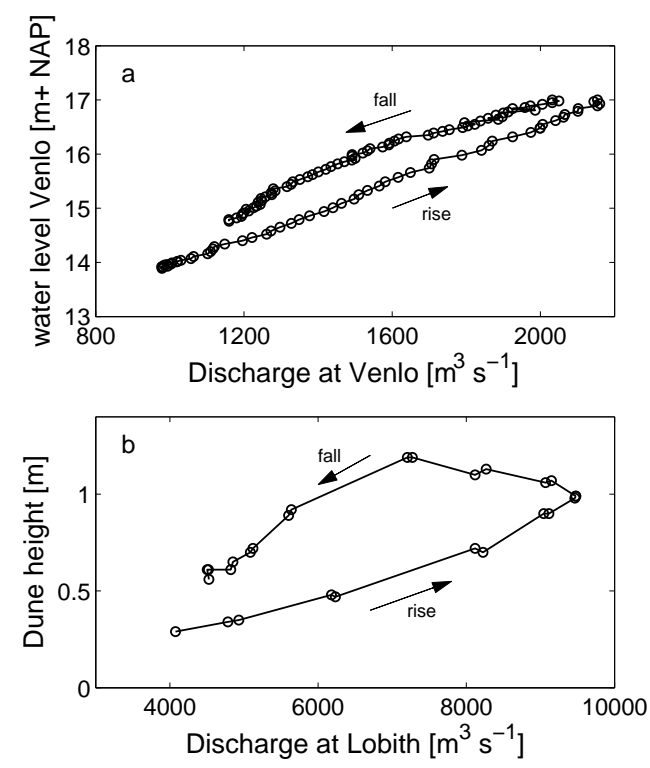

Figure 1.5: (a) Hysteresis in water level in the river Meuse at Venlo during the February 2002 flood (Termes, 2004). NAP is a Dutch ordinance datum. (b) Hysteresis in dune height in the river Rhine near the Pannerdensche Kop during the 1998 flood (data from Directorate Eastern Netherlands (DON) and the Head Office of Rijkswaterstaat; see also Wilbers \& Ten Brinke, 2003).

\subsubsection{Dynamic roughness due to dune evolution during floods}

Figure 1.5a shows a hysteresis effect between water levels and discharge in the river Meuse in the Netherlands. At the same discharge, the water level is different for the rising and the falling stage of the flood wave. Part of this hysteresis is due to the unsteady character of a flood wave (i.e. the Jones effect, see Jansen et al., 1979). However, such a hysteresis effect is also related to dune dynamics during floods.

Measurements in the river Rhine in the Netherlands show a clear hysteresis between dune height and discharge (e.g. Fig. 1.5b; Julien \& Klaassen, 1995; Julien et al., 2002; Wilbers \& Ten Brinke, 2003). The existence of a hysteresis in dune height is also confirmed from flume experiments by e.g. Wijbenga \& Klaassen (1983) and Wijbenga \& Van Nes (1986).

Depending on the flood wave shape, dunes do not reach their maximum dimensions at the peak discharge, but a little later (Fig. 1.5b). This delay occurs because it requires time for the dunes to adapt to the changing flow conditions by means of sediment transport. During the falling stage of a flood wave, the dunes are higher than at the same discharge during the rising stage (Fig. 1.5b). Observations have shown that flow resistance is out-of-phase with discharge, in a similar way as dunes are (e.g. Julien et al., 2002). This suggests that the main part of the hydraulic roughness of the river bed is determined by the size and 
shape of river dunes. Therefore, the hysteresis in dune height also appears in the behaviour of the roughness leading to a roughness with a dynamic character: dynamic roughness. The challenge is to include this dynamic roughness due to dune evolution in hydraulic simulation models to improve water level prediction of flood waves.

\subsection{Modelling dune evolution and dynamic roughness}

\subsubsection{Existing approaches to model river dune evolution}

The time-evolution of dunes has often been studied using laboratory flumes or theoretical models. This revealed a lot about the mechanics of dune formation (e.g. Kennedy, 1963, 1969; Reynolds, 1965; Coleman, 1991; Colombini, 2004) and about the initiation of dunes from a flat bed (e.g. Coleman \& Melville, 1996; Coleman et al., 2005, Venditti et al., 2005, Friedrich et al., 2007).

Under steady flow conditions, dunes can reach a steady state with dunes migrating in downstream direction without changing shape, if a balance between stabilizing and destabilizing effects is achieved (e.g. Fredsøe, 1982; Colombini, 2004). A lot of empirical research aimed to relate this steady state to a range of parameters like flow strength, flow depth or sediment size (e.g. Yalin, 1964; Allen, 1968b; Van Rijn, 1984; Julien \& Klaassen, 1995; Coleman et al., 2005). A major drawback of such empirical methods is that they are limited in application to ranges for which the methods are developed. Also, some theoretical derivations to predict equilibrium dune dimensions for steady flow conditions exist (e.g. Anderson, 1953; Yalin, 1972; Fredsøe, 1982; Karim, 1999). Since these methods are related to instantaneous flow conditions, they cannot treat dynamic roughness during floods.

Table 1.1 gives an overview of selected approaches available in literature to predict dune dimensions or the occurrence of dunes. These models are selected based on their potential for modelling the response of dunes to unsteady flows or the specific insights that the models offer into dune dynamics. Five approaches are distinguished: (1) empirical models, (2) models based on stability analysis techniques, (3) discrete particle models, (4) numerical models for flow over fixed dunes and (5) numerical morphodynamic models with migrating dunes.

The empirical models rely on the concept introduced by Allen (1976) (Tab. 1.1) and as a consequence, these methods heavily rely on equilibrium dune shape predictors designed for steady flows. Since these methods are data-driven, they are difficult to apply outside the calibration ranges. This explains, for example, why Wilbers (2004) needs different sub-models for different river branches.

Linear stability analysis techniques are often used to predict whether dunes will, or will not, occur for certain flow conditions (e.g. Kennedy, 1963; Engelund, 1970; Smith, 1970). To study dune evolution from initiation to fully grown dunes using stability methods, various attempts have been made to include nonlinear effects (Tab. 1.1). These models are typically developed for steady flows and flow separation and related physical processes are usually not taken into account.

Anderson (1990) and Werner (1995) used computer simulations to analyze 
Table 1.1: Overview of selected methods or approaches to model bedform dynamics.

\section{Empirical models including unsteady flow effects}

Allen (1976) Includes time-lag effects using an adaptation constant; dune dimensions do not instantaneously adapt to predicted equilibrium dimensions.

Miwa et al. (1999a,b) Applicable to both uniform and graded sediments. Requires

Wilbers (2004) Includes time-lag effects using approach of Allen (1976). Differusing equilibrium predictors for dune dimensions. ent models required for different rivers. Equilibrium predictors for dune dimensions are required.

\section{Models based on stability analysis techniques}

Kennedy (1963) Potential flow model over movable sinusoidal bedforms. Sediment transport is proportional to a power of the bed velocity.

Fredsøe (1979) Simulates response of individual dunes to sudden changes in discharge, based on shear stress similarity close to the dune top.

Yamaguchi \& Izumi Weakly non-linear analysis, based on 2-DV Reynolds equations (2002) and a force balance on sediment particles.

Zhou \& Mendoza (2005) Non-linear bedform growth model, able to predict dune evolution from initiation to equilibrium configurations.

3. Discrete particle models using stochastic elements

Anderson (1990) Self-organization model for aeolian ripple evolution. Based on calculation of sediment particle trajectories.

Niño et al. (2002) Algorithms representing the motion of individual grains show many aspects of the physics of bedforms.

Gallagher (2007) Simulation model capturing physics of offshore megaripples with flow separation by using stochastic rules.

4. Numerical hydrodynamic models for flow over fixed dunes

Yoon \& Patel (1996) Solves Reynolds-averaged Navier-Stokes equations, employing $k-\omega$ turbulence model.

Stansby \& Zhou (1998) Solves Reynolds-averaged Navier-Stokes equations, employing $k-\varepsilon$ turbulence model. Applies non-hydrostatic pressure in regions where its influence is significant.

Yue et al. (2006) Large-eddy simulation model, with the free surface approximated as a shear free boundary.

\section{Numerical morphodynamic models with migrating bedforms}

Onda \& Hosoda (2004) Depth-averaged Boussinesq-type flow equations, including deceleration and acceleration effects due to flow over wavy beds.

Jerolmack \& Mohrig Stochastic surface evolution model, using a non-linear relation(2005) ship between sediment flux and topography.

Tjerry \& Fredsøe (2005) Curvilinear flow model with $k-\varepsilon$ turbulence model, enabling to compute the shape and dimensions of individual dunes.

Giri \& Shimizu (2006) Non-hydrostatic flow model with the unsteady terms retained. Giri et al. (2007) applied this model to unsteady flows.

Németh et al. (2007); Numerical implementations of the Hulscher (1996)-model to pre-

Van den Berg (2007) dict evolution of offshore sandwaves. Uses hydrostatic shallow water equations, with constant eddy viscosity. Bed-slope effects are included in the bed load transport calculations.

Kroy et al. (2002) Morphodynamic model of aeolian dune dynamics using linearized flow equations and a parameterization of flow separation. 
the self-organization of wind ripples, employing stochastic algorithms representing grain dynamics. These early works were able to capture the rich dynamics of wind-blown bedforms and were later extended to a continuum model by Yizhaq et al. (2004). Niño et al. (2002) applied a similar approach to the prediction of subaqueous bedform evolution, showing good agreement with laboratory data. Also, Gallagher (2007) applied a discrete particle approach to model the evolution of offshore megaripples with flow separation. In all these simulation models, a shadow zone behind the bedforms mimics the role of flow separation and the dimensions of the flow separation zone are controlled by the impact angle of grains. However, the physical behaviour of the flow and the impact of flow separation on bedform dynamics are not described by this approach.

A wide range of simulation models of turbulent flow over rigid, non-erodible dunes are available in literature (Tab. 1.1). Only recently, increasing computational power has led to reliable numerical morphodynamic codes for the full cycle of bedform evolution (Nelson et al., 2005; Tjerry \& Fredsøe, 2005; Giri \& Shimizu, 2006), which are able to predict the time-evolution of dune dimensions, dune shapes and dune migration. Flow separation and related sediment transport processes are incorporated using complicated flow models that capture not only the mean properties of the flow but also the statistics. Therefore, these detailed and complicated models are yet unfeasible to predict dune evolution over the time scale of a flood wave.

To overcome these computational limitations, various approaches have been developed to predict river dune evolution using simplifications regarding solving the flow field over bedforms. Both the models of Onda \& Hosoda (2004) and Jerolmack \& Mohrig (2005) successfully simulated bedform evolution from initiation towards an equilibrium with bedforms of different scales continuously merging and splitting. Although these models require limited computational time, the role of flow separation in the dune evolution process cannot easily be captured by these models.

Like river dunes, barchan shaped desert dunes are formed by predominantly unidirectional currents and have slip faces with a region of permanent flow separation in the dune lee (e.g. Sauermann et al., 2000). The flow field over barchan dunes is often treated using linear expansions of the flow field, combined with saltation models for grain dynamics (e.g. Kroy et al., 2002; Schwämmle \& Herrmann, 2004; Hersen, 2004). A main difference between river dunes and aeolian dunes is that in the former case a free surface is present. This limits the validity of the expansion approach if the dunes become large relative to the water depth, as is the case for saturated steady-state river dunes.

Hulscher \& Dohmen-Janssen (2005) argued that offshore sand waves and river dunes are similar features, with respect to their dimensions and processes responsible for their formation. Offshore sand wave dynamics occur at large spatial scales ( kilometres) and long temporal scales ( years). To simulate the time-evolution of offshore sandwaves at these scales, shallow water equations with hydrostatic pressure are often applied (e.g. Németh et al., 2007; Van den Berg, 2007). Because of the hydrostatic pressure assumption, these models do not capture flow separation. 


\subsubsection{Existing approaches to model (dynamic) roughness}

The form drag and thus flow resistance caused by dunes can be directly obtained from integration of the (non-hydrostatic) pressure distribution over dunes (e.g. Haque \& Mahmood, 1983; Yoon \& Patel, 1996). However, obtaining the pressure distribution numerically (Tab. 1.1) is computationally expensive, especially for migrating dunes under unsteady discharge conditions. To avoid the necessity of computing the pressure distribution over dunes to obtain the form drag, computed dune dimensions can be translated to a roughness coefficient by using empirical relationships. Such empirical methods often focus on steady flows (e.g. Vanoni \& Hwang, 1967; Yalin, 1972; Van Rijn, 1984; Karim, 1995).

Wilbers (2004) studied dynamic roughness due to unsteady flow conditions in the river Rhine by including time-lags in his empirical dune evolution model and using three existing roughness predictors (i.e. those of Vanoni \& Hwang, 1967, Engelund, 1977 and Van Rijn, 1984). Wilbers (2004) argued that for roughness predictions, the brinkpoint height should be used instead of dune height and the influence of secondary dunes should be taken into account according to their abundance. The method of Wilbers (2004) strongly relies on empirical estimators for dune dimensions limiting the general applicability of this method. Moreover, brinkpoint heights and secondary bedforms are often difficult to obtain from field measurements.

Giri et al. (2007) simulated dune evolution and stage-discharge relationships due to unsteady flows, using the process-based morphodynamic model of Giri \& Shimizu (2006). Resistance to flow could be captured by the model, enabling to study effects of dunes on water levels. This model is computationally expensive, particularly because of the complexity related to solving the flow inside the flow separation zone.

\subsection{Modelling dynamic roughness in rivers during floods}

\subsubsection{Problem formulation}

Hydraulic simulation models generally lack a description of dynamic roughness due to river dune evolution during floods. A suitable dynamic roughness that can be incorporated in a hydraulic simulation model should consist of two essential elements: $(i)$ a process-based simulation model of dune evolution that requires limited computational effort, and (ii) a roughness model translating computed dune dimensions to a roughness coefficient. To simulate dune evolution during flood waves, it is important that the dune evolution model captures relevant time scales.

The simulation model of Giri et al. (2007) captures both dune morphodynamics and flow resistance for unsteady flows, but it cannot be applied to river-reach scales and flood wave time scales for operational purposes due to the required computational effort. The empirical model of Wilbers (2004) is applicable at these scales, however, since this method is data-driven, it is uncertain to apply outside calibration ranges. Simulation models of dune evolution based on stochastic principles and empirical relationships give only limited insights in 
the processes involved, limiting the application range of such models.

Simulation models for dune evolution often assume that flow separation is key to describe bedforms (e.g. Giri \& Shimizu, 2006; Gallagher, 2007). In contrast, stability models do not account for flow separation at all (e.g. Zhou \& Mendoza, 2005) and stochastic models include it using simple rules (e.g. Niño et al., 2002; Jerolmack \& Mohrig, 2005). The dune evolution model of Onda \& Hosoda (2004) includes flow separation into a resistance coefficient, without explicitly solving its effects on the flow field. This illustrates that the effects of flow separation on dune dynamics and evolution towards a steady-state configuration are not yet fully understood.

\subsubsection{Research objective}

To develop a process-based simulation model of dynamic roughness due to river dune evolution, which is applicable at a river-reach spatial scale and flood wave time scale, and that requires limited computational time.

\subsubsection{Research questions}

In line with this objective, the following research questions are formulated:

Q1: How can we represent flow separation over subaqueous river dunes, such that it can be included in a morphodynamic simulation model of river dune evolution?

Q2: To what extent is it possible to simulate the time-evolution of river dunes realistically with an idealized mathematical morphodynamic model by using this representation of flow separation?

Q3: To what extent is flow separation crucial for modelling river dune evolution and time scales involved?

Q4: How can we extend a hydraulic simulation model with the dune evolution model to predict dynamic roughness due to developing dunes in rivers?

Q5: What is the effect of river dune evolution, and particularly the hysteresis effect in dune height, on water levels during flood waves?

\subsubsection{Research approach}

The river dune evolution model will be based on the offshore sand wave model of Németh et al. (2006), who showed that for unidirectional flows, dune-like sand waves (i.e. asymmetric in flow direction) could be simulated. The formation and saturation at an equilibrium height are due to circulation cells in the vertical plane, transporting sand from the troughs to the crest of a sand wave and gravitational bed-slope effects counteracting this process. Similar stabilizing and destabilizing principles have been demonstrated to be crucial for river dune 
evolution (e.g. Fredsøe, 1982; Colombini, 2004; Charru, 2006). Therefore, this model forms the starting point for the study presented in this thesis.

Van den Berg (2007) developed an efficient simulation code, based on the model of Hulscher (1996) and Németh et al. (2006); this simulation code is used in this thesis. The flow model consists of the two-dimensional shallow water equations in a vertical plane (2-DV) with a hydrostatic pressure assumption and sediment transport is based on the turbulence-averaged bed shear stress. The hydrostatic pressure assumption limits the required computational effort, but separated flows are not captured by the model. To keep computational effort minimal, we include flow separation in a parameterized way, based on physical arguments and experimental data.

\subsection{Thesis outline}

Chapter 2 presents a parameterization of flow separation that is based on experimental data of turbulent flow over subaqueous bedforms. It is investigated which parameters control the dimensions of the flow separation zone (Q1). The resulting parameterization of the separation streamline is used to develop a process-based morphodynamic simulation model to predict river dune evolution in Chapter 3. In Chapter 3 we analyze the processes responsible for the formation and saturation dynamics of dunes. Dune characteristics, such as growth, migration, saturation and time to equilibrium, as well as dimensions such as height and length are compared to various data sets of flume experiments (Q2). In this chapter we also investigate the role of flow separation on dune evolution (Q3).

In Chapter 4, a dynamic roughness model is presented, which is based on the dune evolution model and an empirical roughness predictor. This dynamic roughness model is coupled with the 1-dimensional hydraulic simulation model SobeK to include dynamic roughness due to dunes $(\mathbf{Q 4})$. The new, extended, SoBeK model is applied to two different types of flood waves to analyze the effects of river dune evolution on water level predictions (Q5).

In Chapter 5, the approach followed in this thesis and model simplifications and assumptions are discussed. Also, it is discussed to which water systems the model can, or cannot, be applied. Chapter 6 reflects on the research questions by giving the main conclusions of this thesis and recommendations for future research. 



\title{
Chapter 2
}

\section{A parameterization of flow separation over subaqueous dunes ${ }^{\star}$}

\begin{abstract}
Flow separation plays a key role in the development of dunes, and modelling the complicated flow behaviour inside the flow separation zone requires much computational effort. In order to make a first step towards modelling dune development at reasonable temporal and spatial scales, a parameterization of the shape of the flow separation zone over two-dimensional dunes is proposed herein, in order to avoid modelling the complex flow inside the flow separation zone. Flow separation behind dunes, with an angle-of-repose slip face, is characterized by a large circulating leeside eddy, where a separation streamline forms the upper boundary of the recirculating eddy. Experimental data of turbulent flow over 2-D subaqueous bedforms are used to parameterize this separation streamline. The bedforms have various heights and height to length ratios, and a wide range of flow conditions is analyzed. This paper shows that the shape of the flow separation zone can be approximated by a third-order polynomial as a function of the distance away from the flow separation point. The coefficients of the polynomial can be estimated, independent of flow conditions, based on bedform shape at the flow separation point and a constant angle of the separation streamline at the flow reattachment point.
\end{abstract}

\section{$2.1 \quad$ Introduction}

Flow over sandy river beds often leads to the formation of a regular bed morphology such as dunes (e.g. Allen, 1968b; Best, 2005). Because of flow separation and associated energy dissipation, dunes significantly influence flow resistance (e.g. Vanoni \& Hwang, 1967; Wijbenga, 1990; Ogink, 1988; Julien et al., 2002). For many water management purposes it is of great importance to enable prediction of dune dimensions and the resulting flow resistance, especially during floods.

To simulate turbulent flow over dunes numerically, the bed is often assumed rigid and non-erodible. However, increasing computational power has recently

\footnotetext{
*This chapter is published as: Paarlberg, A. J., C. M. Dohmen-Janssen, S. J. M. H. Hulscher, and P. Termes (2007). A parameterization of flow separation over subaqueous dunes. Water Resources Research 43 (W12417), doi:10.1029/2006WR005425.
} 
led to the development of morphodynamic models treating the flow, bed morphology and sediment transport in a coupled manner. Tjerry \& Fredsøe (2005) calculate dune dimensions and shapes of solitary dunes, by relating sediment transport to the time-averaged bed shear stress. Nelson et al. (2005) have shown that a large eddy simulation model with non-hydrostatic pressure and a rigid lid water surface boundary, in combination with a sediment transport model taking turbulent fluctuations of the bed shear stress into account, realistically models dune development. In continuation of this work, Giri \& Shimizu (2006) improved the model of Nelson et al. (2005) by using flow equations with the unsteady term retained and a free water surface condition. Although model results are promising, a disadvantage of these numerical models is their complexity regarding solving the flow field, especially when the flow has to be calculated repeatedly for each bed morphology update. Furthermore, it is yet unfeasible to yield simulations with flood waves and long domains.

In their morphodynamic model, Jerolmack \& Mohrig (2005) excluded the necessity of computing the flow field by assuming a nonlinear relationship between the local bed shear stress and bed topography. To reduce the required computational effort, Onda \& Hosoda (2004) used a depth-averaged hydrostatic flow model, including vertical acceleration terms, to simulate dune development. Although Jerolmack \& Mohrig (2005) and Onda \& Hosoda (2004) were able to simulate dune morphology over long domains, flow separation and its effects on the flow field and sediment transport were not included in their simulation models. However, there are several indications that flow separation and associated turbulence and shear layer formation, are important for dune morphodynamics (e.g. Nelson et al., 1995; Bennett \& Best, 1995; Walker \& Nickling, 2002; Sumer et al., 2003).

Hulscher \& Dohmen-Janssen (2005) argued that offshore sand waves and river dunes are similar features, with respect to their dimensions and processes responsible for their formation. Paarlberg et al. (2005) applied a model, originally developed to predict the dimensions of offshore sand waves (see Van den Berg \& Van Damme, 2005), to river conditions. The flow model is based on the 2-dimensional vertical (2-DV) hydrostatic shallow water equations with a constant eddy viscosity over the flow depth and with bed load sediment transport included using a Meyer-Peter Müller type of equation. It was shown that in cases without flow separation, dune development could be reproduced qualitatively. However, because of the hydrostatic pressure assumption, flow separation could not be captured by the model. To enable simulation of dune development from an initial disturbance to fully grown equilibrium dunes, flow separation therefore needs to be taken into account in any morphodynamic model.

To predict the evolution of solitary aeolian desert dunes, Kroy et al. (2002) included a parameterization of flow separation in their morphodynamic model. Kroy et al. (2002) parameterized the shape of the separation streamline, which forms the upper boundary of the flow separation zone, on the basis of numerical computations of air flow over bedforms. The flow was computed using the separation streamline as an artificial 'bed' in the region of flow separation, effectively avoiding the necessity of modelling the complicated flow behaviour 
inside the flow separation zone.

To keep computational effort to a minimum, but retain the process of flow separation in a simple manner in the morphodynamic model of Paarlberg et al. (2005), a similar approach to that adopted by Kroy et al. (2002) can be used. The present paper will analyze whether the shape of the flow separation zone can be parameterized in the case of water flow over bedforms. To this end, experiments of turbulent flow over 2-D subaqueous bedforms are analyzed, with different bedform heights and aspect ratios (ratio of dune height to dune length), and under various flow conditions.

In Section 2, an overview of the data used in this paper is given, and velocity profiles are analyzed to determine the shape of the flow separation zone for the different experiments. In Section 3, the separation streamline is parameterized using a third-order polynomial function, which is fitted to the individual experiments. The parameters or bedform properties controlling the dimensions of the flow separation zone are then investigated, resulting in an estimate of the length of the flow separation zone based on bedform properties. This allows imposition of the shape of the separation streamline, both at the flow separation point and at the flow reattachment point. The paper shows that the shape of the flow separation zone can be estimated independently of flow conditions, using solely bedform properties.

\subsection{Flow separation}

\subsubsection{Used data sets}

The parameterization of the separation streamline requires detailed measurements of the reverse flow near the bed inside the flow separation zone, and hence only flume data are detailed enough to use for the parameterization. The data used in the present paper is summarized in Table 2.1, where a sub-division is made between: $i$ ) dunes with a horizontal bed at the flow separation point, ii) dunes with a negative slope at the flow separation point, and iii) backwardfacing steps. All measurements comprise time-averaged velocity data.

In cases where bed load transport is dominant, dunes are often asymmetric with a leeside slope at the angle of repose $\left(\sim-30^{\circ}\right)$, and a region of permanent flow separation in the lee (Fig. 2.1a) (Smith \& McLean, 1977; Kostaschuk \& Villard, 1996; Best, 2005). Part of the data used consists of flume experiments with such dunes (Termes, 1984; Van Mierlo \& De Ruiter, 1988; Nelson et al., 1993; McLean et al., 1999). In nature, however, dunes are often of more complex shape. Therefore, dunes with negative slopes at the brinkpoint, the point where the leeside slope suddenly changes to the angle-of-repose (Fig. 2.1b), are also included (Buckles et al., 1984; Kornman, 1995; Bennett \& Best, 1995). Since flow separation over backward-facing steps is largely similar to that over dunes with angle-of-repose slip faces, experiments with backward-facing steps are also included in the analysis (Raudkivi, 1963; Nakagawa \& Nezu, 1987; Etheridge \& Kemp, 1978).

For the experiments with backward-facing steps, the separation point is lo- 


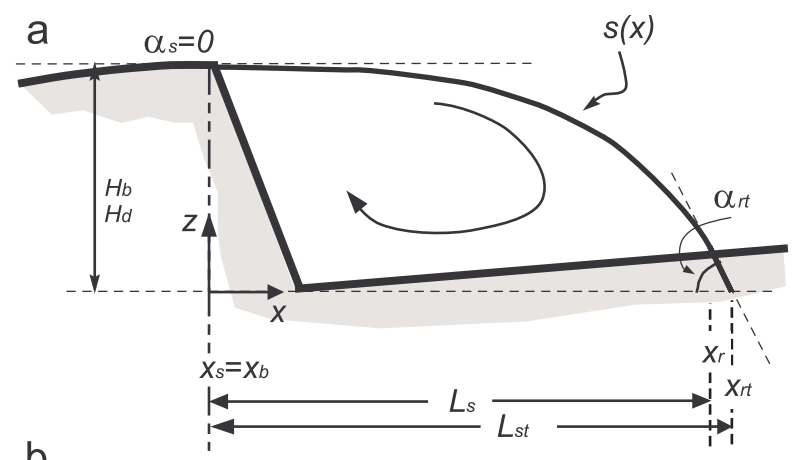

b

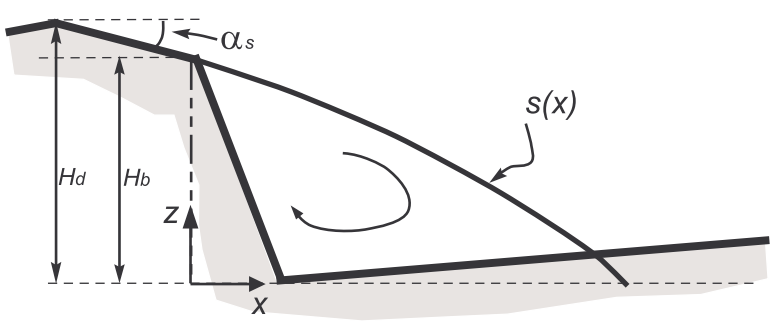

Figure 2.1: Schematic representation of flow separation in the lee of a dune with: a) horizontal bed at the flow separation point, and b) negative bed slope at the flow separation point, including a sketch of the separation streamline. Flow separation is assumed to occur at the brinkpoint $\left(x_{\mathrm{b}}\right)$. See nomenclature for used parameters.

cated at the edge of the step. In the case of dunes, separation is assumed to occur at the brinkpoint. For most experiments this point is clearly defined, except for the experiments of Buckles et al. (1984) and Bennett \& Best (1995). For these two experiments, the location of the brinkpoint is estimated at the point where the bed slope is about $-6^{\circ}$, by analyzing the point where the leeside slope has the sharpest decline (exact locations can be found in Table 2.1).

\subsubsection{Shape of the flow separation zone}

Inside the flow separation zone, a recirculation eddy with reverse flow near the bed is present. This means that the net discharge through a vertical crosssection between the bed and the separation streamline is zero. In other words, the upstream directed discharge between the bed and the point of zero velocity is equal to the downstream directed discharge between the point of zero velocity and the separation streamline. Based on this assumption, the vertical position of the separation streamline $\left(z=z_{\mathrm{sep}}\right)$ is found from:

$$
\int_{z_{\mathrm{b}}}^{z_{\mathrm{sep}}} u(z) d z=0
$$

where $z$ is the vertical coordinate, with the bed at $z=z_{\mathrm{b}}$. 


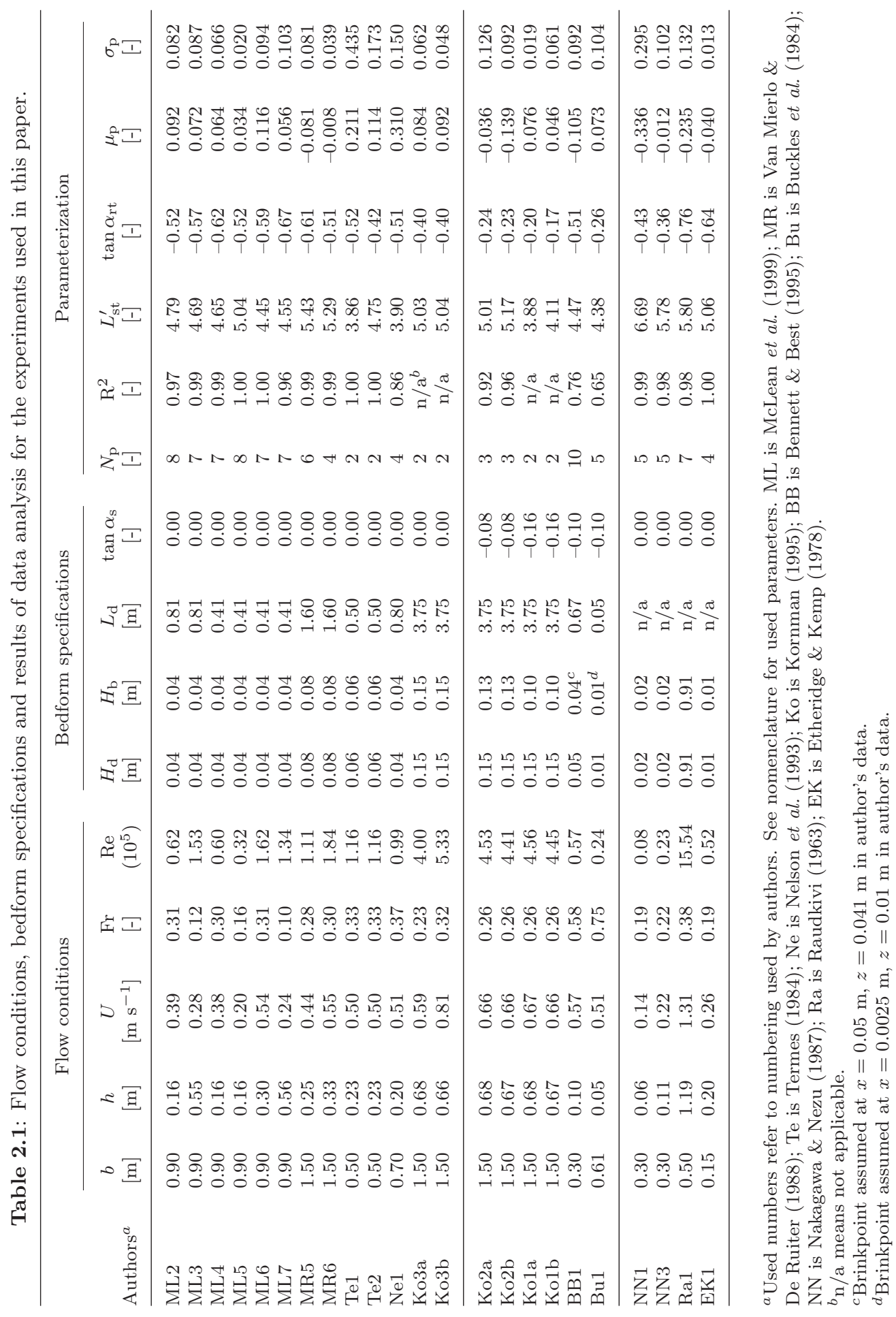




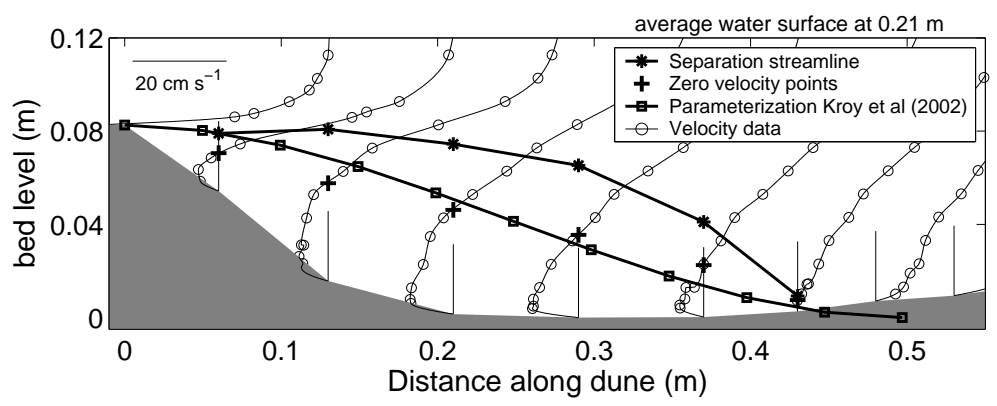

Figure 2.2: Illustration of velocity data, zero velocity points and separation streamline for experiment T5 of Van Mierlo \& De Ruiter (1988). The separation streamline is compared to the parameterization of Kroy et al. (2002).

Figure 2.2 shows cubic interpolated velocity data, the points of zero velocity (i.e. $u(z)=0$ ) and the separation streamline for experiment T5 of Van Mierlo

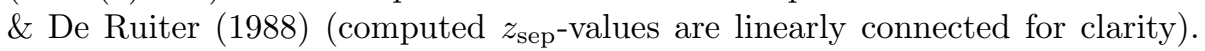
It should be noted that measurements over the steep leeside slope of dunes are least detailed, and that extrapolation over a significant portion of the velocity profile within the flow separation zone must be made. This leads to the highest uncertainty in the location of the separation streamline $\left(z_{\mathrm{sep}}\right)$ over the leeside slope.

Kroy et al. (2002) parameterize the shape of the separation streamline by imposing a smooth connection at both the flow separation and reattachment point. They estimated the length of the flow separation zone $\left(L_{\mathrm{s}}\right)$ based on a pre-defined maximum slope of the separation streamline $\left(-14^{\circ}\right)$. Since Kroy et al. (2002) studied solitary dunes, the flow reattachment point occurs on a flat bed. In Figure 2.2, the parameterization of Kroy et al. (2002) for the shape of the separation streamline is included. For most of the experiments analyzed in the present paper, and especially when the bed is horizontal at the flow separation point (i.e. $\alpha_{\mathrm{s}}=0$, Figure 2.1a), the parameterization of Kroy et al. (2002) turns out to fit the zero velocity data, instead of the separation streamline. This is mainly caused by the assumption of Kroy et al. (2002) that the length of flow separation is found from imposing a maximum slope of the separation streamline, and the assumption that the separation streamline smoothly connects to a flat bed at the reattachment point.

\subsection{Parameterization of the separation streamline}

In this section, a separation streamline $s(x)$ is determined for each individual experiment, by fitting a third-order polynomial function in $x$, the distance from the flow separation point, to the vertical locations $z=z_{\text {sep }}$ found from Eq. (2.1). To enable comparison between the experiments, both the longitudinal coordinate $x$ and the vertical coordinate $z$ are scaled against the brinkpoint height of 
a bedform $\left(H_{\mathrm{b}}\right)$. Once the separation streamline is known, the reattachment point can be determined, and it is investigated which parameters control the length of the flow separation zone.

\subsubsection{Determination of separation streamline}

The separation streamline is parameterized using the same third-order polynomial function as used by Kroy et al. (2002):

$$
\tilde{s}(\xi)=\frac{s(\xi)}{H_{\mathrm{b}}}=s_{3} \xi^{3}+s_{2} \xi^{2}+s_{1} \xi+s_{0},
$$

where $\xi=\left(x-x_{\mathrm{s}}\right) / H_{\mathrm{b}}$, and $s_{0} \ldots s_{3}$ are coefficients. The shape of the separation streamline, as illustrated in Figure 2.2, can be approximated by imposing a smooth connection of the separation streamline to the bed at the flow separation point $(\xi=0)$, yielding for coefficients $s_{0}$ and $s_{1}$ :

$$
\begin{gathered}
s_{0}=\tilde{s}(0)=1 \\
s_{1}=\frac{d \tilde{s}(0)}{d \xi}=\tan \alpha_{\mathrm{s}} .
\end{gathered}
$$

Kroy et al. (2002) imposed two conditions at the flow reattachment point as well, however in our case the flow reattachment point is not known a priori. Therefore, the coefficients $s_{2}$ and $s_{3}$ are fitted to the vertical locations $z=$ $z_{\text {sep }}$ found from Equation (2.1). The fitting procedure results in a separation streamline for each individual experiment and Figure 2.3 shows the results for four experiments of McLean et al. (1999).

For the experiment of Termes (1984) and Kornman (1995) it was necessary to set coefficient $s_{3}$ to zero in Equation (2.2), since too few velocity profiles are located within the flow separation zone. For the experiments of Buckles et al. (1984) and Nelson et al. (1993), it was also necessary to use $s_{3}=0$, since otherwise no monotonic decreasing regression line was found and consequently no reattachment point could be found.

To use the parameterized separation streamline in a morphodynamic model, it is important to describe the shape of the separation streamline correctly. This paper shows that the shape of the separation zone is captured with sufficient accuracy using a third-order polynomial function, with coefficients $s_{0}$ and $s_{1}$ set by realistic boundary conditions, and setting coefficients $s_{2}$ and $s_{3}$ using regression analysis. The observed behaviour that the separation streamline reattaches downstream at a certain angle (Fig. 2.2), is also captured by the parameterization.

Table 2.1 lists the coefficients of determination for the fitted separation streamlines $\left(\mathrm{R}^{2}\right)$. Especially for the experiments of McLean et al. (1999), Van Mierlo \& De Ruiter (1988) and experiments with backward-facing steps good fits are obtained. By using a second-order polynomial function, the overall shape of the separation zone could not be captured, especially near the region of flow reattachment. Extending the parameterization to a fourth-order 


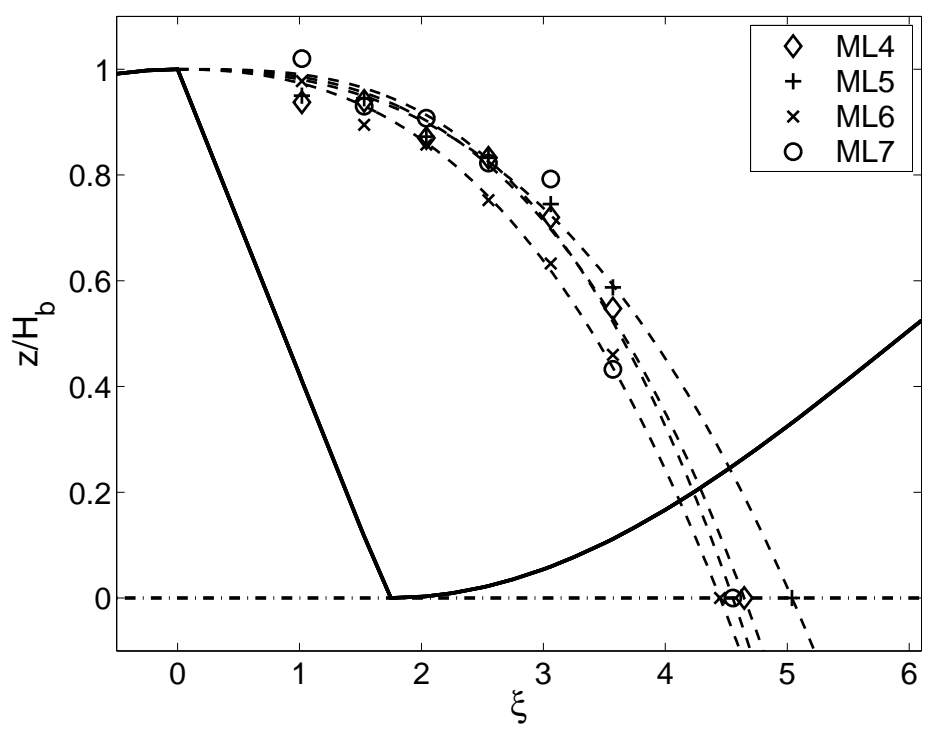

Figure 2.3: Separation streamlines for data of McLean et al. (1999). Dashed lines are the regressed separation streamlines (symbols at trough elevation distinguish the four experiments).

polynomial function yielded unrealistic separation zone shapes, since the extra fitting coefficient led to fitting noise, rather than the average shape of the flow separation zones. Schatz \& Herrmann (2006) used an elliptical function to parameterize the separation streamline for air flow over aeolian dunes. Their method also requires four coefficients, however to set these coefficients, the reattachment point has to be known a priori.

\subsubsection{Determination of the flow reattachment point}

For each experiment, the shape of the flow separation zone is now known, allowing determination of the (time-averaged) location of the flow reattachment point. However, since the experiments used in this paper are performed with different bedform geometries (i.e. different bedform heights and/or lengths, Table 2.1), the bed slope at the flow reattachment point is not equal between the different experiments. To be able to compare between the various experiments, a location $x_{\mathrm{rt}}$ is defined, where the cubic separation streamline would intersect a flat bed whose elevation is the same as the trough elevation (Fig. 2.1a). This defines the separation zone length $L_{\mathrm{st}}=x_{\mathrm{rt}}-x_{\mathrm{s}}$ and a nondimensional separation zone length $L_{\mathrm{st}}^{\prime}=L_{\mathrm{st}} / H_{\mathrm{b}}$. The angle of the separation streamline with the hypothetical flat bed (dash-dotted lines in the figures) is defined as $\tan \alpha_{\mathrm{rt}}$. At the reattachment point $\left(\xi=L_{\mathrm{st}}^{\prime}\right)$ this yields: 


$$
\begin{gathered}
\tilde{s}\left(L_{\mathrm{st}}^{\prime}\right)=0 \\
\frac{d \tilde{s}\left(L_{\mathrm{st}}^{\prime}\right)}{d \xi}=\tan \alpha_{\mathrm{rt}} .
\end{gathered}
$$

Combining this with equations $(2.2)$ and (2.4) this yields at $\xi=L_{\mathrm{st}}^{\prime}$ :

$$
s_{3} L_{\mathrm{st}}^{\prime 3}+s_{2} L_{\mathrm{st}}^{\prime 2}+\tan \alpha_{\mathrm{s}} L_{\mathrm{st}}^{\prime}+1=0
$$

and

$$
3 s_{3} L_{\mathrm{st}}^{\prime 2}+2 s_{2} L_{\mathrm{st}}^{\prime}+\tan \alpha_{\mathrm{s}}=\tan \alpha_{\mathrm{rt}} .
$$

Using the fitted curves determined in Section 3.1, Equation (2.7) is solved to obtain $L_{\mathrm{st}}^{\prime}$ and Equation (2.8) yields $\tan \alpha_{\mathrm{rt}}$ for each individual experiment. Results are summarized in Table 2.1 and for experiments ML4-7 the positions of $\xi=L_{\text {st }}^{\prime}$ are given in Figure 2.3.

\subsubsection{Length of the flow separation zone}

Figure 2.4 shows that the length of the flow separation zone increases for increasing brinkpoint heights (Fig. 2.4a) and that the nondimensional length of the flow separation zone $\left(L_{\text {st }}^{\prime}=L_{\text {st }} / H_{b}\right)$ varies roughly between 4 and 6 . This range is confirmed by various sources, with the nondimensional separation zone length often reported around 4-6 (e.g. Engel, 1981; Van Mierlo \& De Ruiter, 1988; Niño et al., 2002; Fernandez et al., 2006). Figure 2.4b-d show no obvious relationship between characteristic flow parameters and the flow separation zone length. This could also be concluded from Figure 2.3, showing largely identical separation streamlines for four experiments where the fixed dune shape is equal, but flow conditions are different. It is also in agreement with Engel (1981) who showed experimentally that the nondimensional length of the flow separation zone is largely independent of the Froude number and the relative water depth (ratio of water depth to dune height), and with Walker \& Nickling (2002), who stated that the reattachment distance behind desert dunes only slightly increased with incident wind speed.

Several authors suggest that the length of the flow separation zone is controlled, apart from brinkpoint height, by the local bed slope at the flow separation point (Paarlberg et al., 2005; Schatz \& Herrmann, 2006). Therefore, Figure 2.5 shows the nondimensional length of the flow separation zone as a function of the local bed slope at the separation point. The experiments used in the present analysis have either a horizontal bed or a negative bed slope at the flow separation point (i.e. $\tan \alpha_{\mathrm{s}} \leq 0$, Table 2.1). Four slope-classes are used and each class is represented by a mean its standard deviation. Linear regression through the data yields (Fig. 2.5):

$$
L_{\mathrm{st}}^{\prime}=6.48 \tan \alpha_{\mathrm{s}}+5.17 .
$$

By performing numerical simulations of air flow over fixed isolated aeolian dunes, Schatz \& Herrmann (2006) also found a linear relation between the 

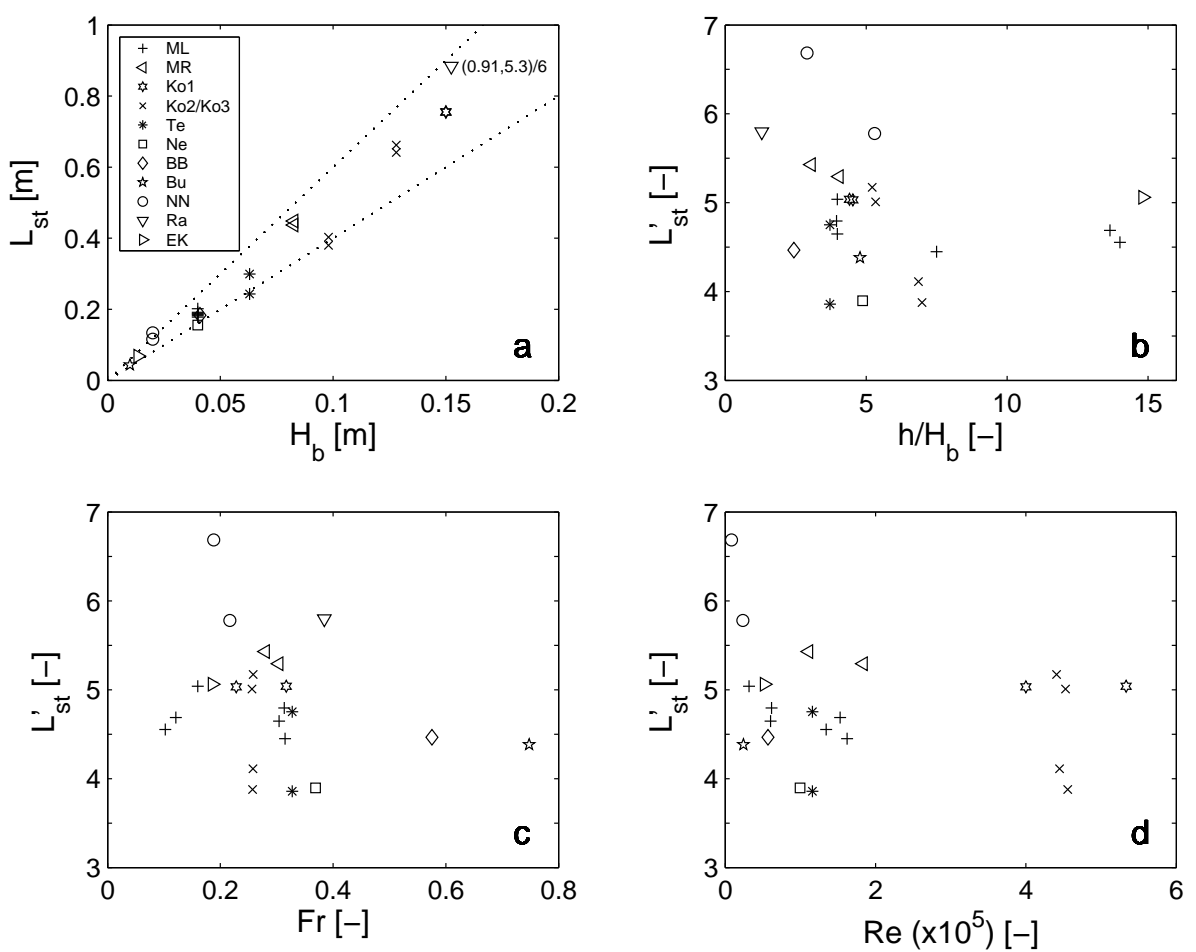

Figure 2.4: (a) Relationship between the brinkpoint height and the (dimensional) separation zone length (see Figure 2.1 and nomenclature for parameters and Table 2.1 for abbreviations used in the legend). The data for the experiment of Raudkivi (1963) is scaled by a factor 1:6 for clarity. The dotted lines represent $L_{\mathrm{st}}=4 H_{\mathrm{b}}$ and $L_{\mathrm{st}}=$ $6 H_{\mathrm{b}}$. Dependency of the nondimensional separation zone length is shown on (b) the ratio of water depth to brinkpoint height, (c) the Froude number, and (d) the Reynolds number. 


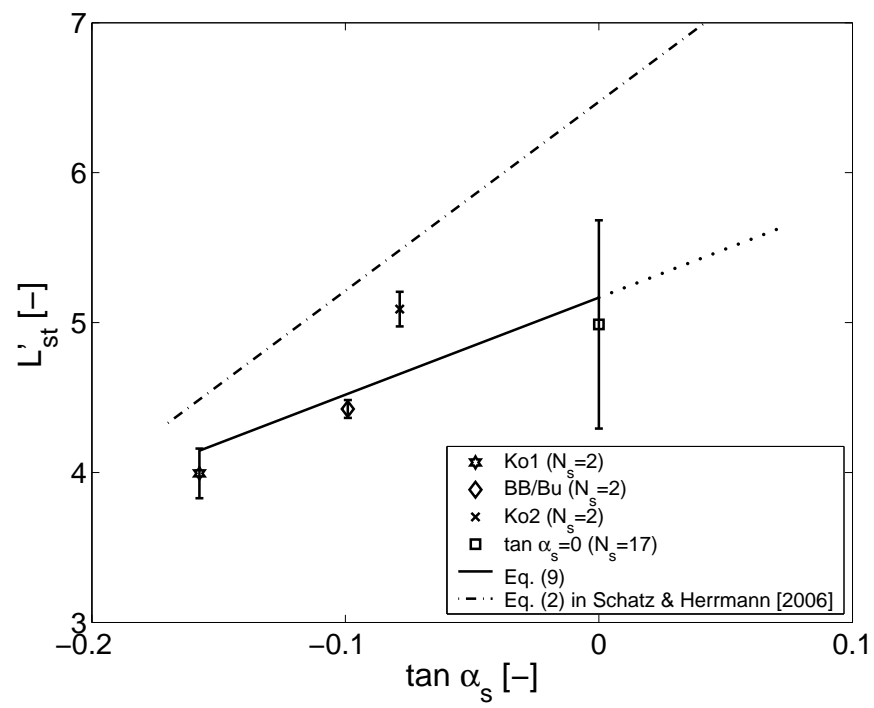

Figure 2.5: Nondimensional length of the flow separation zone $\left(L_{\mathrm{st}}^{\prime}\right)$ as a function of the bed slope at the flow separation point $\left(\tan \alpha_{\mathrm{s}}\right)$. The data are grouped into four slope-classes with $N_{\mathrm{s}}$ the number of observations in that class; per class the mean and its standard deviation are shown. The solid line is a linear fit through the mean nondimensional separation zone lengths, and the dash-dotted line is Equation (2) of Schatz \& Herrmann (2006).

separation zone length and the bed slope at the flow separation point. Schatz \& Herrmann (2006) found the nondimensional flow separation zone length to extend roughly 10-30\% further downstream than found in this paper (Fig. 2.5). In their conceptual model of leeside airflow however, Walker \& Nickling (2002) suggest that the separation zone extends further over isolated solitary dunes than over closely spaced dunes because of decreased surface roughness. Schatz \& Herrmann (2006) showed using a numerical simulation that the separation zone length over closely spaced dunes with a horizontal bed at the flow separation point (i.e. $\tan \alpha_{\mathrm{s}}=0$ ), is about $25 \%$ smaller than over isolated dunes. This means that for dunes with a horizontal bed, Schatz \& Herrmann (2006) found a nondimensional separation zone length of $L_{\mathrm{st}}^{\prime} \approx 4.85$, which is well within the range of $L_{s t}^{\prime}$ found in this paper (Fig. 2.5).

\subsubsection{Parameterization based on bedform properties}

The length of the flow separation zone is shown to be largely independent of flow conditions (Fig. 2.4b-d), but depends on brinkpoint height (Fig. 2.4a) and bed slope at the flow separation point (Fig. 2.5). Therefore, the four coefficients $s_{0} \ldots s_{3}$ are determined based on bedform properties. Coefficients $s_{0}$ and $s_{1}$ are set using Equations (2.3) and (2.4). The remaining coefficients $s_{2}$ and $s_{3}$ can be determined from Equations (2.7) and (2.8), if the location of the reattachment 

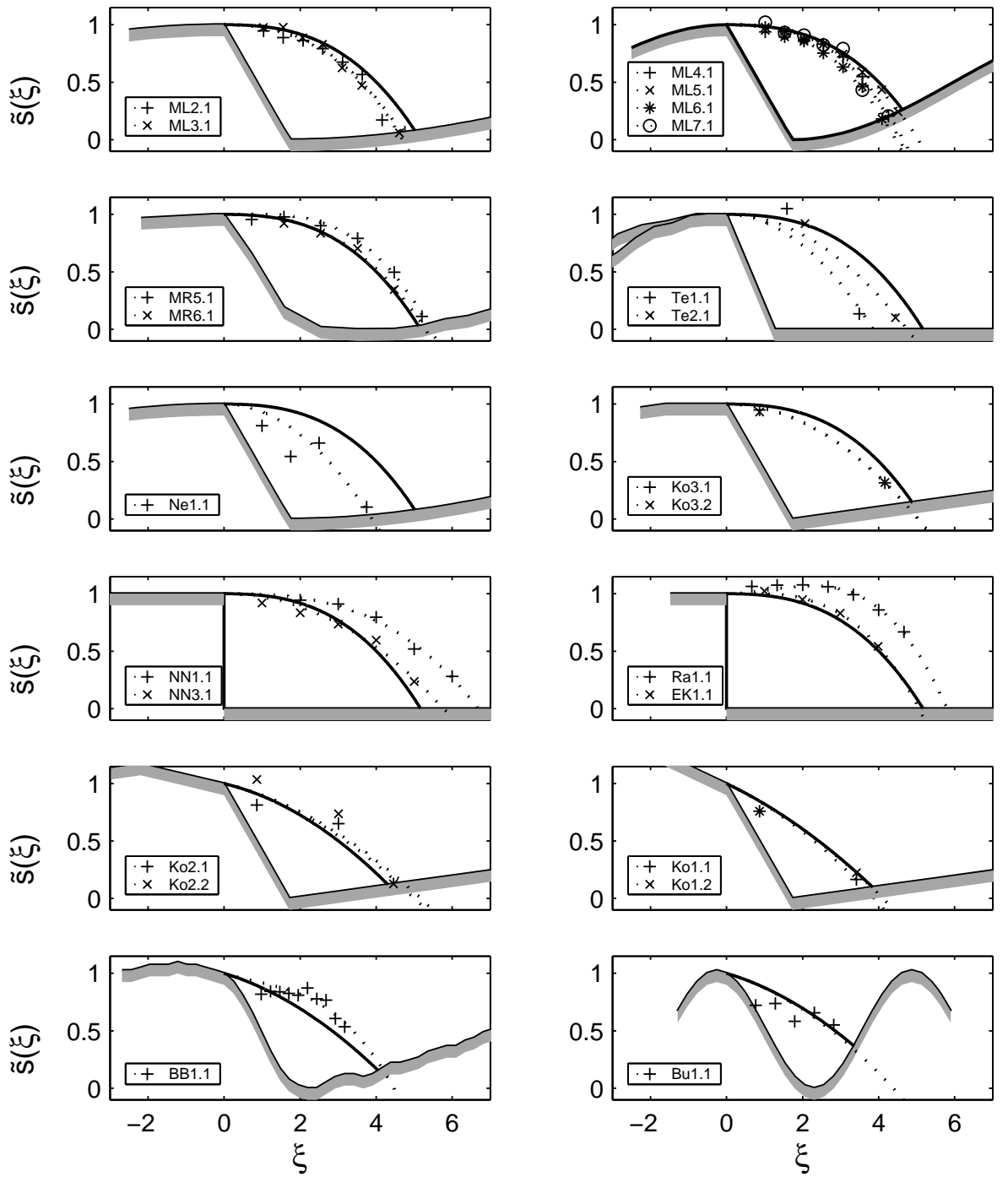

Figure 2.6: Comparison of the parameterization with the separation streamlines found from the regression analysis. Bed profiles are underlain by a gray shading for clarity. Within the flow separation zone, the solid lines represent the parameterization, the symbols represent the measured vertical positions along the separation streamlines $\left(z_{\mathrm{sep}}\right)$, and the dotted line represents the fitted separation streamlines to these positions. 
point and the slope of the separation streamline at the flow reattachment point are known. The position of the flow reattachment point $\left(\xi=L_{\text {st }}^{\prime}\right)$ can be estimated using Equation (2.9) with the brinkpoint height and the bed slope at the flow separation point as inputs. For the coefficients $s_{2}$ and $s_{3}$ this yields:

$$
\begin{aligned}
& s_{3}=\frac{\tan \alpha_{\mathrm{rt}}}{L_{\mathrm{st}}^{\prime 2}}+\frac{\tan \alpha_{\mathrm{s}}}{L_{\mathrm{st}}^{\prime 2}}+\frac{2}{L_{\mathrm{st}}^{\prime 3}} \\
& s_{2}=-s_{3} L_{\mathrm{st}}^{\prime}-\frac{\tan \alpha_{\mathrm{s}}}{L_{\mathrm{st}}^{\prime}}-\frac{1}{L_{\mathrm{st}}^{\prime 2}} .
\end{aligned}
$$

In the case of a horizontal bed at the flow separation point (i.e. $\tan \alpha_{\mathrm{s}}=0$ ), the average angle of the separation streamline at the reattachment point is $\tan \alpha_{\mathrm{rt}}=-0.53(\sigma=0.11)$, yielding $s_{3}=-5.4 \times 10^{-3}$ and $s_{2}=-9.7 \times 10^{-3}$. In the case of a negative bed slope at the flow separation point, the angle of the separation streamline at the flow reattachment point is not known, because only limited data for these cases are available. To be able to use one boundary condition less at the flow reattachment point, the coefficient $s_{3}$ is set to zero in Eqs. (2.10) and (2.11), if $\tan \alpha_{\mathrm{s}}<0$.

The shape of the flow separation zone can now be estimated with Eq. (2.2), using Eqs. (2.3), (2.4), and (2.9)-(2.11) to set the coefficients of the polynomial. Figure 2.6 compares the parameterization with the separation streamlines extracted from the experiments (Section 2.3.1). To assess for each experiment how well the parameterization compares to the data, the relative error $E_{\mathrm{p}}$ between the measured positions of the separation streamlines $\left(z_{\mathrm{sep}}\right)$ and the parameterized separation streamline $\left(z_{\text {par }}\right)$ is determined, for each measurement point $i$ within the flow separation zone:

$$
E_{\mathrm{p}, i}=\frac{z_{\mathrm{par}, i}-z_{\mathrm{sep}, i}}{H_{\mathrm{b}}}, \quad i=1 . . N_{\mathrm{p}},
$$

where $N_{\mathrm{p}}$ is the number of measurements within the flow separation zone (Tab. 2.1). For each experiment, the mean $\left(\mu_{\mathrm{p}}\right)$ and standard deviation $\left(\sigma_{\mathrm{p}}\right)$ of the errors computed with Eq. (2.12) are presented in Table 2.1. A zero mean, together with a zero standard deviation would imply a perfect fit; a positive mean implies that the parameterized separation streamline is on average above the fitted separation streamline. The average value of the mean error $\mu_{\mathrm{p}}$ is 0.02 $(\sigma=0.14)$, with an average standard deviation $\sigma_{p}$ of $0.11(\sigma=0.09)$, meaning that the parameterization based on dune properties captures the average shape of the flow separation zone.

Figure 2.6 shows that for dunes with a horizontal bed at the flow separation point, the agreement between the data and the parameterization is fairly good, especially for the experiments of McLean et al. (1999) and Van Mierlo \& De Ruiter (1988). For backward-facing steps, the size of the flow separation zone is generally underestimated by the parameterization. This might be due to the fact that backward-facing steps have a secondary corner eddy just downstream the edge of the step near the bed. For dunes, this secondary corner eddy 
is not present or at least less pronounced, because the angle of the lee is about $-30^{\circ}$, instead of $-90^{\circ}$ (i.e. vertical) for backward-facing steps.

The bottom four plots in Figure 2.6 consider the experiments with a negative bed slope at the flow separation point, where the coefficient $s_{3}$ is set to zero. Also here, good agreement is observed between the data and the parameterization.

\subsection{Discussion}

\subsubsection{Application of the parameterization in a 2-DV morphody- namic model}

The aim for future research is to use the proposed parameterization in a twodimensional vertical (2-DV) dune development model where the flow is treated as hydrostatic, meaning that the details of separated flows cannot be predicted (Paarlberg et al., subm.; Chapter 3). Following the approach of Kroy et al. (2002), the parameterized separation streamline can be used to provide an artificial 'bed' over which the hydrostatic assumption is approximately true. Thus only the hydrostatic flow outside the flow separation zone has to be calculated, which saves the computational effort related to modelling the flow within and around the flow separation zone.

Initial results indicate that river dune migration and formation can be captured with a morphodynamic model where the flow separation zone behaviour is parameterized (Paarlberg et al., 2006; Paarlberg et al., subm.; Chapter 3). Using this approach, details related to the flow behaviour within the flow separation zone, such as the shear layer developing downstream of the flow separation point (e.g. McLean et al., 1999; Fernandez et al., 2006), are not included. For the aeolian case, Kroy et al. (2002) argue that dune migration and formation do not very sensitively depend on the flow behaviour within the flow separation zone. Although the process of flow separation in unidirectional air and water flows is quite similar, future research should investigate (Chapter 3) whether it is sufficient to know solely the shape of the flow separation zone in order to facilitate predicting river dune development, or if this parameterization has to be extended with details within and around (shear layer) the flow separation zone.

\subsubsection{Application of the 2-DV parameterization to complex river dune configurations}

The proposed parameterization estimates the shape of the flow separation zone in the leeside of straight-crested two-dimensional vertical (2-DV) dunes, with angle-of-repose slip faces. In the field however, often more complex dune configurations occur. In large rivers, the average leeside slope of dunes is often lower than about $-8^{\circ}$ (Best, 2005). Best \& Kostaschuk (2002) showed that the flow separation zone in the leeside of a low-angle dune, with a maximum leeside slope of $-14^{\circ}$, is non-permanent with intermittent flow separation for up to $4 \%$ of the time. Additionally, river dunes often have 3-D structures, such as amplitude variations or crestline curvature. Allen (1968b) illustrated flow pat- 
terns over 3-D dunes revealing complex flow separation zone dynamics due to generated vorticity and convergence and divergence of flow (Best, 2005). This raises the question how to apply the proposed separation zone parameterization to low-angle dunes and 3-D dune configurations.

Since low-angle dunes possess no clearly defined (or even absent) brinkpoint and flow separation is non-permanent, the 2-DV parameterization is difficult to apply to low-angle dunes. Future studies should investigate over which leeside slopes the flow separates (defining a critical bed slope), and to what extent. If this information is available, the parameterization can be applied using a critical bed slope as brinkpoint; in morphological calculations, the flow separation zone should be ignored for the time it is not present. It should be noted that the morphodynamic model of Paarlberg et al. (subm.) (Chapter 3) only considers bed load transport. Possibly this assumption limits the occurrence of low-angle dunes, since their occurrence may be related to the presence of suspended sediment transport (Best \& Kostaschuk, 2002; Best, 2005).

Recent studies by Venditti (2007) and Maddux et al. (2003a,b) showed that the flow field over simple regular 3-D dunes is significantly different from that over their 2-D counterparts. Secondary currents and flow convergence and divergence over the 3-D shapes significantly influence the separation zone dynamics.

Maddux et al. (2003a,b) used fixed dunes which were 2-D across the flume width, having cosine-shaped stoss-sides in streamwise direction and a variable height of the crest line, thereby creating a 3-D form. Equation (2.9) determines the separation zone length using the bed slope at the flow separation point $\left(\alpha_{s}=0\right.$ in this case) and brinkpoint height as input. If the parameterization follows the main flow direction, the flow separation zone extends further downstream over the maxima in dune height, as was found by Maddux et al. (2003a). However, Maddux et al. (2003a) also showed that secondary currents and flow convergence and divergence over the 3-D shapes significantly influenced turbulence generation. This could be taken into account by including the lateral flow component, and applying the parameterization along streamlines instead of along the main flow direction.

In the experiments of Venditti (2007) the crest line was curved, but constant in height and cross-sectional 2-D shape. For dunes where the crest-center is ahead of the banks ('lobe'-shaped dunes), the flow separation zone extended further downstream than was the case with the 2-D counterpart. In situations where the crest is behind that of the banks ('saddle'-shaped dunes), convergence of flow in the hollow in the leeside suppressed the formation of a flow separation zone resulting in less turbulence but higher velocities. For these shapes our parameterization is inadequate, since the dune height is constant in these experiments. This suggests the importance of including streamlines and streamline curvature in the parameterization.

Thus to apply the separation zone parameterization to such 3-D river dune configurations, the 2-DV dune model should be extended to a 3-D morphodynamic model, such as the model of Hulscher (1996). This allows to investigate how the shape of the separation zone depends on 2-DH dune-structures, e.g. by following streamlines and allowing for convergence and divergence of the 
parameterized separation zone. For natural irregular 3-D dune fields, it might be necessary to derive a different parameterization, e.g. by including turbulent quantities or vorticity.

\subsection{Conclusions}

In this paper, a parameterization of flow separation associated with straightcrested subaqueous sand dunes is proposed, which can easily be applied in 2-DV morphodynamic models to avoid modelling the complex flow behaviour inside the flow separation zone. The shape of the flow separation streamline can be approximated by a third-order polynomial as a function of the distance away from the flow separation point.

The length of the flow separation zone is shown to be largely independent of flow conditions, but depends on the brinkpoint height and decreases when there is a negative bed slope at the brinkpoint. A linear relationship is found between the bed slope at the flow separation point and the length of the flow separation zone, allowing to estimate the location of the flow reattachment point.

The coefficients of the third-order polynomial are set using physical boundary conditions at the flow separation point and at the flow reattachment point. A smooth connection to the bed is assumed at the flow separation point. Since the angle of the separation streamline at the reattachment point is found to be almost constant, this angle is used as boundary condition in that point. The shape of the separation streamline, and thus the flow separation zone, is captured well by the proposed parameterization, for dunes with different heights and height to length ratios and for a wide range of flow conditions. 


\title{
Chapter 3
}

\section{Modelling river dune evolution using a parameterization of flow separation ${ }^{\star}$}

\begin{abstract}
This paper presents an idealized morphodynamic model to predict river dune evolution. The flow field is solved in a vertical plane assuming hydrostatic pressure conditions. The sediment transport is computed using a Meyer-Peter Müller type of equation, including gravitational bed-slope effects and a critical bed shear stress. To avoid the necessity of modelling the complex flow inside the flow separation zone, we follow a similar approach earlier used to simulate the dynamics of wind blown desert dunes. In case of flow separation, the separation streamline acts as an artificial bed and sediment avalanches down the leeside distributing evenly on the leeside at the angle of repose. Model results show that bed-slope effects play a crucial role in the determination of the fastest growing wave length from a linear analysis. Flow separation is shown to be crucial to take into account if the dune lee exceeds a certain threshold slope. If flow separation is not included, dune shapes are incorrectly predicted and the dune height saturates at an early stage of bedform evolution, yielding an underprediction of dune height and time to equilibrium. If flow separation is included, the equilibrium dune height and time to equilibrium agree better with measurements. The local bed slope at the dune crest plays a critical role for obtaining an equilibrium dune height. The simulation model is able to predict the main characteristics of dune evolution, such as dune asymmetry, dune growth and saturation at a certain dune height for various experimental conditions. Dune properties, such as height, length, aspect ratio and migration rate compare reasonably well to various data sets.
\end{abstract}

\subsection{Introduction}

Interactions between the flow, the sediment transport and the bed morphology, often lead to the formation of rhythmic patterns on river beds, such as dunes (e.g. Allen, 1968b; Ten Brinke et al., 1999; Carling et al., 2000b; Parsons et al., 2005). Due to unidirectional river flows, river dunes migrate in downstream direction and have typical asymmetric shapes. Flow separation in the lee of dunes

\footnotetext{
* The contents of this chapter are submitted, without Appendix A, to Journal of Geophysical Research - Earth Surface
} 
and associated energy losses, significantly influence flow resistance (e.g. Einstein \& Barbarossa, 1952; Engelund, 1966; Vanoni \& Hwang, 1967; Wijbenga, 1990; Ogink, 1988; Julien et al., 2002). For many water management purposes, it is essential to predict the time-evolution of river dunes, in order to assess their influence on flow resistance and on water levels.

To analyze the initiation of dunes from flat bed, often linear stability analysis techniques are applied (e.g. Kennedy, 1963; Engelund, 1970; Smith, 1970; Fredsøe, 1974; Richards, 1980). Such linear stability models predict whether dunes will, or will not, occur for certain flow conditions. To study the temporal evolution of dunes using stability methods, various attempts have been made to include nonlinear feedback mechanisms between the flow and bedform amplitude (e.g. Ji \& Mendoza, 1997; Yamaguchi \& Izumi, 2002; Zhou \& Mendoza, 2005). Zhou \& Mendoza (2005) derived a nonlinear growth model predicting amplitude growth and saturation of dunes. This perturbation model does not take flow separation into account, while there are several indications that flow separation and associated turbulence and shear layer formation are important for dune morphodynamics (e.g. Sharp, 1963; Nelson et al., 1995; Bennett \& Best, 1995; Walker \& Nickling, 2002; Sumer et al., 2003).

Only recently, increasing computational power has led to reliable numerical codes to simulate dune evolution by solving coupled systems of flow, sediment transport and bed morphology (Nelson et al., 2005; Tjerry \& Fredsøe, 2005; Giri \& Shimizu, 2006). These numerical codes are able to predict the timeevolution of dune dimensions, dune shapes and dune migration. The treatment of flow separation and related transport of sediment are key elements in these models, and require complicated flow models that capture not only the mean properties of the flow but also the statistics. Furthermore, such models require an accurate transfer function relating near-bed flow with sediment dynamics. At present, the useful application of these numerical codes in water management is still limited, because the models require fast computers and long computational times.

Various approaches have been developed to predict bedform evolution using simplifications regarding solving the flow field. Onda \& Hosoda (2004) developed a one-dimensional (1-D) numerical model with depth-averaged Boussinesqtype flow equations and hydrostatic pressure, including deceleration and acceleration effects due to flow over wavy beds. Non-hydrostatic effects related to flow separation are incorporated in the friction term. Jerolmack \& Mohrig (2005) assumed a nonlinear relationship between the bed topography and the spatial distribution of the bed shear stress over that topography. Both the models of Onda \& Hosoda (2004) and Jerolmack \& Mohrig (2005) successfully simulated bedform evolution over quite long domains, from initiation to an equilibrium with bedforms of different scales continuously merging and splitting. These models are very useful to yield predictions of dune evolution with limited computational time, but the role of flow separation in dune dynamics could not be captured by these models.

Interestingly, also in other environments bedforms are observed. Wind blown desert dunes and related migration patterns were successfully studied using 


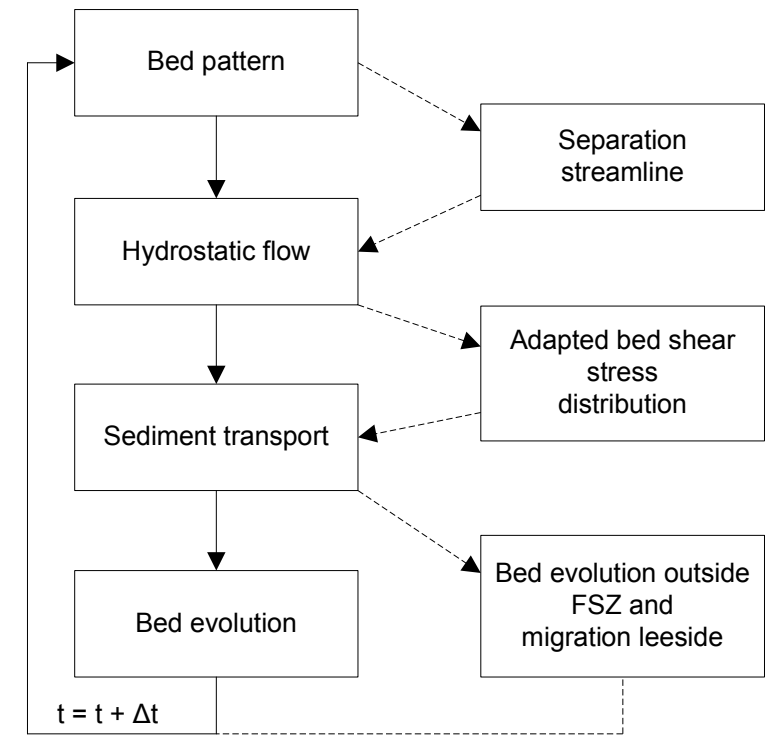

Figure 3.1: Setup of the morphodynamic model of this paper. The left side of the figure (solid arrows) represents the basic morphodynamic cycle, which is followed as long as flow separation does not occur. The right part of the figure (dashed arrows) represents the additions related to the parameterization of flow separation (FSZ: flow separation zone).

linear expansions of the flow field, combined with saltation models for grain dynamics (e.g. Kroy et al., 2002; Schwämmle \& Herrmann, 2004; Hersen, 2004). Such an approach could be useful to study the evolution of river dunes as long as they are small compared to the water depth. However, saturated steadystate river dunes (i.e. dunes that migrate downstream with an equilibrium dune height) have heights that are typically of the same order as the water depth, meaning that the flow equations have to be solved nonlinearly to reproduce typical flow fields over saturated steady-state river dunes.

To predict the time-evolution of offshore sand waves, from initial bed disturbances to equilibrium, different nonlinear numerical codes of the Hulscher (1996) model are developed (Van den Berg \& Van Damme, 2005; Németh et al., 2006; Németh et al., 2007; Van den Berg, 2007). These models demonstrated that sand wave formation and saturation towards an equilibrium height is due to circulation cells in the vertical plane, transporting sand from the troughs to the crest of a sand wave, and gravitational bed-slope effects counteracting this process. Németh et al. (2006) showed that for unidirectional flows, dune-like sand waves (i.e. asymmetric in flow direction) could be simulated. However, since the used flow model is based on hydrostatic flow equations, separated flows cannot be treated and only small-amplitude sand waves could be studied by Németh et al. (2006). 
A similar problem was encountered by Zeman \& Jensen (1987) for modelling the complex flow over hills using a linear flow model, which is incapable of simulating reverse flows. To overcome this problem, Zeman \& Jensen (1987) suggested to use a separation bubble to represent the flow separation zone. This approach effectively avoids the necessity to simulate the complex flow and sediment transport behaviour in this region, and was successfully adopted in several simulation models for aeolian dunes (e.g. Momiji \& Bishop, 2002; Kroy et al., 2002; Sauermann et al., 2003).

Our aim is to develop a process-based simulation model of river dune evolution that is useful for operational water management. Such a model should limit the required computational effort. Therefore, we will investigate in this paper, whether the process-based morphodynamic model of Németh et al. (2006) can be extended with a parameterization of flow separation, to enable simulation of finite-amplitude river dune evolution. We investigate whether this approach realistically predicts various aspects of river dune evolution, such as dune asymmetry, dune migration and saturation at a certain equilibrium dune height. The role of flow separation will be specifically addressed and relevant parameters and processes that cause bedform growth and saturation are discussed.

The general set-up of the morphodynamic simulation model for river dune evolution is presented in Figure 3.1. The right side of the figure (dashed arrows), represents the additions related to the parameterization of flow separation to the basic morphodynamic cycle (solid arrows). If the bed slope of the dune lee exceeds a certain threshold value, the flow is assumed to separate and the upper boundary of the flow separation zone, the separation streamline, is determined. Using experimental data of flow fields over dunes, Paarlberg et al. (2007) found that the separation streamline over dunes with angle-of-repose slip faces can be approximated by a third-order polynomial function, and that the coefficients of that polynomial can be estimated independently of flow conditions (Chapter 2). This separation streamline forms a virtual 'bed' in the region of flow separation, and the hydrostatic flow over this virtual bed can be computed.

Section 3.2 presents the flow equations, along with boundary conditions and the parameterization of the separation streamline to compute the flow in case of flow separation. The sediment transport and bed evolution equations, both with and without flow separation, are described in Section 3.3. The calibration of model parameters is discussed in Section 3.4. In Section 3.5 the model results are assessed qualitatively and a quantitative comparison with flume experiments is made. Section 3.6 presents a discussion on the model and its results and the conclusions are presented in Section 3.7.

\subsection{Flow model}

The derivation of the flow model, starting from the Navier-Stokes equations in a vertical plane (i.e. 2-DV), can be found in Appendix A of this chapter. Appendix A shows that a scaling analysis, using typical parameters for a river situation, allows for some simplifications to the flow equations. Most importantly, $(i)$ the momentum equation in vertical direction reduces to the hydrostatic pressure 


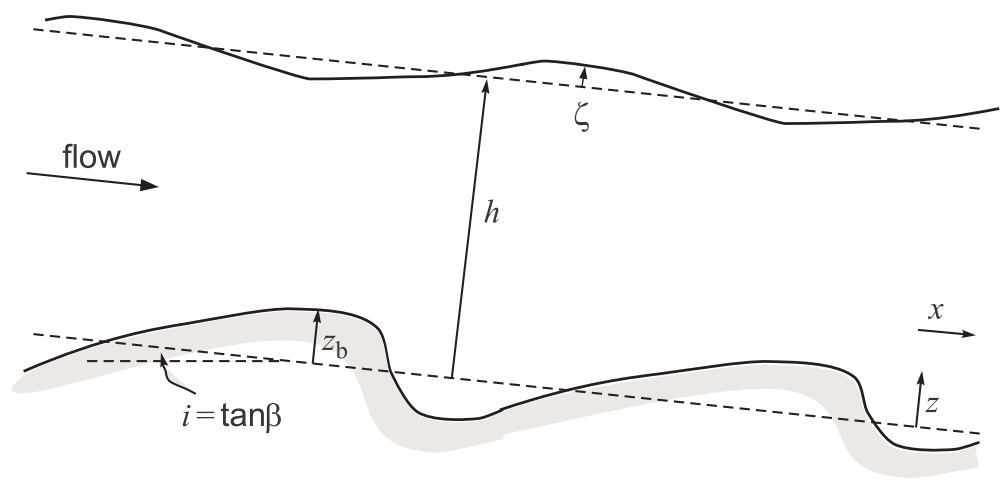

Figure 3.2: Definitions of the average flow depth $h$, the bed elevation $z_{\mathrm{b}}$, the watersurface elevation $\zeta$ and the channel slope $i$. In the given coordinate system, $x$ is the streamwise coordinate and $z$ the vertical coordinate.

condition, (ii) the time variations in the horizontal momentum equation can be dropped (i.e. a quasi-steady approach) and (iii) a rigid lid is applied at the water surface (Appendix A). These approximations are valid for (squared) Froude numbers $\ll 1$. Since Froude numbers for flume conditions are generally larger than in rivers, the model has to be applied with some care to flume conditions. The final set of scaled equations is presented in Appendix A6. In this paper, we use the unscaled versions of the equations.

\subsubsection{Steady flow equations with hydrostatic pressure}

The flow is described by the two-dimensional shallow water equations in a vertical plane, using the hydrostatic pressure assumption. The momentum equation in $x$-direction and the continuity equation read:

$$
\begin{gathered}
u \frac{\partial u}{\partial x}+w \frac{\partial u}{\partial z}=-g \frac{\partial \zeta}{\partial x}+A_{\mathrm{v}} \frac{\partial^{2} u}{\partial z^{2}}+g i, \\
\frac{\partial u}{\partial x}+\frac{\partial w}{\partial z}=0 .
\end{gathered}
$$

The velocities in the $x$ - and $z$-directions (Fig. 3.2) are $u$ and $w$, respectively. The water surface elevation is denoted by $\zeta, i$ is the average channel slope, and $g$ and $A_{\mathrm{v}}$ denote the acceleration due to gravity and the vertical eddy viscosity, respectively. In Equation (3.1) the terms on the left-hand side are advective terms, and on the right-hand side the terms represent a pressure gradient, turbulent diffusion and gravity force due to a sloping bed (Fig. 3.2), respectively. 


\subsubsection{Boundary conditions}

Two boundary conditions at the water surface $(z=h)$ are: $(i)$ no flow through the surface, and $(i i)$ no shear stress at the surface (see Appendix A):

$$
\begin{aligned}
& u \frac{\partial \zeta}{\partial x}=w \\
& \frac{\partial u}{\partial z}=0 .
\end{aligned}
$$

The kinematic boundary condition at the bed $\left(z=z_{\mathrm{b}}\right)$ is that there is no flow through the boundary:

$$
u \frac{\partial z_{\mathrm{b}}}{\partial x}=w .
$$

As basic turbulence closure, we use a $z$-independent eddy viscosity, leading to a parabolic velocity profile (e.g. Hulscher, 1996). To correctly represent the bed shear stress for a constant eddy viscosity, we need a partial slip condition at the bed $\left(z=z_{\mathrm{b}}\right)$ :

$$
\tau_{\mathrm{b}}=A_{\mathrm{v}} \frac{\partial u}{\partial z}=S u_{\mathrm{b}}
$$

where $\tau_{\mathrm{b}}$ is the volumetric bed shear stress $\left[\mathrm{m}^{2} \mathrm{~s}^{-2}\right]$ and the resistance parameter $S$ controls the resistance at the bed (Hulscher \& Van Den Brink, 2001; Besio et al., 2004). Soulsby (1990) showed that a constant eddy viscosity over the flow depth, in combination with a partial slip condition at the bed, results in a good representation of the vertical flow structure and the bed shear stress. Furthermore, a partial slip condition was previously successfully applied to tidal flows (e.g. Prandle, 1982; Maas \& Van Haren, 1987; Schramkowski \& de Swart, 2002). For open channel flows, Engelund (1970) used a bed boundary condition similar to a partial slip condition, by allowing for a horizontal velocity at the bed. Relationships for the eddy viscosity $A_{\mathrm{v}}$ and resistance parameter $S$ will be determined in Section 3.4.

In this paper we choose to use periodic boundary conditions, requiring an additional equation to guarantee uniqueness of the solution:

$$
\int_{0}^{L_{\mathrm{dom}}} \zeta d x=0,
$$

where $L_{\text {dom }}$ is the length of the periodic domain. For details about the numerical solution procedure for the flow equations, see Van den Berg \& Van Damme (2005) and Van den Berg (2007).

In the present paper, we employ periodic boundary conditions (both for the flow and the sediment transport modules). The channel slope (Fig. 3.2 and term ' $g i$ ' in Eq. 3.1) is the driving force for the flow, meaning that the (specific) discharge is not specified in the model, but follows inherently from the solution of the equations. The main parameters that control this discharge are the eddy viscosity and bed resistance parameter. Apart from two calibration 
coefficients that will be specified later (Sec. 3.4), these parameters only depend on the channel slope and the water depth. If the dune height increases for both a constant channel slope and water depth, the simulated specific discharge decreases. This is not in line with flume experiments where the constant discharge is accompanied by an increasing water depth due to increasing bed roughness. Therefore, in model simulations, the average flow depth $h$ is changed iteratively such that the specific discharge found as solution of the flow equations equals that of the experiment (within $1 \%$ accuracy).

\subsubsection{Flow separation criterion}

Sinusoidal bedforms of low amplitude do not necessarily cause the flow to separate. However, if the amplitude of a sinusoidal bedform grows and it becomes asymmetrically shaped in downstream direction, leeside slopes increase so that the flow eventually separates. To include this in the morphodynamic model, we define a critical leeside slope; if this critical slope is exceeded, flow separation is taken into account in a parameterized way (Fig. 3.1).

Best \& Kostaschuk (2002) used measurements over low-angle dunes to show that intermittent (i.e. non-permanent) flow separation occurs over dunes with maximum lower leeside slopes of $-14^{\circ}$. At present, the dynamics of flow over low-angle dunes and under which conditions they form is not yet fully known (Best, 2005), and it is therefore not possible to state at which exact leeside slope the flow will separate. However, some indications on the value of this critical leeside slope exist. Azad (1996) reports intermittent flow separation to occur downstream from conical diffusers, in which the change in angle at the diffuser expansion is often less than $10^{\circ}$ (Best, 2005). For the aeolian case, Anderson (1990) argued that an analysis using simple rules for particle dynamics breaks down at a relatively early stage of ripple evolution, when the leeslope of the developing forms begins to exceed the impact angle of grains. Using a finite impact angle for the grains (typically $-10^{\circ}$ ) a shadow zone is formed behind ripples (conform Niño et al., 2002). Although such a shadow zone is not directly comparable to a hydrodynamic separation zone, it appears that if the leeslope exceeds $10^{\circ}$, shadowing (i.e. flow separation) needs to be taken into account.

In this paper, we choose to use a critical leeside slope of $-10^{\circ}$, meaning that flow separation is not modelled for dunes with leeside slopes milder than $-10^{\circ}$. Thus, intermittent flow separation is not taken into account; once the leeslope criterion is exceeded, the flow separation zone is considered to be permanent. The sensitivity to the choice of critical leeside slope is investigated in the discussion (Sec. 3.6).

\subsubsection{Parameterization of the separation streamline}

Figure 3.3 shows the typical shape of a flow separation zone over a dune with a fully developed angle-of-repose lee face. The flow separates at the dune crest (which is equal to the brinkpoint in this case), and a reattachment zone is located approximately 5 dune heights downstream of the dune crest (Paarlberg et al., 2007; Chapter 2). A separation streamline can be identified which forms the 
a
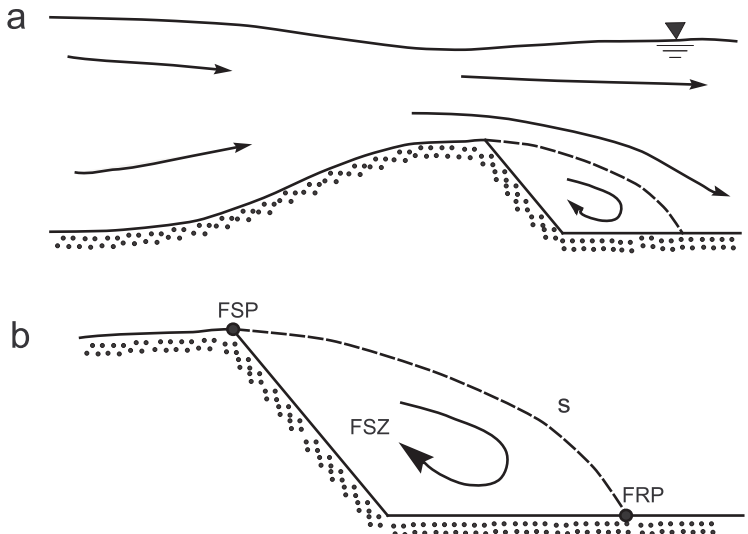

Figure 3.3: Schematic representation of flow separation in the dune lee. (a) flow over a complete dune; (b) detail of the flow separation zone (FSZ). The dashed line is the separation streamline (s), with the flow separating at the flow separation point (FSP), and reattaching at an angle to the bed at the flow reattachment point (FRP).

upper boundary of the flow separation zone. Paarlberg et al. (2007) determined the separation streamline $s$ (Fig. 3.3), and thus the shape of the flow separation zone, using experimental data of turbulent flow over subaqueous dunes as a third-order polynomial. Paarlberg et al. (2007) showed that the coefficients of this polynomial can be estimated, independently of flow conditions, based on the dune shape at the flow separation point and a fixed angle of the separation streamline at the flow reattachment point (see Chapter 2).

Following Kroy et al. (2002), the hydrostatic flow is computed by using the separation streamline $s$ as artificial 'bed' and the flow within the flow separation zone is not explicitly treated. The applied partial slip condition over the separation streamline equals the one over the bed. This is a simplification of reality regarding the flow field and turbulence and shear layer formation associated with flow separation. However, we are mainly interested in the morphological behaviour rather than solving all details of the flow field.

\subsection{Sediment transport and bed evolution model}

\subsubsection{Bedload transport formula including bed-slope effects}

In cases where bed load transport is dominant, dunes are asymmetrically shaped with a leeside slope at approximately the angle of repose $\left(\sim-30^{\circ}\right)$ (Smith \& McLean, 1977; Kostaschuk \& Villard, 1996). In the present paper, we do not incorporate suspended sediment transport, as this is regarded not crucial in modelling river dune formation and migration in bed load dominated rivers. For relatively large Froude numbers or Shields numbers, the influence of suspended sediment transport is significant. Using a numerical analysis, Tjerry \& Fredsøe (2005) showed that at relatively high Shields numbers, dunes tend to get longer 
and more symmetrically shaped if most of the sediment is transported in suspension. Engelund (1970) showed that suspended sediment transport is especially important in supercritical flow regimes with Froude numbers close to or exceeding 1 . In the flume experiments considered in this paper, Froude numbers are generally in the order of $0.3-0.5$, and for field conditions the numbers are often even smaller, meaning that the effects of suspended sediment transport can be safely neglected.

The local bed load transport rate is evaluated using the turbulence-averaged bed shear stress as obtained with Equation (3.6). Although this approach neglects transport details associated with turbulence fluctuations of the bed shear stress (Nelson et al., 1995), it enables to study temporal dune evolution. In this paper, we apply the sediment transport formula of Meyer-Peter \& Müller (1948), including gravitational bed-slope effects:

$$
q_{b}= \begin{cases}\alpha\left(\tau(x)-\tau_{\mathrm{c}}(x)\right)^{n}\left(1+\eta \frac{\partial z_{\mathrm{b}}}{\partial x}\right)^{-1} & \text { if } \tau>\tau_{\mathrm{c}} \\ 0 & \text { if } \tau \leq \tau_{\mathrm{c}}\end{cases}
$$

in which $\tau$ is the bed shear stress $\left[\mathrm{m}^{2} \mathrm{~s}^{-2}\right]$ and $\tau_{\mathrm{c}}$ a critical bed shear stress (other parameters are explained below). The proportionality constant $\alpha\left[\mathrm{s}^{2}\right.$ $\mathrm{m}^{-1}$ ] describes how efficiently the sand particles are transported by the bed shear stress (Van Rijn, 1993) and strongly determines the time scale of bed evolution. Its value can be estimated with:

$$
\alpha=\frac{m}{\left(\rho_{\mathrm{s}} / \rho_{\mathrm{w}}-1\right) g},
$$

where $\rho_{\mathrm{s}} / \rho_{\mathrm{w}}$ is the specific grain density $(=2.65)$ and $m$ is an empirical coefficient. The bed slope parameter $\eta$ reflects the downhill preference of moving sediment and is inversely related to the tangent of the angle of repose $\varphi$ (e.g. Sekine \& Parker, 1992):

$$
\eta=\frac{1}{\tan (\varphi)}
$$

We will show that the gravitational bed-slope effects are important to determine the fastest growing wave length using linear analysis (Sec. 3.4), and for saturation at an equilibrium dune height (Sec. 3.5.3). In fluvial systems, the shear stress is often of the same order as the critical shear stress. Moreover, it is influenced by bed-slope effects (Fredsøe \& Deigaard, 1992, p.205). The critical bed shear stress $\left(\tau_{\mathrm{c}}\right)$ is corrected for bed-slope effects using the following expression:

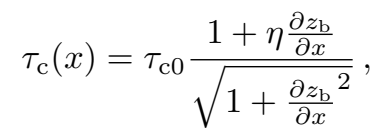

with $\tau_{\mathrm{c} 0}$ the critical bed shear stress for flat bed, defined as:

$$
\tau_{\mathrm{c} 0}=\theta_{\mathrm{c} 0} g\left(\rho_{\mathrm{s}} / \rho_{\mathrm{w}}-1\right) D_{50},
$$

in which $\theta_{\mathrm{c} 0}$ is the critical Shields parameter and $D_{50}$ is the median grain size $[\mathrm{m}]$. 

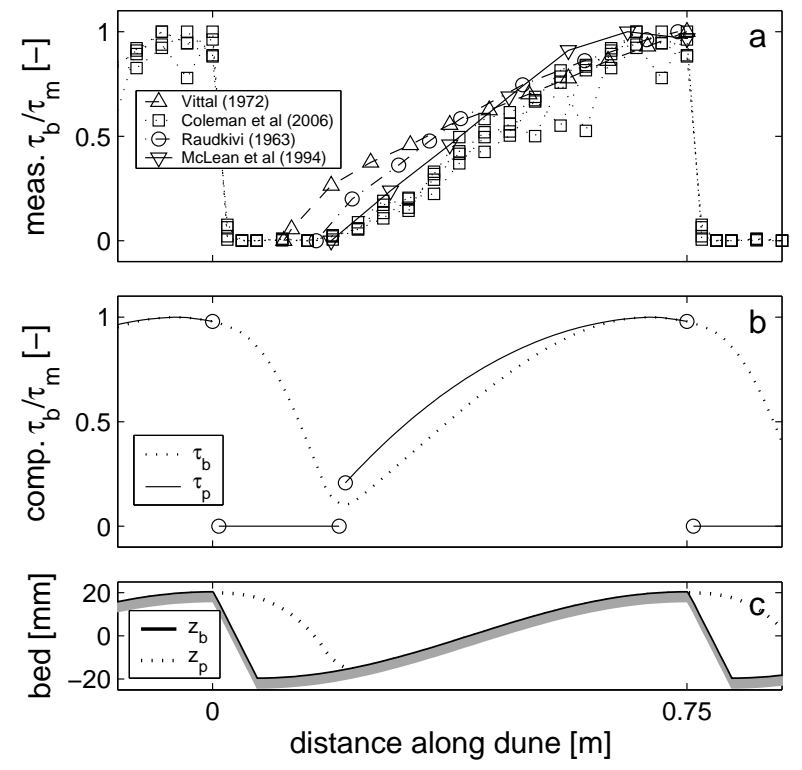

Figure 3.4: Illustration of the procedure to parameterize the bed shear stress distribution over a dune in case of flow separation. (a) measured bed shear stresses, normalized by the maximum measured bed shear stress for that case $\left(\tau_{\mathrm{m}}\right)$; (b) computed bed shear stress $\tau_{\mathrm{b}}$ over the parameterized bed $z_{\mathrm{p}}$, and parameterized bed shear stress $\tau_{\mathrm{p}}$ according to Equation (3.13); circles represent the discontinuities as discussed in the text; (c) bed level $z_{\mathrm{b}}$ and parameterized bed level $z_{\mathrm{p}}$.

Based on flume experiments, Meyer-Peter \& Müller (1948) suggested a value of 8 for the empirical coefficient $m$ and a critical Shields number of 0.047. A recent reanalysis performed by Wong \& Parker (2006), using the data of MeyerPeter \& Müller and additional data, revealed that the coefficients as proposed by Meyer-Peter \& Müller (1948) yield an overprediction of the sediment transport rate by a factor of 2.0-2.5. Wong \& Parker (2006) obtained a better fit using $m=4$ and a critical Shields number of 0.05 , which are the values that are applied in the present paper.

\subsubsection{Bed shear stress distribution in case of flow separation}

Correct modelling of the bed shear stress distribution over dunes is crucial, since it directly determines the local sediment transport rate (Eq. 3.8), and thus dune evolution. In case of flow separation, the hydrostatic flow is computed over the parameterized bed $z_{\mathrm{p}}$ (dotted line in Fig. 3.4c), yielding the bed shear stress distribution over the dunes (dotted line in Fig. 3.4b). Measurements of bed shear stresses (Raudkivi, 1963; Vittal, 1972; McLean et al., 1994; Coleman et al., 2006), normalized by the maximum bed shear stress for that experiment (Fig. 3.4a) show that in the flow separation zone, the turbulence-averaged bed shear stress reduces to zero. Therefore, in our simulation model, the bed shear 
stress is set to zero within the flow separation zone (horizontal solid lines in Fig. 3.4b), yielding zero sediment transport rates. This procedure yields two discontinuities in the bed shear stress distribution over a dune, i.e. at the flow separation point and at the flow reattachment point. The discontinuity at the flow separation point will be resolved in the next section.

To overcome the discontinuity at the flow reattachment point we need a parameterization of the bed shear stress distribution over the stoss-side of the dunes. In case of flow separation, no critical shear stress is apparent near reattachment, because of the large turbulent fluctuations in the reattachment zone. To apply the sediment transport relationship (Eq. 3.8) continuously without and with flow separation, we include the critical bed shear stress also in case of flow separation (further downstream on the stoss side a critical bed shear stress does exist). The most transparent manner to obtain this behaviour is to $(i)$ set the stress to the critical stress at the flow reattachment point, effectively yielding a zero transport rate at that point, and ( $i i)$ impose a positive gradient at the flow reattachment point to ensure sediment transport from the flow reattachment point in downstream direction.

The measurements presented in Figure 3.4a, show that downstream of the flow reattachment point, the bed shear stress gradually increases from zero to a maximum value towards the crest of the downstream dune. To mimic this behaviour, the bed shear stress distribution over a dune in case of flow separation is parameterized as $\tau_{\mathrm{p}}$, using a third-order polynomial function:

$$
\tau_{\mathrm{p}}(x)= \begin{cases}0 & \text { if } x_{\mathrm{s}}<x \leq x_{\mathrm{r}}(\mathrm{FSZ}) \\ a_{3} x^{\prime 3}+a_{2} x^{\prime 2}+a_{1} x^{\prime}+a_{0} & \text { if } x_{\mathrm{r}} \leq x \leq x_{\mathrm{m}}(\text { stoss-side })\end{cases}
$$

in which $x_{\mathrm{s}}$ is the flow separation point, $x_{\mathrm{r}}$ the reattachment point, $x_{\mathrm{m}}$ the $x$-coordinate of the maximum bed shear stress, $x^{\prime}=x-x_{\mathrm{r}}$, and $a_{0} \ldots a_{3}$ are coefficients. For reasons described above, coefficient $a_{0}$ equals the critical bed shear stress at the flow reattachment point $\left(\tau_{\mathrm{r}}\right)$. Coefficient $a_{1}$ is specified as:

$$
a_{1}=\left.\frac{d \tau_{\mathrm{p}}}{d x}\right|_{x_{\mathrm{r}}}=\tau_{\mathrm{A}} \frac{\tau_{\mathrm{m}}-\tau_{\mathrm{r}}}{x_{\mathrm{m}}-x_{\mathrm{r}}} .
$$

The parameter $\tau_{\mathrm{A}}$ is estimated from the measurements as $\tau_{\mathrm{A}}=2$. This means that the gradient in the bed shear stress at the flow reattachment point is twice the average shear stress gradient between $x_{\mathrm{r}}$ and $x_{\mathrm{m}}$. This choice of $\tau_{\mathrm{A}}$ reflects the observation that a lot of sediment is transported at the flow reattachment point, mainly as a result of turbulence generated in the flow reattachment zone (e.g. Sumer et al., 2003; Tjerry \& Fredsøe, 2005).

Classical theories on dune formation show that phase shifts between the bed topography and the bed shear stress are crucial for modelling dune morphology. The maximum bed shear stress $\left(\tau_{\mathrm{m}}\right)$ often occurs upstream of the dune crest due to fluid inertia. To take this effect into account in Equation (3.13), the coefficients $a_{2}$ and $a_{3}$ are set by imposing a smooth connection to the bed shear stress (and gradient in bed shear stress) at $x_{\mathrm{m}}$, which are computed over the 

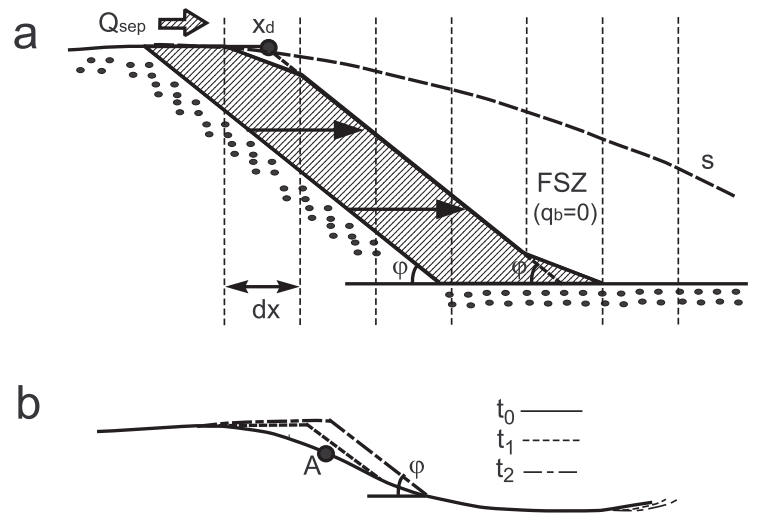

Figure 3.5: Illustration of the sediment transport and bed evolution in case of flow separation. (a) The volume of sediment that passes the flow separation point during one timestep $\left(Q_{\mathrm{sep}}\right)$ distributes evenly over the leeside, with the leeside at the angle of repose $(\varphi) . x_{\mathrm{d}}$ is the horizontal position where the leeside starts; $\mathrm{dx}$ is the horizontal grid distance. (b) If flow separation starts to occurs (i.e. if $\mathrm{d} z_{\mathrm{b}} / \mathrm{d} x=-10^{\circ}$ at position A), the leeside builds at the angle of repose from the dune crest, with $t_{0} \ldots t_{2}$ indicating successive time steps.

parameterized bed $\left(z_{\mathrm{p}}\right)$. The solid line in Figure $3.4 \mathrm{~b}$ gives a typical example of the parameterized bed shear stress in case of flow separation, which compares reasonably well to the measurements presented in Figure 3.4a.

\subsubsection{Bed evolution}

Without flow separation, topographic changes follow from the Exner equation, using the sediment transport rate computed with Equation (3.8):

$$
\left(1-\epsilon_{\mathrm{p}}\right) \frac{\partial z_{\mathrm{b}}}{\partial t}=-\frac{\partial q_{\mathrm{b}}}{\partial x}
$$

where $\epsilon_{\mathrm{p}}$ is the bed porosity (typically $\epsilon_{\mathrm{p}} \sim 0.4$ ).

In case of flow separation, the bed shear stress distribution follows from Equation (3.13) and the evolution of the stoss side of a dune can simply be solved using the continuity equation (3.15). As was mentioned in the previous section, the sediment transport rate is zero within the flow separation zone. The volumetric sediment transport passing the flow separation point is assumed to settle quickly in the flow separation zone and avalanches down the lee face where it distributes evenly (see Fig. 3.5a). The leeside slope is assumed constant and equal to the angle of repose for submerged natural sand, which is about $-30^{\circ}$.

Flow separation sets in if the bed slope of a bedform exceeds a threshold of $-10^{\circ}$ (see Section 3.2.3). This means that there is a discrepancy between this bed slope and the angle of repose when flow separation sets in. To overcome this discrepancy, the leeside builds up from the bedform crest under the angle 
Table 3.1: General parameters for a model run.

\begin{tabular}{llll}
\hline Parameter & Symbol & Value & Dimension \\
\hline acceleration of gravity & $g$ & 9.81 & $\mathrm{~m} \mathrm{~s}^{-2}$ \\
proportionality constant & $m$ & 4 & - \\
nonlinearity parameter & $n$ & 1.5 & - \\
specific grain density & $\rho_{\mathrm{s}} / \rho_{\mathrm{w}}$ & 2.65 & - \\
sediment porosity & $\epsilon_{\mathrm{p}}$ & 0.4 & - \\
critical shields parameter & $\theta_{\mathrm{c} 0}$ & 0.05 & - \\
angle of repose & $\varphi$ & 30 & $\circ$ \\
grid points in $x$-direction & $\mathrm{Npx}$ & 120 & - \\
grid points in $z$-direction & $\mathrm{Npz}$ & 25 & - \\
time step flow solver & $\mathrm{dt}$ & 1 & $\mathrm{~S}$ \\
\hline
\end{tabular}

of repose, ensuring sediment continuity (Fig. 3.5b). In this way, a fully developed leeside at the angle of repose, with a region of permanent flow separation, typically develops within 10 timesteps in the model. Using this approach, we have constructed a model that is able to compute the evolution of a dune from a case without separation to a case with flow separation, continuously.

The bottom update is done using explicit forward Euler time integration and in Equation (3.8) both $z_{\mathrm{b}}$ and $\tau_{\mathrm{b}}$ are treated explicitly. Figure 3.5b shows that in one time step, the bed is horizontally extended from the separation point to the point where the lee-slope starts. In reality this will be a more "curved" process. Therefore the bed is smoothed at the flow separation point over 5 grid points before the flow is computed (a dune typically covers 120 grid points in horizontal direction). Since the parameterized separation streamline reattaches to the bed at a certain angle (Fig. 3.3b), also at the reattachment point the bed is smoothed over 5 grid points. Both smoothing algorithms are for 5 points, which is the minimal required number of points to prevent numerical instabilities in the flow solver.

\subsection{Parameter settings and calibration of the partial slip model}

The general and numerical parameters that are required to perform simulations, are presented in Table 3.1. The grid spacing in both horizontal and vertical direction is equidistant. Sufficient resolution in vertical direction is required to resolve the flow recirculation cells as discussed in Hulscher \& Dohmen-Janssen (2005).

In uniform and steady open channel flows, the eddy viscosity profile over the flow depth can be described by a parabolic profile (see e.g. Fredsøe \& Deigaard, 1992). Integration of such a profile over the flow depth gives a relationship for the depth-averaged eddy viscosity:

$$
A_{\mathrm{v}} \sim \frac{1}{6} \kappa u_{*} h
$$




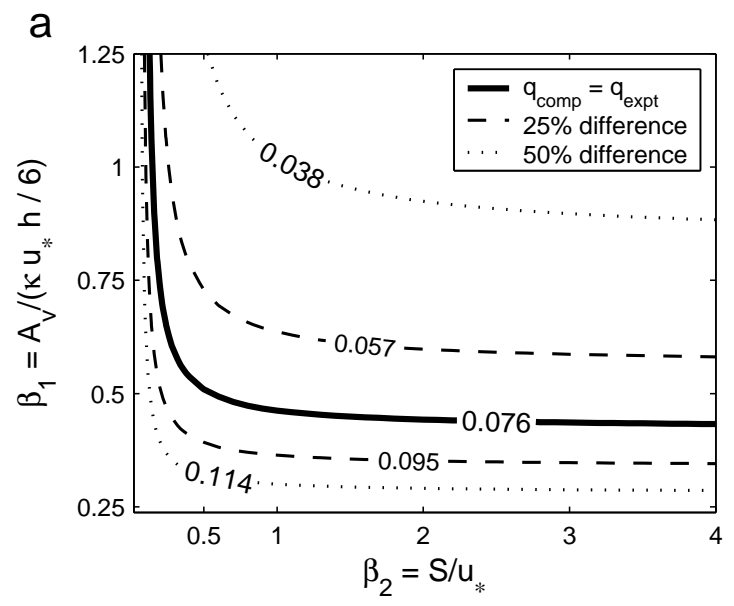

Figure 3.6: Calibration of the partial slip model using Flow A of Venditti et al. (2005). (a) simulated flow over a flat rough bed, represented as the computed specific discharge $q_{\mathrm{comp}}\left[\mathrm{m}^{2} \mathrm{~s}^{-1}\right]$, for various values of the calibration coefficients $\beta_{1}$ and $\beta_{2}$, compared to the discharge in the experiment $q_{\text {expt }}$. b) linear stability plot for $\beta_{1}=\beta_{2}=0.5$, showing growth- and migration rate curves in the linear regime. 
in which $\kappa$ is the Von Kármán constant $(=0.407)$, and $u_{*}$ is the shear velocity $(=\sqrt{g h i})$. Note that this equation is very similar to the one used by Engelund (1970). Several authors have related the resistance parameter $S$ to the shear velocity (Engelund, 1970; Maas \& Van Haren, 1987; Zhou \& Mendoza, 2005):

$$
S \sim u_{*}
$$

Since we use periodic boundary conditions in the morphodynamic model, we cannot specify the discharge as model forcing (see Section 3.2.2). Therefore, choosing $S$ and $A_{\mathrm{v}}$ has to result in a correct discharge for the simulation, and to this end $S$ and $A_{\mathrm{v}}$ are specified as:

$$
A_{\mathrm{v}}=\beta_{1} \frac{1}{6} \kappa u_{*} h
$$

and

$$
S=\beta_{2} u_{*},
$$

where $\beta_{1}$ and $\beta_{2}$ are calibration coefficients.

For a flat bed, the equation of motion (Eq. 3.1) reduces to:

$$
0=A_{\mathrm{v}} \frac{\partial^{2} u}{\partial z^{2}}+g i
$$

and can be solved analytically to obtain the specific discharge $q$ using boundary conditions $(3.4)$ and $(3.6)^{1}$ :

$$
q=U h=\frac{u_{*}^{2} h\left(h S+3 A_{\mathrm{v}}\right)}{3 A_{\mathrm{v}} S}=\frac{2 u_{*} h\left(\beta_{2}+\frac{1}{2} \beta_{1} \kappa\right)}{\beta_{1} \beta_{2} \kappa},
$$

where $U$ is the depth-averaged flow velocity. The coefficients $\beta_{1}$ and $\beta_{2}$ are calibrated using "Flow A" as reported in Venditti et al. (2005), where the initial water depth $h=0.153 \mathrm{~m}$, the flume slope $i=0.0012$, the specific discharge $q=0.076 \mathrm{~m}^{2} \mathrm{~s}^{-1}$, and the median grain size $D_{50}=0.50 \mathrm{~mm}$. Figure $3.6 \mathrm{a}$ shows the computed specific discharge (Eq. 3.21) for different values of $\beta_{1}$ and $\beta_{2}$, and the solid line represents the specific discharge that was measured by Venditti et al. (2005) for this specific experiment. Various combinations of $\beta_{1}$ and $\beta_{2}$ yield the measured specific discharge. The simulated discharge is largely insensitive for the value of $\beta_{2}$ if $\beta_{2} \gtrsim 0.5$. In this paper we choose to use $\beta_{1}=\beta_{2}=0.5$, which gives $U=11.8 u_{*}$ (Eq. 3.21). Using the widely applied Chézy equation, this yields a Chézy coefficient of $37 \mathrm{~m}^{1 / 2} \mathrm{~s}^{-1}$, which is a quite common value for flume experiments with sandy beds (e.g. Blom et al., 2003, their Table 1).

Figure $3.6 \mathrm{~b}$ shows a stability plot for $\beta_{1}=\beta_{2}=0.5$, obtained from a numerical linear stability analysis, assuming sinusoidal bedforms and no flow separation

\footnotetext{
${ }^{1}$ the kinematic boundary conditions are not relevant in case of a flat bed, because there are no gradients in $x$-direction
} 


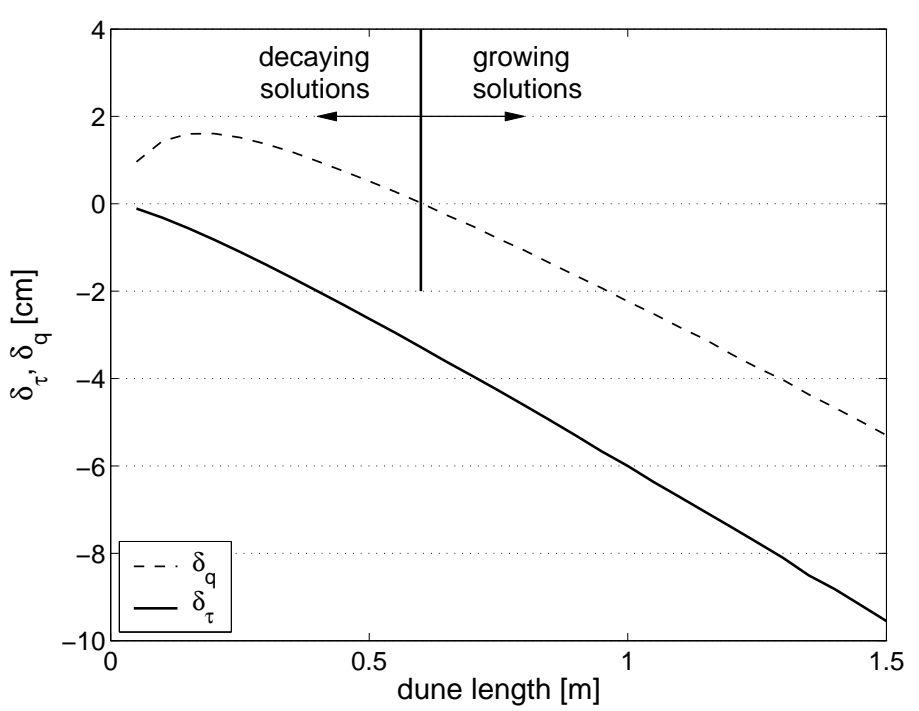

Figure 3.7: Displacement distances between maximum shear stress $\left(\delta_{\tau}\right)$ and maximum sand flux $\left(\delta_{q}\right)$ with respect to the top of a dune profile as a function of dune length (dune height is equal for every dune length).

(see Dodd et al. (2003) for details on stability theory). The fastest growing wave length is $\sim 1.05 \mathrm{~m}$, with a migration rate of about $5 \mathrm{~m} \mathrm{hr}^{-1}$. In their experiments, Venditti et al. (2005) found initial migration rates of 5-15 $\mathrm{m} \mathrm{hr}^{-1}$, and Venditti (2003) reports a wave length in equilibrium of $\sim 1.17 \mathrm{~m}$. By assuming that the wave length found using a linear analysis, is representative for the wave length in steady state equilibrium, this supports our choice for the coefficients $\beta_{1}$ and $\beta_{2}$.

Local sediment fluxes are not exactly in phase with the bed shear stress, since local bed slopes influence the sediment transport rate (Eq. 3.8). Effectively, this means that the maximum sediment flux does not necessarily occur at the dune crest. This effect is crucial to determine the fastest growing wave length, as is illustrated in Figure 3.7. Fluid inertia causes a displacement between the position of the maximum bed shear stress with respect to the dune crest $\left(\delta_{\tau}\right)$. This displacement is always negative with respect to the dune crest due to fluid inertia and increases for increasing dune lengths because the inertial effects increase with dune length. However, the displacement between the maximum flux and the dune crest $\left(\delta_{q}\right)$, can also be positive due to local bed-slope effects. Small sinusoidal bedforms can only grow in amplitude, if an upstream displacement exists between the top of the bed profile and the position of maximum sediment flux over the bedform $\left(\delta_{\mathrm{q}}\right)$ (e.g. Kroy et al., 2002; Charru, 2006). Figure 3.7 shows that in our model, the displacement $\delta_{\mathrm{q}}$ is positive for small dunes causing these short dunes to be stable (Fig. 3.7). 

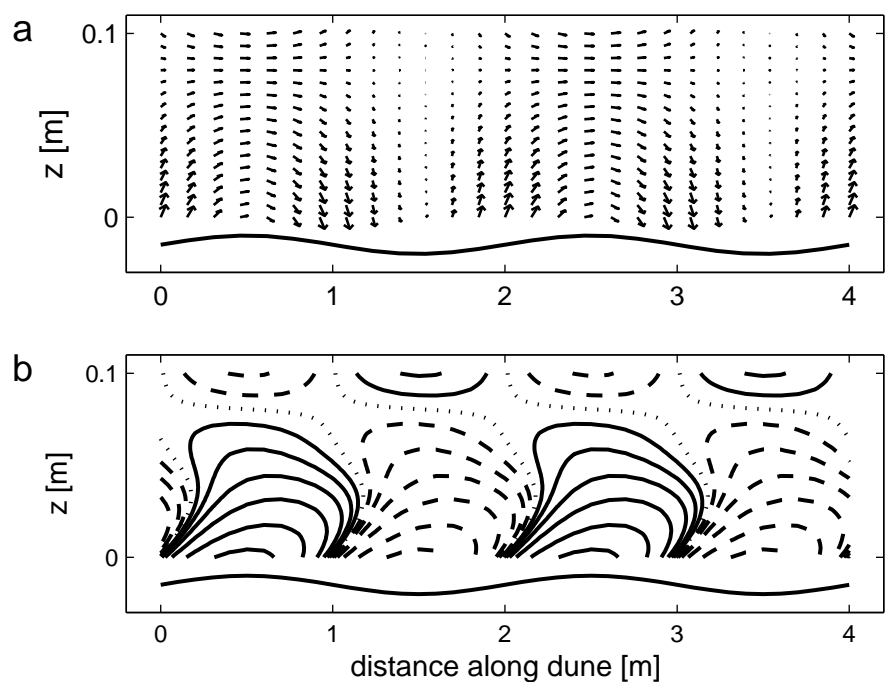

Figure 3.8: Flow response to a small bed disturbance consisting of two identical dunes (sketched at bottom). (a) residual time-independent flow field. (b) vorticity $\left(V=\frac{\partial u}{\partial z}-\frac{\partial w}{\partial x}\right)$, indicating $V=0$ (dotted lines), $V>0$ (solid lines), and $V<0$ (dashed lines). On the vertical axis is the vertical coordinate, and on the horizontal axis the streamwise coordinate. Unidirectional flow is from left to right.

\subsection{Model results}

\subsubsection{Flow field structure}

The residual time-independent flow field calculated with the model (Fig. 3.8a) shows that the water motion has a circulation pattern with residual velocities oriented towards the crest. This means that sediment is picked up at the stossside of a dune and is deposited at the leeside, giving rise to the migration of dunes. In his classical work on bed instability, Engelund (1970) showed that transport of vorticity in the flow field plays an important role in dune formation. Figure $3.8 \mathrm{~b}$ illustrates that vorticity is transported downstream, with clear circulation patterns present. The circulation cells found with the present model are similar to those found for offshore sand waves generated in tidal flows (Hulscher, 1996; Németh et al., 2007).

\subsubsection{General model behaviour}

Figure 3.9 shows the temporal dune evolution for a setting similar to Flow A of Venditti et al. (2005). Every line shows a bed profile, with a time interval of 5 minutes. The initial bed topography consists of a symmetrical sinusoidal wave with initial dune height $\Delta_{\mathrm{i}}=0.1 D_{50}$. The dune length is constant during a simulation and is obtained from a numerical linear stability analysis (see Fig. 3.6b). Initially the bedforms remain more or less symmetrical and the bedform height slowly increases. For larger amplitudes, nonlinear effects be- 


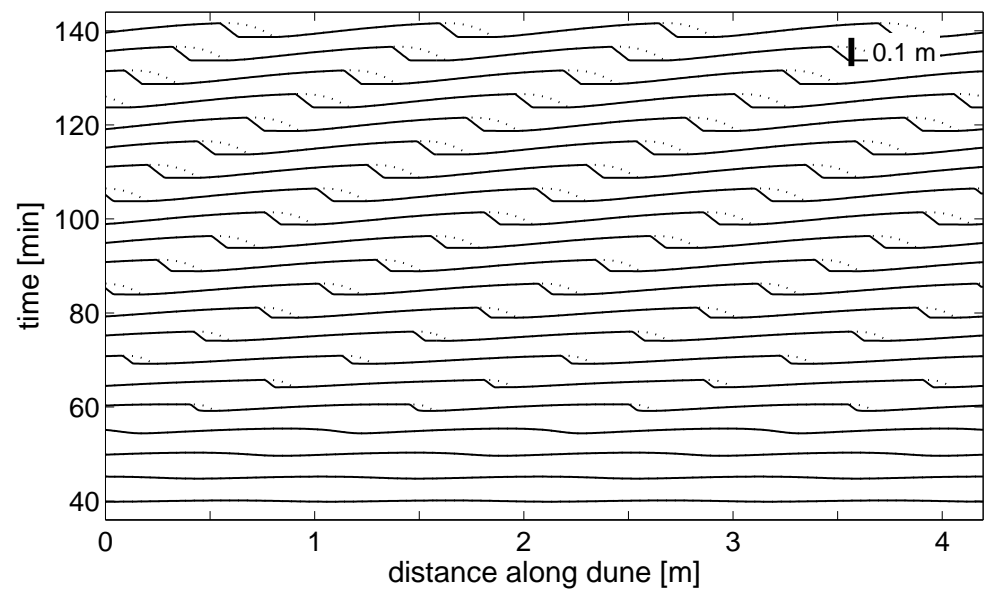

Figure 3.9: Dune evolution for a simulation of Flow A of Venditti et al. (2005). Every line represents a bed profile, with a time interval of 5 minutes. Dotted lines represent the separation streamlines at the top of the flow separation zone.

come more pronounced and the sinusoidal bedforms become asymmetrical with steeper sloping leesides. After about an hour, the flow starts to separate and the leeside builds up following the angle of repose (Fig. 3.5).

The temporal evolution of some characteristic parameters is shown in Figure 3.10. Figure 3.10a shows that the dune height (defined as the vertical distance between a crest and its downstream trough) initially increases slowly, which is because local bed slopes are small. During evolution, the dunes get more asymmetrically shaped and grow in amplitude (Fig. 3.9), leading to a steeper growth curve. Due to the increased dune height, and thus increased bed roughness, also the water depth increases during a simulation (Fig. 3.10a). Finally, the dunes attain an equilibrium where the dune height and water depth remain constant, while the dunes still migrate in downstream direction without changing shape (Fig. 3.9). Measurements of water depth and dune height are included in Figure 3.10a showing good agreement in equilibrium.

The time to equilibrium is determined independently of the initial bedform amplitude by defining it as the time it takes for a dune to develop from dune height $\Delta=0.05 \Delta_{\mathrm{e}}$ to $\Delta=0.95 \Delta_{\mathrm{e}}$, where $\Delta_{\mathrm{e}}$ is the equilibrium dune height. The equilibrium dune height is defined such that the dune height remains constant over at least 50 computational time steps. Applying this criterion of the time to equilibrium to Venditti's data gives a time to equilibrium of $\sim 1.5 \mathrm{hr}$. For our simulations, the time to equilibrium is $\sim 1.4 \mathrm{hr}$ (Fig. 3.10). Apparently, the model estimates this characteristic time scale very well.

The migration rate of simulated dunes is determined based on the phase shift between the Fourier transforms of two successive bed topographies. The model simulations show that initially, when the dunes are still low, the migration rate is $\sim 5 \mathrm{~m} \mathrm{hr}^{-1}$. In equilibrium, the migration rate is $\sim 2.7 \mathrm{~m} \mathrm{hr}^{-1}$, which is in 

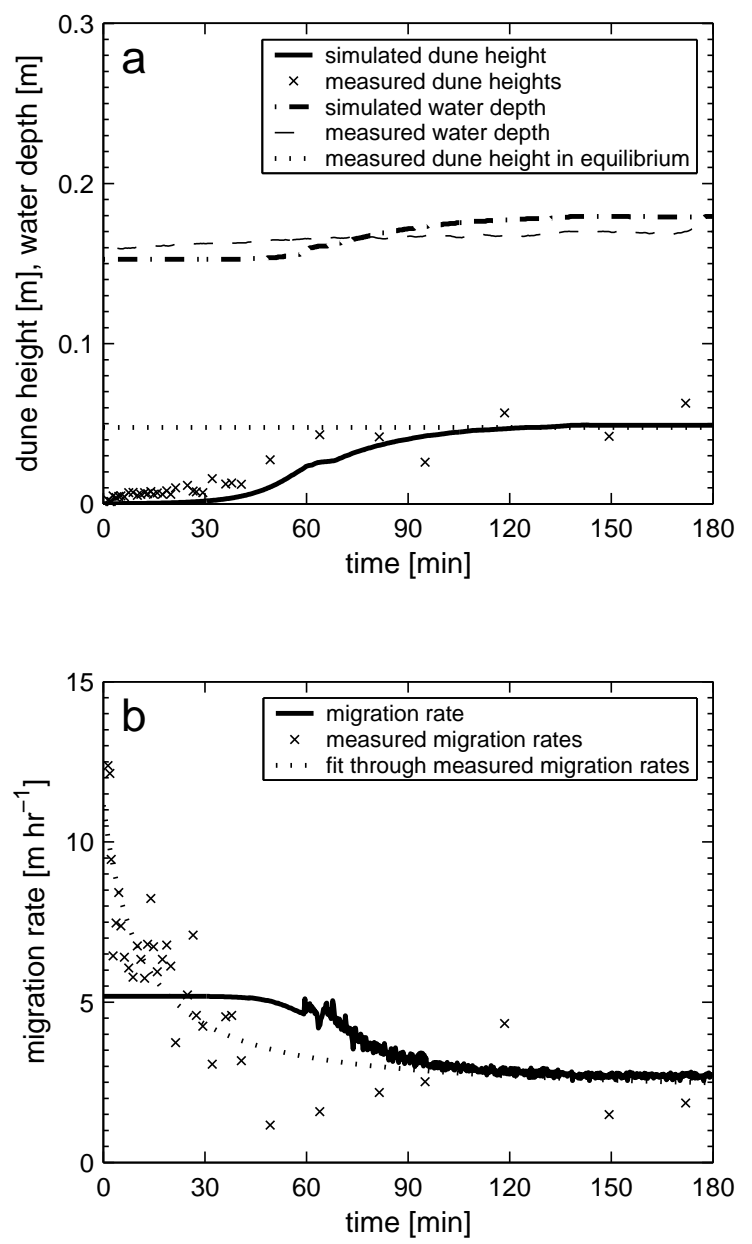

Figure 3.10: Simulation results for Flow A of Venditti et al. (2005). a) comparison of simulated and measured dune height and water depth; b) comparison of simulated and measured migration rate (fit is from Venditti, 2003). The dune height is defined as the vertical distance between the crest and its successive trough. The migration rate is based on the phase difference of the Fourier transform between two successive bed profiles. 
very good agreement with the value found by Venditti et al. (2005) (Fig. 3.10b). Comparing Figures 3.10a and 3.10b, shows that the migration rate is inversely proportional to the dune height, as was already suggested by Exner (1920) and later by e.g. Niño et al. (2002). The discrepancies between simulated and observed dune heights and migration rates is largest in the initial phase of dune formation. It is important to realize that in our simulations the dune length is constant. However, in the experiments, the initial dune length is small and in combination with a small amplitude, these small dunes can migrate quickly. This initial phase is not captured by our model leading to the observed discrepancy.

\subsubsection{Processes related to growth and saturation}

In this section we analyze dune growth and saturation towards an equilibrium dune height for both a case without and with flow separation included, to analyze whether flow separation changes dune evolution. Figure 3.11 shows the parameters that play a role in the growth and saturation dynamics for the same simulation as presented in Section 3.5.2.

First we analyze the case without taking flow separation into account, although the dune lee gets steeper than the criterion of $-10^{\circ}$. In Section 3.4 it was shown that bedforms grow in amplitude, if an upstream displacement exists between the dune crest and the position of maximum sediment flux $\left(\delta_{\mathrm{q}}\right)$, since this causes deposition at the dune crest. For the first 70 minutes of dune formation, the upstream displacement of $\delta_{\mathrm{q}}$ (Fig. 3.11a) indeed causes deposition at the dune crest (Fig. 3.11c), yielding dune growth (Fig. 3.11d). After about an hour, a marked decrease of the displacement $\delta_{\tau}$ is observed (Fig. 3.11a), i.e. the position of the maximum stress shifts closer to the dune crest. As a result, after about 70 minutes, the displacement $\delta_{\mathrm{q}}$ shifts slightly downstream of the crest. This causes a delicate balance between erosion at the dune crest (Fig. 3.11c) and deposition just downstream of the dune crest (not shown), yielding a dune that migrates downstream with constant dune height. Effectively, the dune amplitude saturates to an equilibrium quite abruptly (Fig. 3.11d) if the maximum lee slope that develops is about $-18^{\circ}$, i.e. just after the moment that flow separation is expected to become important.

Now we analyze a simulation taking flow separation into account. For this case, the displacements $\delta_{\tau}$ and $\delta_{\mathrm{q}}$ are presented in Figure 3.11b. After about an hour, flow separation sets in, indicated by the sharp changes in displacements. Both displacements vanish almost completely, if the dune crest reaches the slip face after about 65 minutes. In case of flow separation, the flow is computed over the separation streamline in the region of flow separation. The local bed slope at the flow separation point, which is not necessarily zero, is important in the determination of the shape of the separation streamline (Paarlberg et al., 2007; Chapter 2). A positive slope at the dune crest, yields a downstream displacement of the top of the artificial bed over which the flow is computed. This causes the displacement between the bed shear stress and the dune crest $\left(\delta_{\tau}\right)$ to reduce to almost zero, i.e. it comes closer to the dune crest (Fig. 3.11b). Due to 

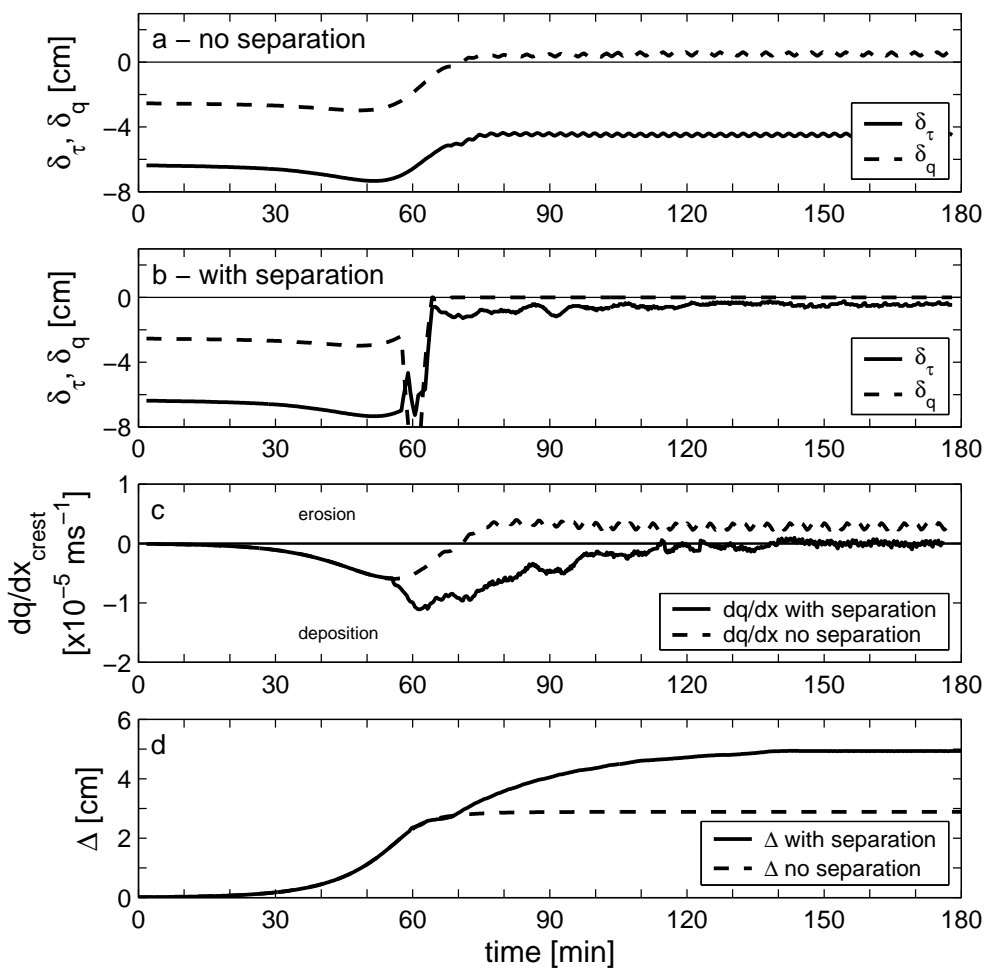

Figure 3.11: Parameters that play a role in the growth and saturation dynamics of a dune. (a) Displacements between maximum shear stress $\left(\delta_{\tau}\right)$ and maximum sand flux $\left(\delta_{q}\right)$ with respect to the dune crest without flow separation included; (b) the same displacements for a case with flow separation included; (c) erosion (positive) and deposition (negative) at the dune crest; (d) dune height evolution.

bed-slope effects, the displacement $\delta_{\mathrm{q}}$ seems to vanish completely (Fig. 3.11b), which would imply vanishing deposition at the dune crest.

However, careful analysis of the displacement $\delta_{\mathrm{q}}$ reveals small upstream displacements, which are actually smaller than the horizontal grid distance. In case of flow separation, the bed shear stress distribution is parameterized over the stoss side of a dune. This yields a relatively large sediment flux convergence at the dune crest, yielding deposition at the dune crest (Figs. 3.11c,d). This deposition process continues for about an hour, until the displacement $\delta_{\mathrm{q}}$ vanishes completely and an equilibrium dune height is obtained after about 140 minutes. From this analysis, it is clear that the local bed slope plays a crucial role in the saturation to an equilibrium dune height, since it determines (1) the shape of the separation streamline, (2) the bed shear stress distribution and thus the displacement $\delta_{\tau}$, and (3) the displacement $\delta_{\mathrm{q}}$. In this simulation, an equilibrium dune height is obtained if the local bed slope at the dune crest is about $1.5^{\circ}$. 


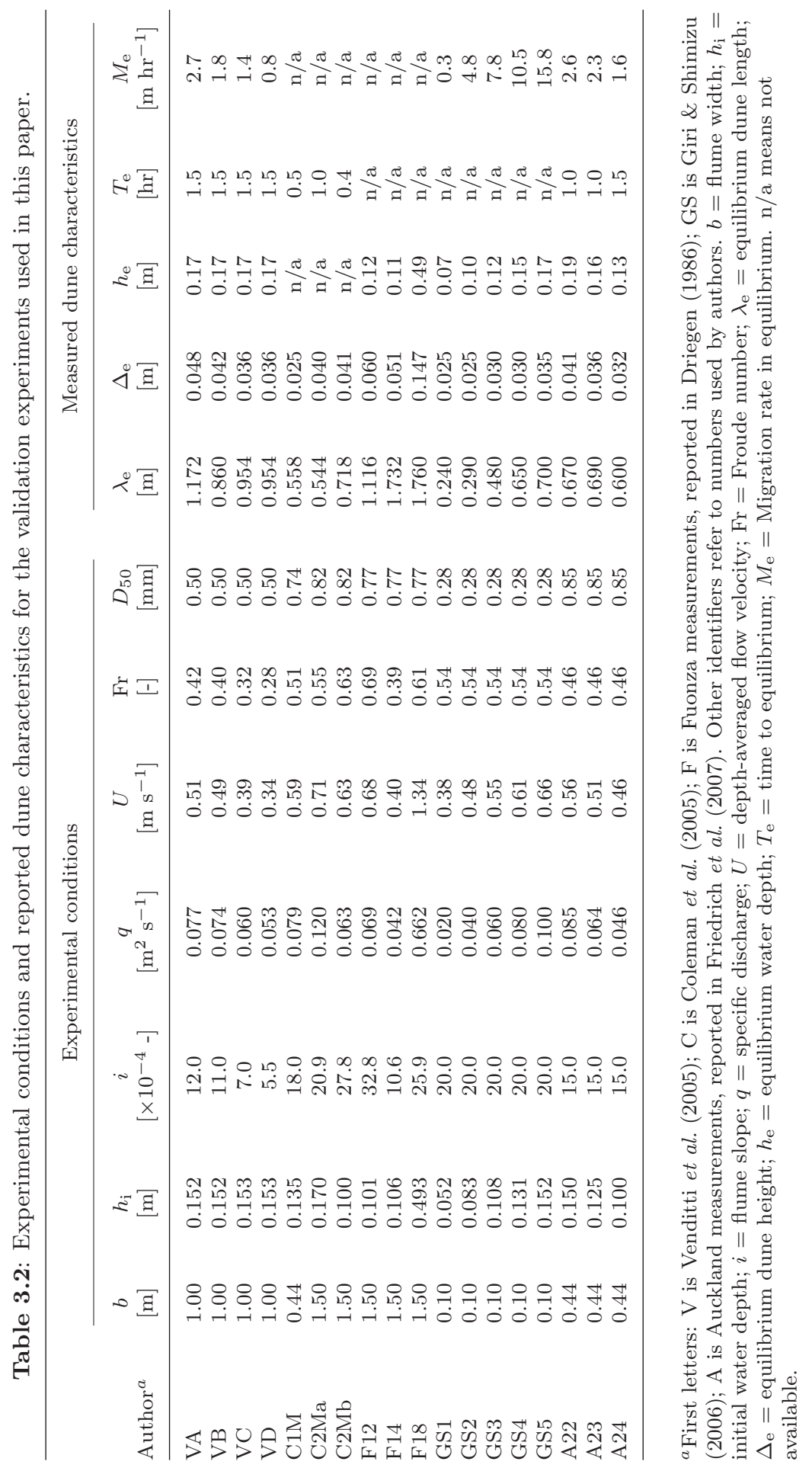



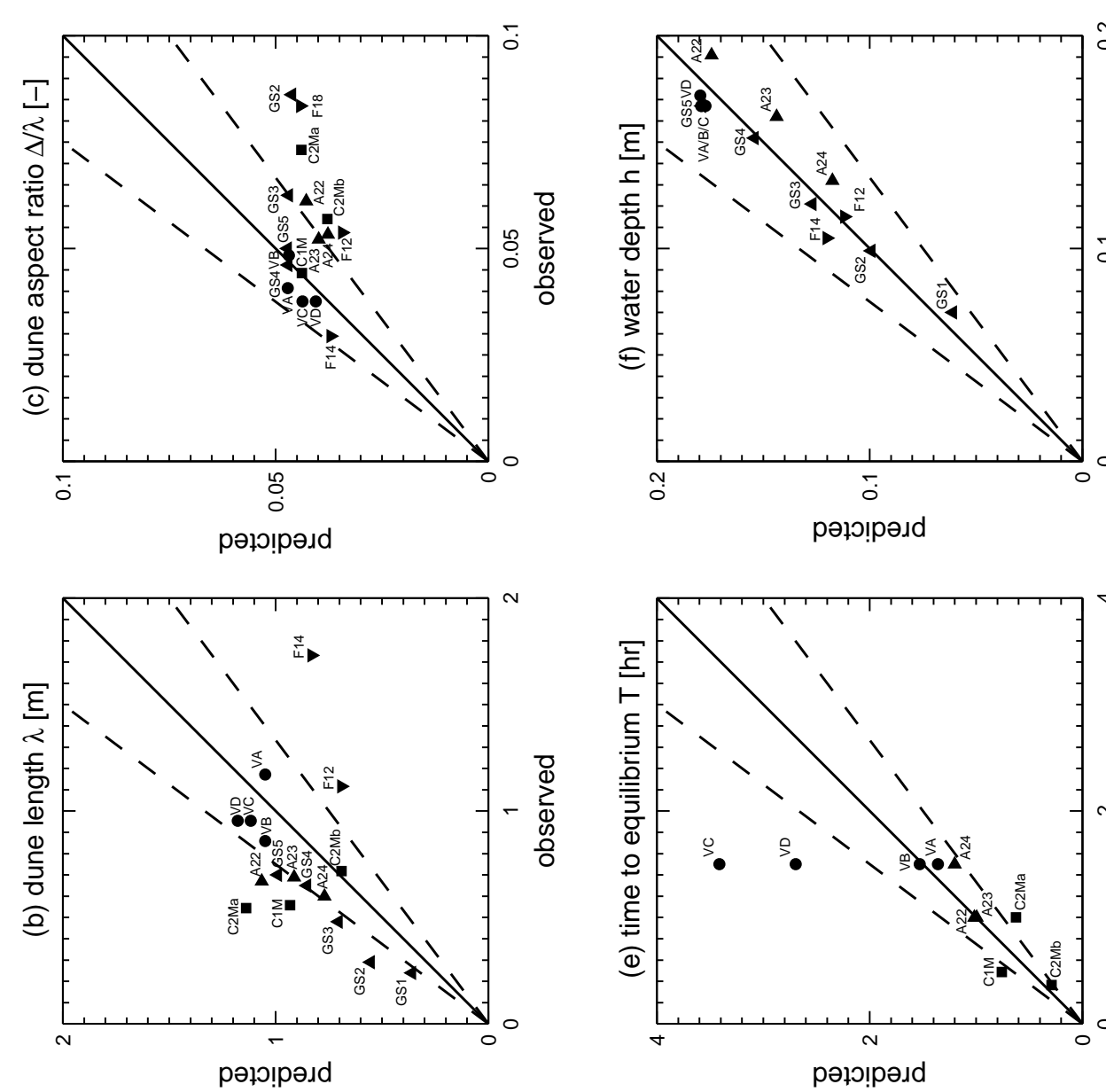

$\stackrel{\Xi}{\Xi}$

政

$\ddot{g}:$

0
0
0
0
0
0
0

్ㅏㅇ

蛋

.
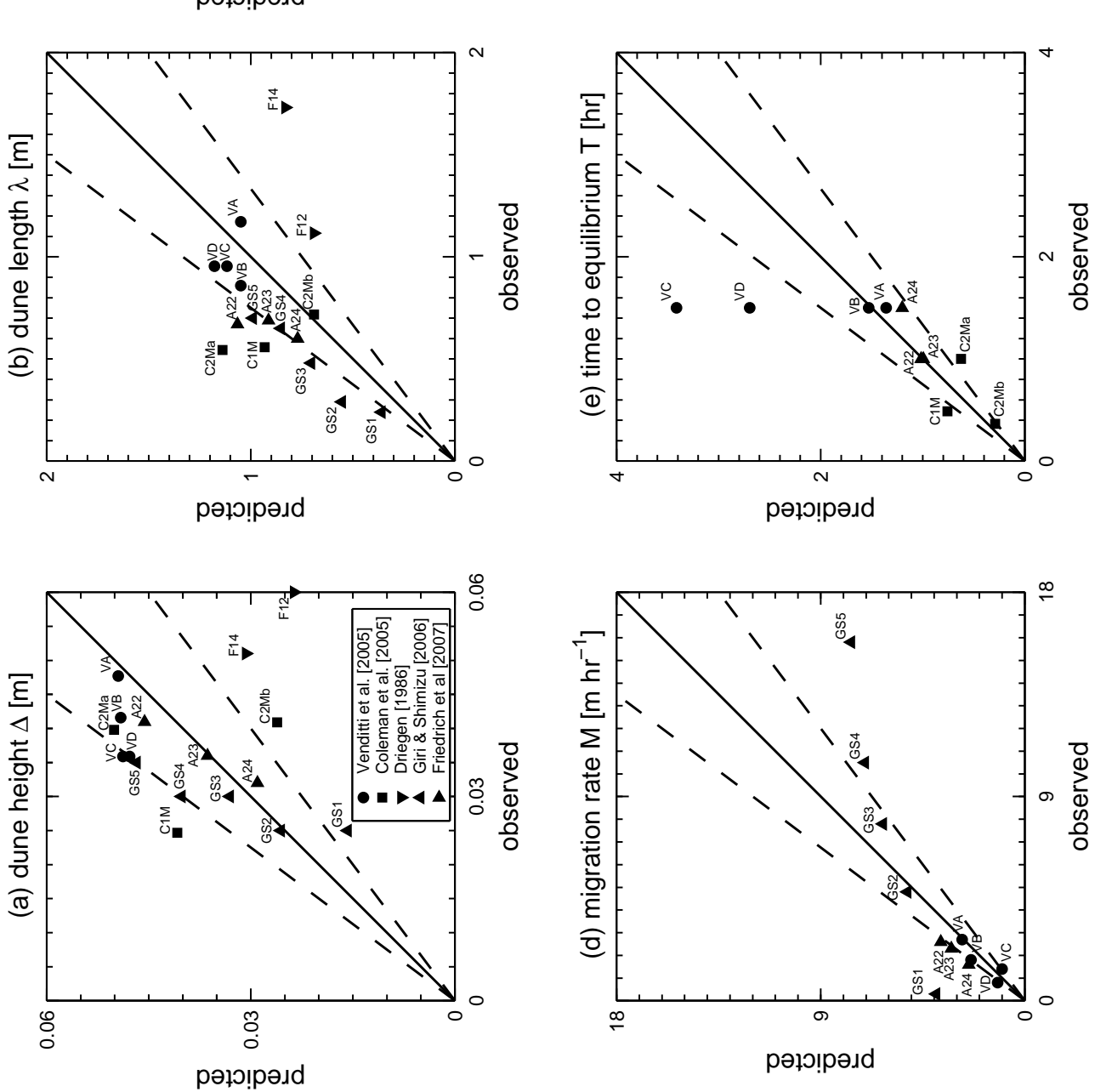

胥赵

च

छี ชิ

क 范

낭 항

ปี ช

敢高众

छี ฮี

글

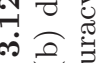

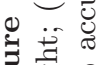




\subsubsection{Comparison with various data sets}

Up to now, the discussion of the model focussed on one experimental condition. In this section, the model performance is tested quantitatively, by simulating different experiments reported in literature, for which the experimental conditions are listed in Table 3.2. In this table, the measured dune dimensions, water depths, migration rates in equilibrium and the times to equilibrium are presented. If available, the measurements are taken from the cited literature, but it is not always clear how they are determined. Dune dimensions are often determined using subjective criteria (Van der Mark et al., 2007; Friedrich et al., 2007). The migration rate of a train of bedforms is difficult to assess, since every bedform has its own migration rate, and some average has to be taken.

The experiments of Giri \& Shimizu (2006) start from a flat bed, for which the initial water depth is not reported. Therefore, the initial flow depth as given in Table 3.2 is estimated by assuming steady flow over the flat bed, and choosing the flow depth such that the reported discharge is obtained in the calculations. Note that for the experiments of Giri \& Shimizu (2006), the Froude number is the same for all considered cases. For the experiments of Coleman et al. (2005), the average water depth in equilibrium is not available, neither is the migration rate. Coleman et al. (2005) report times to equilibrium.

Figure 3.12 shows the comparison between measured and simulated dune characteristics, where all figures concern values in equilibrium. Simulated initial dune lengths are determined from a (numerical) linear stability analysis for the specific experimental conditions in each case; after that, the dune length remains constant during a simulation. Figures 3.12a-c compare computed and observed dune heights, dune lengths and dune aspect ratios, respectively. Overall, the dune dimensions are predicted reasonably well, with most of the experiments between the $25 \%$ accuracy bands (Fig. 3.12a-c). The observation that the equilibrium dune length is predicted reasonably well (Fig. 3.12b), illustrates that the dune length found from a linear analysis is a reasonable estimate for the dune length in equilibrium. The simulated equilibrium dune heights are generally $\sim 33 \%$ of the initial average water depth $h_{\mathrm{i}}$, and $\sim 28 \%$ of the equilibrium average water depth $h_{\mathrm{e}}$, which is well in range with values found in literature.

The dune aspect ratio is important for roughness predictions, considering that the equilibrium roughness predictor of for instance Van Rijn (1984) incorporates the dune aspect ratio as an important parameter. Since for a considerable number of cases the dune length is $10-30 \%$ overestimated, the dune aspect ratio is generally underpredicted. It seems that the dune aspect ratio is predicted, independently of flow conditions, at $\sim 0.045$, meaning that the dune length and dune height are linked. This observation will be analyzed further in the next section.

Figures $3.12 \mathrm{~d}$ and $3.12 \mathrm{e}$ show that the migration rate and time to equilibrium compare reasonably well, although limited data is available. It is remarkable that the migration rate is not predicted correctly for both the lowest and the highest flow strength of the experiment of Giri \& Shimizu (2006), which might be related to the relatively small flume width in their experiments. Figure $3.12 \mathrm{f}$ 
Table 3.3: Sensitivity analysis of the model results for changing calibration coefficients of the partial slip model (case 1) and deviations from the fastest growing wave length (case 2).

\begin{tabular}{|c|c|c|c|c|c|c|c|}
\hline $\operatorname{case}^{a}$ & $\begin{array}{l}\beta_{2} \\
{[-]}\end{array}$ & $\begin{array}{l}\beta_{1} \\
{[-]}\end{array}$ & $\begin{array}{c}\mathrm{FGM}^{b} \\
{[\mathrm{~m}]}\end{array}$ & $\begin{array}{l}\lambda_{\mathrm{e}}{ }^{c} \\
{[\mathrm{~m}]}\end{array}$ & $\begin{array}{l}\Delta_{\mathrm{e}} \\
{[\mathrm{m}]}\end{array}$ & $\begin{array}{c}\Delta_{\mathrm{e}} / \lambda_{\mathrm{e}} \\
{[-]}\end{array}$ & $\begin{array}{c}T_{\mathrm{e}} \\
{[\mathrm{hr}]}\end{array}$ \\
\hline ref & 0.50 & 0.50 & 1.049 & $1.049(1.0)$ & 0.049 & 0.047 & 0.7 \\
\hline $1 \mathrm{a}$ & 0.25 & 0.64 & 2.621 & $2.621(1.0)$ & 0.075 & 0.029 & 6.0 \\
\hline $1 \mathrm{~b}$ & 0.50 & 0.51 & 1.054 & $1.054(1.0)$ & 0.049 & 0.047 & 1.4 \\
\hline $1 \mathrm{c}$ & 1.00 & 0.46 & 0.566 & $0.566(1.0)$ & 0.031 & 0.054 & 0.4 \\
\hline $1 d$ & 2.00 & 0.44 & 0.376 & $0.376(1.0)$ & 0.023 & 0.061 & 0.2 \\
\hline $2 \mathrm{a}$ & 0.50 & 0.50 & 1.049 & $0.632(0.6)$ & 0.016 & 0.025 & 1.3 \\
\hline $2 \mathrm{~b}$ & 0.50 & 0.50 & 1.049 & $0.843(0.8)$ & 0.039 & 0.047 & 1.1 \\
\hline $2 \mathrm{c}$ & 0.50 & 0.50 & 1.049 & $1.265(1.2)$ & 0.059 & 0.047 & 1.8 \\
\hline $2 \mathrm{~d}$ & 0.50 & 0.50 & 1.049 & $1.476(1.4)$ & 0.069 & 0.047 & 2.2 \\
\hline
\end{tabular}

${ }^{a}$ For parameters see Table 3.2; for each simulation, the initial dune height is equal (i.e. $\Delta_{\mathrm{i}}=$ $\left.0.1 D_{50}\right) ;{ }^{b} \mathrm{FGM}$ is the fastest growing wave length found from linear stability analysis; ${ }^{c} \lambda_{\mathrm{e}}$ is the wave length used in a simulation and between brackets is the fraction $\lambda_{\mathrm{e}}$ /FGM.

shows the comparison between observed and computed average water depths in equilibrium. The agreement is excellent, meaning that the simulation model gives a good estimate of flow resistance and energy losses in the flow separation zone.

\subsubsection{Sensitivity analysis}

In this section we analyze the effect of the calibration parameters for the partial slip model and deviations from the fastest growing wave length as initial dune length on dune evolution. Also, we investigate how various flow- and sediment transport parameters affect dune dimensions and time scales of dune evolution (i.e. migration rate and time to equilibrium). The simulation as presented in Section 3.5.2 serves as reference case for the sensitivity analysis (i.e. based on Flow A of Venditti et al., 2005).

Since the parameters of the partial slip model are partly based on a calibration (using coefficients $\beta_{1}$ and $\beta_{2}$ ), variations of these coefficients might have large implications for the simulation results. Case 1 in Table 3.3 analyzes the effects of changes in the values of these coefficients. The four combinations of $\beta_{1}$ and $\beta_{2}$ are all on the solid thick line in Figure 3.6a, yielding a correct discharge in the simulations. Table 3.3 shows that for the cases $1 \mathrm{c}$ and $1 \mathrm{~d}$, the higher resistance at the bed (i.e. higher values of $\beta_{2}$ compared to the reference situation, 'ref' in Tab. 3.3) yields shorter fastest growing wave lengths. Times to equilibrium substantially decrease and dune aspect ratios increase with respect to the reference situation. For the long wave in case 1a, it takes very long for an equilibrium to be obtained as a result of the low growth rate for this length.

For the remainder of this sensitivity analysis, we focus on the case $\beta_{1}=$ $\beta_{2}=0.5$. Case 2 in Table 3.3 analyzes the effect of deviations from the fastest 

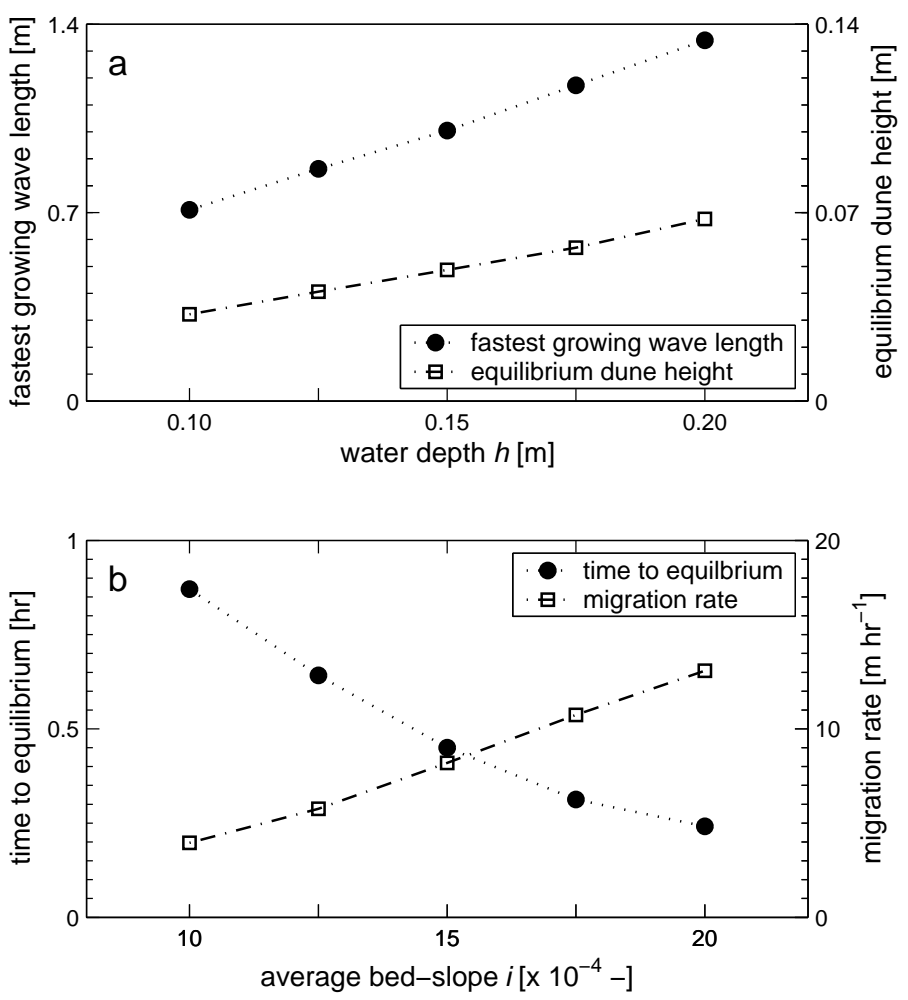

Figure 3.13: Sensitivity analysis for flow parameters.

growing wave length ${ }^{3}$. A $40 \%$ smaller dune length (case 2a) yields a situation without flow separation, due to a very small growth rate of the dune. The other cases show that the dune aspect ratio is the same as in the reference case, with slightly different times to equilibrium due to differences in growth rate.

In summary, the rather constant aspect ratio as observed in Figure 3.12 might be linked to the parameter settings of the partial slip model (i.e. on coefficients $\beta_{1}$ and $\beta_{2}$ ). Variations in the resistance parameter yield variations in the dune aspect ratio, however, dune lengths, dune heights and times to equilibrium do not agree with the measurements in those cases. Therefore, the setting $\beta_{1}=\beta_{2}=0.5$ seems to reproduce the experimental conditions most accurately.

Figure $3.13 \mathrm{a}$ shows that the initially fastest growing wave length $\left(\lambda_{\mathrm{fgm}}\right)$ depends linearly on the initial average water $\operatorname{depth} h_{\mathrm{i}}$ for the specific flow conditions. More precisely, $\lambda_{\mathrm{fgm}} \approx 7 h_{\mathrm{i}}$. In our simulations, the dune length does

${ }^{3}$ Thus in a simulation the dune length is not equal to the fastest growing wave length as determined from a stability analysis, but is altered according to the numbers in Table 3.3 

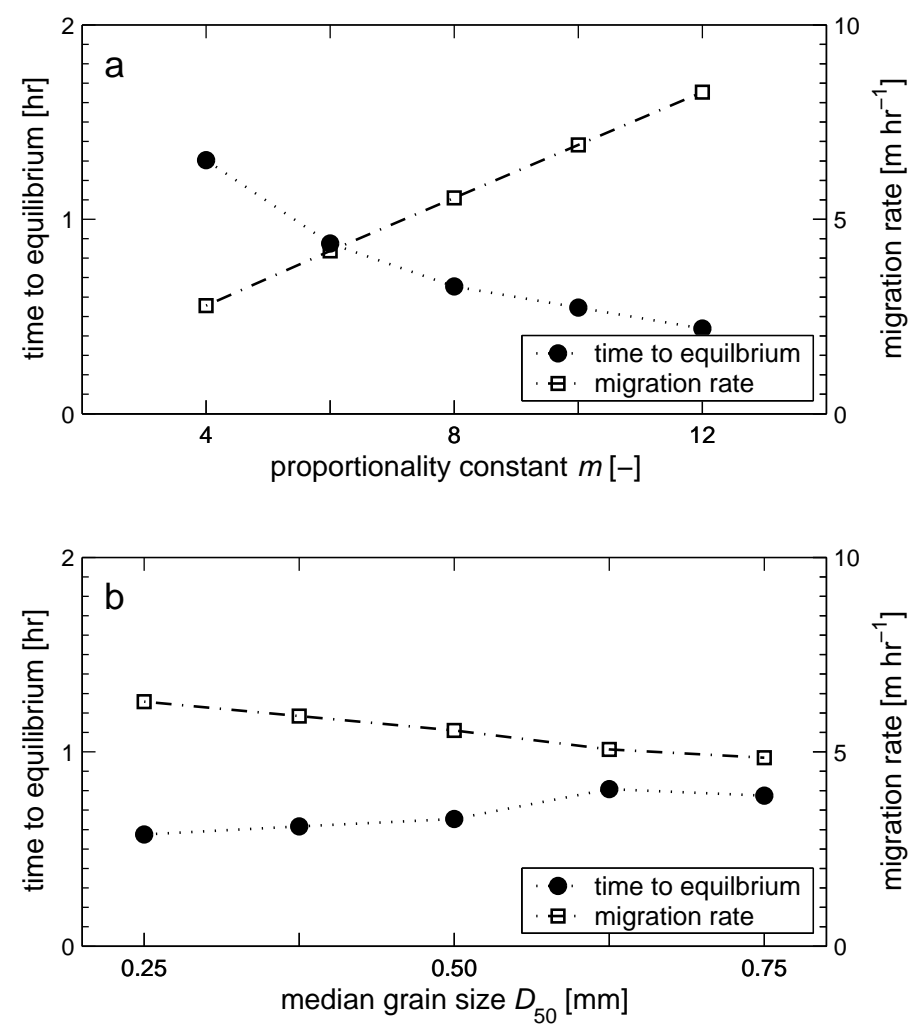

Figure 3.14: Sensitivity analysis for parameters in sediment transport formula.

not vary, thus the initial fastest growing wave length is also the dune length in equilibrium $\left(\lambda_{\mathrm{e}}\right)$. However, since the water depth increases towards equilibrium, $\lambda_{\mathrm{e}} \approx 6 h_{\mathrm{e}}$. This is in agreement with various previous studies (e.g. Yalin, 1972; Van Rijn, 1984; Julien \& Klaassen, 1995). It turns out that for increasing dune length, the equilibrium dune height increases as well (Fig. 3.13a). In effect, the dune aspect ratio remains almost constant at $\sim 0.047$, as was also observed in the Section 3.5.4.

An increasing flume slope, and thus Froude number (if the flow depth remains constant), has a significant effect on the time scales of dune evolution (Fig. 3.13b). If the flume slope increases for constant water depth, the flow velocities and bed shear stresses increase. The migration rate increases almost linearly with the slope, whereas the time to equilibrium decreases for increasing slope. In contrast, an increasing flume slope does not influence dune dimensions (not shown). This can be understood as follows. The fastest growing wave length found from linear stability analysis is controlled by displacements between the position of the maximum flux with respect to the dune crest (Section 3.4). A changing slope does only influence the magnitude of the turbulence- 
averaged shear stress and not the distribution over a dune; therefore, the fastest growing wave length does not depend on the channel slope. In summary, the water depth is the only flow parameter that is able to alter the fastest growing wave length, and thus dune dimensions. The channel slope influences times to equilibrium and migration rates.

Besides the bed shear stress, several parameters control the sediment flux (Eq. 3.8), and thus dune formation. The proportionality constant $m$ has no influence on equilibrium dune dimensions (not shown), since it is a linear parameter in the sediment transport equation and does not change the fastest growing wave length. In contrast, it has an effect on the time scales of dune evolution (Fig. 3.14) because of increased sediment fluxes. The median grain size $D_{50}$ influences the magnitude of the critical bed shear stress (Eq. 3.11); as a result, the fastest growing wave length slightly increases, for increasing grain size (not shown). Figure 3.14b shows that for increasing sediment grain size, the time to equilibrium slightly increases, while the migration rate decreases.

The influence of parameter $n$ in the sediment transport equation on model results is complicated, since its influence is nonlinear. Using experimental observations this parameter is estimated at $\sim 1.5$ (Wong \& Parker, 2006). Small variations in $n$ have a strong influence on both the equilibrium dimensions and the time scales of dune evolution. For $n=1.75$ (i.e. $+17 \%$ ), the fastest growing wave length decreases by about $10 \%$ compared to the reference simulation and the equilibrium dune height decreases by $20 \%$. This means that the dune aspect ratio decreases by about $11 \%$, which can be understood as follows. The separation criterion is based on the maximum slope of the dune lee. Due to the nonlinear influence of $n$, not only the fastest growing wave length is altered, but also the dune shape at the moment that flow separation sets in is likely to be different from that in the reference situation. Therefore, dune evolution after flow separation sets in is different, and a different aspect ratio is obtained. The migration rate decreases by $\sim 75 \%$ for $n=1.75$ compared to the reference case. A decreased value of $n=1.25$ has the opposite effect as described above.

In the model, the critical angle of flow separation is $-10^{\circ}$ and the angle of repose is $-30^{\circ}$. Varying these parameters by $\pm 30 \%$, has no effect on equilibrium dune dimensions and time scales of dune evolution. The parameter $\tau_{\mathrm{A}}$, representing the gradient in the bed shear stress in case of flow separation at the flow reattachment point (Eq. 3.13), was estimated as $\tau_{\mathrm{A}}=2$. Varying $\tau_{\mathrm{A}}$ between 1.5 and 2.5, does not influence the qualitative behaviour of dune formation, but equilibrium dune dimensions and time scales of dune evolution are sensitive to this parameter. A value of $\tau_{\mathrm{A}}=1.5$ yields $10 \%$ lower dunes, while a value of $\tau_{\mathrm{A}}=2.5$ yields $11 \%$ higher dunes compared to the reference simulation. For increasing values of $\tau_{\mathrm{A}}$ the erosion rates over the stoss-side of the dunes increases, yielding higher dunes and slightly larger bed slopes at the stoss-side.

\subsection{Discussion}

A sensitivity analysis has shown that, apart from the calibration coefficients $\beta_{1}$ and $\beta_{2}$, the water depth mainly controls predicted dune dimensions. This is 
because the water depth is introduced as a scaling length in both the relationship for the eddy viscosity and bed resistance parameter. As a result, the initially fastest growing wave length is strongly linked to the initial water depth. The initial dune height is much smaller than the fastest growing wave length, since it depends on the grain size. Therefore, the dune length controls bed gradients and convergence and divergence of sediment fluxes along a dune, eventually setting the equilibrium dune height. The channel slope and parameters of the sediment transport equation mainly influence times to equilibrium and migration rates. This emphasizes the importance of correct estimation of the value of $m$, if one is interested in time scales of bedform evolution. Also the value of $n$ is important, since it influences both dune shapes and equilibrium dimensions. Model results are shown not to depend on the choice of the flow separation criterion and angle of repose. In contrast, model results are sensitive to subtle changes in the parameterized bed shear stress distribution over the stoss-side of a dune.

Similar to earlier stability models (e.g. Smith, 1970; Engelund, 1970), the flow model employs a constant eddy viscosity $\left(A_{\mathrm{v}}\right)$ over the flow depth as turbulence closure, which is a crude approximation of reality. In line with Engelund (1970), we do not expect that a more sophisticated turbulence closure would yield fundamental changes to the results. However, a sensitivity analysis has shown that the fastest growing wave length is rather sensitive to the choice of the calibration coefficients $\beta_{1}$ and $\beta_{2}$ (Section 3.5.5). For increasing values of the resistance parameter $S$ (i.e. near bed velocity decreases and velocity gradient increases, and in the limit of $S \rightarrow \infty$ this amounts to a no slip condition), shorter waves are found, which evolve faster to an equilibrium. The quantitative comparison of the model results against flume experiments (Section 3.5.4) shows that dune dimensions are predicted reasonably well with $\beta_{1}=\beta_{2}=0.5$. Thus, at least for flume conditions, the calibrated values are believed to yield realistic velocity profiles and bed shear stresses.

The same partial slip condition is applied over the separation streamline as is done over the bed in the region outside the flow separation zone. Partly this is physical, since at the upper boundary of the flow separation zone, there exists a (downstream) velocity. However, it might be non-physical that the boundary condition is the same as outside the region of flow separation. Mixing patterns in the flow separation zone influence the eddy viscosity just above it, which could be included as a direct influence on the eddy viscosity. However, not much influence is expected on dune dimensions and shapes, since the boundary stresses computed over the flow separation zone are not used to evaluate sediment transport rates; the separation streamline and partial slip condition are only needed to treat the flow as hydrostatic.

In the presented morphodynamic model, bed load sediment transport is evaluated using the turbulence-averaged bed shear stress as flow parameter. Nelson et al. (1995) argued that this is not accurate in case of non-uniform flow with developing boundary layers associated with significant spatial variations in turbulence structures, as is the case with dunes (e.g. McLean et al., 1994; Nelson et al., 1995; Fernandez et al., 2006). Nelson et al. (2005) and Giri \& Shimizu (2006) realistically simulated dune morphodynamics using a stochastic sediment 
transport model taking fluctuations of the bed shear stress on turbulent time scales into account. On the other hand, Tjerry \& Fredsøe (2005) obtained realistic dune shapes, by relating sediment transport to the turbulence-averaged bed shear stress. In the chosen model set-up, we are unable to predict all details of sediment transport related to turbulent fluctuations, but the general pattern of dune evolution can be evaluated with sufficient accuracy with relatively few computational effort, which is an advantage for practical applications.

During a simulation, the dune length remains constant. This is because the initial profile is a uniform sinusoidal disturbance and the employed periodic boundary conditions constrain the final dune length to the initial one. Similar to Giri \& Shimizu (2006) and Van den Berg (2007), we could introduce a spectrum of disturbances as initial condition. Model simulations with such a condition have shown that bedforms with different migration velocities merge, quickly giving rise to the fastest growing wave length as found from a linear analysis. After that, dunes keep merging until one dune covers the domain, which obviously is unrealistic. A combination of periodic boundary conditions (both for flow and sediment transport) and the approach to use a turbulenceaveraged bed shear stress to drive the sediment transport does not allow for new crests in the domain. Improvements regarding this issue could imply switching to non-periodic boundary conditions and a more sophisticated turbulence and sediment transport model. However, since the actual process of how the dune length is obtained over time is not of central interest in this paper, the simulation model determines the (constant) dune length from a numerical linear stability analysis. This approach strongly reduces the required computational effort to simulate dunes from small amplitude towards saturated steady-state dunes.

Once the flow begins to separate the physics of the transport process changes greatly and presumably the fastest growing wave length changes significantly. This is not incorporated in the model, because of periodic boundary conditions and the coupling between the flow solution and parameterized bed shear stress distribution in the case of flow separation. An explanation of the observed rather constant dune aspect ratio may be related to the approach to parameterize flow separation. The approach to use a separation bubble was introduced for the aeolian case, which is different from the fluvial case because of the presence of a free surface. It may be necessary to include more of the effects of flow separation than has been done in the presented morphodynamic model. This remains for future research.

\subsection{Conclusions}

The new morphodynamic model presented in this paper is able to realistically simulate river dune evolution. During their evolution, initially symmetric dunes evolve into asymmetrical dunes with flow separation over angle-of-repose leesides. For a correct estimation of the fastest growing wave length, bed-slope effects are essential, since these effects influence the location of the maximum sediment flux with respect to the dune crest. For evolution towards equilibrium, the inclusion of flow separation is essential since without flow separation 
dunes saturate at an early stage of evolution, leading to both an incorrect dune shape without a slip face and an underprediction of dune height and time to equilibrium.

Characteristic dune parameters, such as dune height, dune length, dune aspect ratio and migration rate compare reasonably well to dunes in flume experiments. The initial dune length which is found from a numerical linear stability analysis agrees quite well with measured dune lengths in equilibrium, indicating that this length is probably not influenced by flow separation. Model results show that dune dimensions such as height and length are mainly controlled by the average flow depth. Time scales of bedform evolution, however, are mainly controlled by the channel slope and the sediment transport rate. Therefore, it is very important to have reliable estimates of the empirical coefficients that are used to determine the sediment transport rate.

Using the proposed parameterization of flow separation avoids the necessity of computing the complicated processes related to flow separation, saving a lot of computational effort. The model forms a promising framework for future research, since it can be applied to river flood waves, to yield fast and reliable estimates of dune dimensions, and associated resistance to flow. 


\section{Appendix A: Derivation of the flow model}

This appendix gives a derivation of the flow equations as used in the present paper. By scaling the Navier-Stokes equations in a vertical plane for a typical river setting, it is shown that some terms can safely be neglected.

\section{A.1 Flow equations}

The two-dimensional vertical (2-DV) Navier-Stokes equations (i.e. dropping velocity and variations in the lateral $y$-direction) in $x$ - and $z$-direction (Fig. 3.2), together with the continuity equation read (all unscaled quantities denoted with an asterisk):

$$
\begin{aligned}
\frac{\partial u^{*}}{\partial t^{*}}+u^{*} \frac{\partial u^{*}}{\partial x^{*}}+w^{*} \frac{\partial u^{*}}{\partial z^{*}} & =-\frac{1}{\rho_{\mathrm{w}}^{*}} \frac{\partial p^{*}}{\partial x^{*}}+\frac{1}{\rho_{\mathrm{w}}^{*}} \frac{\partial \tau_{x x}^{*}}{\partial x^{*}}+\frac{1}{\rho_{\mathrm{w}}^{*}} \frac{\partial \tau_{x z}^{*}}{\partial z^{*}}+g^{*} i \\
\frac{\partial w^{*}}{\partial t^{*}}+u^{*} \frac{\partial w^{*}}{\partial x^{*}}+w^{*} \frac{\partial w^{*}}{\partial z^{*}} & =-\frac{1}{\rho_{\mathrm{w}}^{*}} \frac{\partial p^{*}}{\partial z^{*}}+\frac{1}{\rho_{\mathrm{w}}^{*}} \frac{\partial \tau_{z x}^{*}}{\partial x^{*}}+\frac{1}{\rho_{\mathrm{w}}^{*}} \frac{\partial \tau_{z z}^{*}}{\partial z^{*}}-g^{*} \\
\frac{\partial u^{*}}{\partial x^{*}}+\frac{\partial w^{*}}{\partial z^{*}} & =0
\end{aligned}
$$

in which $t$ is time, $u$ and $w$ are velocity in $x$ - and $z$-direction, respectively, $\rho_{\mathrm{w}}$ is water density, $p$ is pressure, $\tau$ is shear stress, $g$ is acceleration due to gravity and $i$ is the average channel slope. The stresses $\left(\tau^{*}\right)$ are defined by the shear stress tensor $\mathbf{T}^{*}$ and we use the Boussinesq approximation for these stresses (e.g. Fox et al., 2003):

$$
\mathbf{T}^{*}=\left[\begin{array}{cc}
\tau_{x x}^{*} & \tau_{x z}^{*} \\
\tau_{z x}^{*} & \tau_{z z}^{*}
\end{array}\right]=\rho_{\mathrm{w}}^{*} A_{\mathrm{v}}^{*}\left[\begin{array}{cc}
2 \frac{\partial u^{*}}{\partial x^{*}} & \left(\frac{\partial u^{*}}{\partial z^{*}}+\frac{\partial w^{*}}{\partial x^{*}}\right) \\
\left(\frac{\partial u^{*}}{\partial z^{*}}+\frac{\partial w^{*}}{\partial x^{*}}\right) & 2 \frac{\partial w^{*}}{\partial z^{*}}
\end{array}\right]
$$

in which $A_{\mathrm{v}}^{*}$ is an eddy viscosity.

\section{A.2 Boundary conditions}

The boundary conditions at the water surface are $(i)$ no flow through the water surface, and ( $i i)$ vanishing shear tangential to the water surface:

$$
\begin{aligned}
& w^{*}=\frac{\partial \zeta^{*}}{\partial t^{*}}+u^{*} \frac{\partial \zeta^{*}}{\partial x^{*}} \quad \text { at } \quad z^{*}=\zeta^{*}+h, \\
& \mathbf{T}^{*} \cdot \mathbf{n}_{\mathrm{s}}^{*}=\mathbf{0} \quad \text { at } \quad z^{*}=\zeta^{*}+h,
\end{aligned}
$$

in which $\zeta$ is the water surface elevation, $h$ is the average water depth and $\mathbf{n}_{\mathrm{s}}^{*}$ is the unit vector normal to the water surface (pointing upward):

$$
\mathbf{n}_{\mathrm{s}}^{*}=\frac{\left(-\partial \zeta^{*} / \partial x^{*}, 1\right)}{\sqrt{1+\left(\partial \zeta^{*} / \partial x^{*}\right)^{2}}} .
$$

Equation (3.27) in combination with (3.28) can be understood by realizing that the shear vanishes tangential to the water surface which can be sloping. Since 
the stress is continuous at the surface (Eq. 3.27), the pressure at the water surface is equal to the atmospheric pressure $\left(p_{\mathrm{a}}\right)$ :

$$
p^{*}=p_{\mathrm{a}}^{*} \quad \text { at } \quad z^{*}=\zeta^{*}+h .
$$

The boundary conditions at the bed are $(i)$ no flow through the boundary, and (ii) a partial slip condition:

$$
\begin{aligned}
\frac{\partial z_{\mathrm{b}}^{*}}{\partial t^{*}}+u^{*} \frac{\partial z_{\mathrm{b}}^{*}}{\partial x^{*}}=w^{*} & \text { at } z^{*}=z_{\mathrm{b}}^{*}, \\
\mathbf{T}^{*} \cdot \mathbf{n}_{\mathrm{b}}^{*}=\rho_{\mathrm{w}}^{*} S^{*} \mathbf{u}_{\mathrm{b}}^{*} & \text { at } \quad z^{*}=z_{\mathrm{b}}^{*},
\end{aligned}
$$

in $z_{\mathrm{b}}$ is the bed elevation, $S$ is a resistance parameter and $\mathbf{n}_{\mathrm{b}}^{*}$ is the unit vector normal to the bed (pointing upward):

$$
\mathbf{n}_{\mathrm{b}}^{*}=\frac{\left(-\partial z_{\mathrm{b}}^{*} / \partial x^{*}, 1\right)}{\sqrt{1+\left(\partial z_{\mathrm{b}}^{*} / \partial x^{*}\right)^{2}}} .
$$

\section{A.3 Scaling and relevant parameters}

The following scaling is introduced, where capitalized symbols represent typical scaling quantities:

$$
\begin{aligned}
u^{*} & =u U, \\
x^{*} & =x L, \\
z^{*} & =z h, \\
w^{*} & =w \frac{h U}{L}, \\
\zeta^{*} & =\zeta \frac{U^{2}}{g^{*}}, \\
p^{*} & =p \rho_{\mathrm{w}}^{*} g^{*} h, \\
t^{*} & =t \frac{h L}{Q_{b}}=t T_{\text {mor }}, \\
z_{\mathrm{b}}^{*} & =z_{\mathrm{b}} h .
\end{aligned}
$$

The scaling for the shear stresses follows from Equation (3.25). The scaling argument for the water surface elevation $\zeta$ is based on the fact that the pressure force tends to zero if $U$ tends to zero, independent of friction. Thus there must be a balance between the advection terms and the pressure gradient. The scaling for the time means that we scale with the morphological time scale $\left(Q_{\mathrm{b}}\right.$ is the scale for the bed load sediment flux). The flow length scale $L$ is not explicitly formulated, but its conditions are set hereafter. Let us define the following relevant parameters and associated assumptions (for a typical river setting) to 
analyze the system of equations:

$$
\begin{aligned}
\operatorname{Fr}^{2} & =\frac{U^{2}}{g^{*} h} \ll 1, \\
\delta_{1} & =\frac{h}{L} \ll 1, \\
\delta_{2} & =\frac{T_{\mathrm{adv}}}{T_{\text {mor }}}=\frac{Q_{b}}{U h} \ll 1,
\end{aligned}
$$

in which the advective time scale $T_{\mathrm{adv}}=L / U$. Further, $\delta_{1}$ is an aspect ratio, $\delta_{2}$ is the ratio between the advective time scale $T_{\mathrm{adv}}$ and the morphological time scale $T_{\text {mor }}$, and Fr is the Froude number. The flow responds to bottom changes by generating propagating surface waves. The time scale of this adjustment process is assumed to be of the same order as the advective time scale $T_{\text {adv }}$, but small compared to the morphological time scale $T_{\text {mor }}$ (irrespective of the exact value of $Q_{\mathrm{b}}$ ).

Further, we introduce the non-dimensional eddy viscosity $A_{\mathrm{v}}$ and nondimensional resistance parameter $S$ as:

$$
\begin{aligned}
A_{\mathrm{v}} & =\frac{A_{\mathrm{v}}^{*} L}{h^{2} U}, \\
S & =\frac{S^{*} L}{h U} .
\end{aligned}
$$

\section{A.4 Introducing the scaling into the equations and boundary condi-} tions

After introducing the scaling arguments (Eq. 3.33), the momentum equations in $x$ - and $z$-direction, and continuity equation, read:

$$
\begin{gathered}
\delta_{2} \frac{\partial u}{\partial t}+u \frac{\partial u}{\partial x}+w \frac{\partial u}{\partial z}= \\
-\frac{1}{\operatorname{Fr}^{2}} \frac{\partial p}{\partial x}+A_{\mathrm{v}}\left(\delta_{1}^{2} 2 \frac{\partial^{2} u}{\partial x^{2}}+\frac{\partial^{2} u}{\partial z^{2}}+\delta_{1}^{2} 2 \frac{\partial^{2} w}{\partial x \partial z}\right)+\frac{i}{\delta_{1} \operatorname{Fr}^{2}} \\
\delta_{2} \frac{\partial w}{\partial t}+u \frac{\partial w}{\partial x}+w \frac{\partial w}{\partial z}= \\
-\frac{1}{\delta_{1}^{2} \operatorname{Fr}^{2}} \frac{\partial p}{\partial z}+A_{\mathrm{v}}\left(\frac{\partial^{2} u}{\partial x \partial z}+\delta_{1}^{2} 2 \frac{\partial^{2} w}{\partial x^{2}}+2 \frac{\partial^{2} w}{\partial z^{2}}\right)-\frac{1}{\delta_{1}^{2} \operatorname{Fr}^{2}} \\
\quad \frac{\partial u}{\partial x}+\frac{\partial w}{\partial z}=0 .
\end{gathered}
$$

At the water surface, we obtain for the kinematic boundary condition

$$
w=\delta_{2} \operatorname{Fr}^{2} \frac{\partial \zeta}{\partial t}+\operatorname{Fr}^{2} u \frac{\partial \zeta}{\partial x} \quad \text { at } \quad z=\operatorname{Fr}^{2} \zeta+h
$$


and for vanishing shear tangential to water surface (dropping the square-root in Eq. 3.28)

$$
\left[\begin{array}{c}
-2 \operatorname{Fr}^{2} \delta_{1}^{2} \frac{\partial u}{\partial x} \frac{\partial \zeta}{\partial x}+\left(\frac{\partial u}{\partial z}+\delta_{1}^{2} \frac{\partial w}{\partial x}\right) \\
-\operatorname{Fr}^{2} \delta_{1}\left(\frac{\partial u}{\partial z}+\delta_{1}^{2} \frac{\partial w}{\partial x}\right) \frac{\partial \zeta}{\partial x}+2 \delta_{1} \frac{\partial w}{\partial z}
\end{array}\right]=\left(\begin{array}{l}
0 \\
0
\end{array}\right) \quad \text { at } \quad z=\operatorname{Fr}^{2} \zeta+h
$$

At the bed, the kinematic boundary condition becomes:

$$
\delta_{2} \frac{\partial h}{\partial t}+u \frac{\partial z_{\mathrm{b}}}{\partial x}=w \quad \text { at } \quad z=z_{\mathrm{b}}
$$

and the partial slip condition (dropping the square-root in Eq. 3.32) reads:

$$
A_{\mathrm{v}}\left[\begin{array}{c}
-2 \delta_{1}^{2} \frac{\partial u}{\partial x} \frac{\partial h}{\partial x}+\left(\frac{\partial u}{\partial z}+\delta_{1}^{2} \frac{\partial w}{\partial x}\right) \\
-\delta_{1}\left(\frac{\partial u}{\partial z}+\delta_{1}^{2} \frac{\partial w}{\partial x}\right) \frac{\partial h}{\partial x}+2 \delta_{1} \frac{\partial w}{\partial z}
\end{array}\right]=S\left(\begin{array}{c}
u \\
\delta_{1} w
\end{array}\right) \quad \text { at } z=z_{\mathrm{b}} .
$$

\section{A.5 Analysis of the resulting set of equations}

Since $\delta_{2} \ll 1$, a quasi-stationary approach is allowed (i.e. the flow is assumed to adapt instantaneously to topographic changes) and time derivatives in the flow equations and kinematic boundary condition at the water surface are dropped. Thus, terms preceded by the term $\delta_{2}$ are neglected.

Now consider the scaled vertical momentum equation (Eq. 3.37). In this equation, all terms are small (i.e. $\leq 1)$ relative to the term originating from $g^{*}$ (i.e. last term on the right hand side), except for the pressure gradient. Thus, the vertical momentum equation reduces to:

$$
\frac{\partial p}{\partial z}=-1 \text {. }
$$

Integration of this equation over depth $(z)$, using boundary condition (3.29) at the water surface yields:

$$
p(z)=\left(\operatorname{Fr}^{2} \zeta-z\right)+p_{\mathrm{a}},
$$

which can be recognized in physical quantities as the hydrostatic pressure distribution:

$$
p^{*}\left(z^{*}\right)=\rho_{\mathrm{w}}^{*} g^{*}\left(\zeta^{*}-z^{*}\right)+p_{\mathrm{a}}^{*} .
$$

For the pressure gradient in horizontal $x$-direction, under the assumption that the density is constant and the atmospheric pressure does not vary in space, Equation (3.44) yields:

$$
\frac{\partial p}{\partial x}=\operatorname{Fr}^{2} \frac{\partial \zeta}{\partial x}
$$

which can be inserted in the horizontal momentum equation (Eq. 3.36). The two stress terms preceded by $\delta_{1}^{2}$ in Equation (3.36) can be dropped.

Considering the scaled stress boundary conditions at the water surface (Eq. 3.40) and the scaled partial slip condition at the bed (Eq. 3.42) shows that stress gradients in vertical direction with respect to the horizontal velocity $u$ are dominant (i.e. terms with $\frac{\partial u}{\partial z}$, not preceded by $\delta_{1}$ ). Note that for both cases the vertical stress component is negligible compared to the horizontal stresses, since all terms of the vertical stress component contain a factor $\delta_{1}$. 


\section{A.6 Final set of scaled equations}

Momentum equation in $x$-direction, and continuity equation:

$$
\begin{aligned}
u \frac{\partial u}{\partial x}+w \frac{\partial u}{\partial z} & =-\frac{\partial \zeta}{\partial x}+A_{\mathrm{v}} \frac{\partial^{2} u}{\partial z^{2}}+\frac{i}{\delta_{1} \mathrm{Fr}^{2}} \\
\frac{\partial u}{\partial x}+\frac{\partial w}{\partial z} & =0
\end{aligned}
$$

where $A_{\mathrm{v}}$ is a vertical eddy viscosity. Because of the assumption that $\mathrm{Fr}^{2}$ is small, we adopt a rigid lid approximation, meaning that the boundary conditions at the water surface can be evaluated at $z=h$. Due to the rigid lid approximation the boundary conditions at the water surface are:

$$
\begin{array}{r}
w=\operatorname{Fr}^{2} u \frac{\partial \zeta}{\partial x} \quad \text { at } \quad z=h, \\
\frac{\partial u}{\partial z}=0 \quad \text { at } \quad z=h .
\end{array}
$$

The boundary conditions at the bed read:

$$
\begin{array}{cc}
u \frac{\partial z_{\mathrm{b}}}{\partial x}=w \quad \text { at } \quad z=z_{\mathrm{b}}, \\
A_{\mathrm{v}} \frac{\partial u}{\partial z}=S u \quad \text { at } \quad z=z_{\mathrm{b}} .
\end{array}
$$

Note that pressure variations due to water surface gradients are still possible. Note also that in flume studies the square of the Froude number is generally small, but in the present paper $\operatorname{Fr}^{2} \leq 0.48$, meaning that the model solutions (especially regarding the flow field) should be treated with care.

\section{A.7 Coordinate transformation}

In the numerical solver, a transformation is used that maps a domain with a bed topography to one with a flat bed, such that a rectangular structured grid can be used. The following transformation is used (Van den Berg \& Van Damme, 2005; Van den Berg, 2007):

$$
\hat{x}=x, \quad \hat{z}=\frac{z-z_{\mathrm{b}}(x)}{1-z_{\mathrm{b}}(x)}, \quad \hat{\zeta}=\frac{1}{1-z_{\mathrm{b}}(x)} \zeta,
$$

leading to a coordinate system $\hat{x}=[0,1], \hat{z}=[0,1]$. Note that this transformation introduces derivatives of the transformation as well, which is further explained in Van den Berg \& Van Damme (2005) and Van den Berg (2007). The bottom boundary conditions can be evaluated at the position $\hat{z}=0$, and the boundary conditions at the water surface should be evaluated at $\hat{z}=1$. 


\title{
Chapter 4
}

\section{Modelling dynamic roughness during floods}

\begin{abstract}
Hydraulic simulation models, such as the 1-dimensional (1-D) hydraulic model SoBEK, are often calibrated on roughness coefficients. This means that uncertainties and errors end up in the roughness coefficients. In sand-bed rivers, the roughness coefficient of the main channel is largely determined by flow resistance due to the presence of dunes. Although dune dynamics and hysteresis effects may vary for different flood wave types, the roughness coefficients of many hydraulic models are either constant, or are represented as unique values depending on the discharge at best. Thus, hydraulic simulation models may yield incorrect water level predictions, if they are applied to flood waves and discharges for which they were not calibrated. This paper presents a new method to incorporate dune dynamics, and especially hysteresis effects due to dune evolution, into the hydraulic model SoBEK. A dynamic roughness model is coupled with SOBEK, without actually changing the SoBEK code. This dynamic roughness model consists of a process-based dune evolution model and the empirical roughness predictor of Van Rijn (1984). Simulation results show significant effects of dune evolution on roughness coefficients and on water levels. A broad-peaked flood wave yields larger effects on water levels than a sharp-peaked flood wave. The relatively long duration of the maximum discharge for the broad-peaked flood wave yields higher dunes, since dunes can grow further in height during this period. The proposed modelling approach yields physical insight into the effects of time-dependent dune evolution on the main channel roughness coefficients in hydraulic models. The approach can be used in hydraulic model calibrations, to reduce the uncertainties in roughness coefficients.
\end{abstract}

\subsection{Introduction}

In the Netherlands, 1-D and 2-D hydraulic simulation models are used to predict water levels in river systems. Based on simulation results, it is verified whether flood protection levels are still met. The output of such hydraulic models is mainly controlled by flow resistance coefficients (e.g. Casas et al., 2006; Vidal et al., 2007; Morvan et al., 2008). Various elements in a river system contribute to the flow resistance, such as groynes, bedforms, vegetation in floodplains or 
other elements obstructing the flow. Over the past decade, several elements in hydraulic models were improved (i.e. accuracy of bathymetry, cross section schematization, characterization of floodplain vegetation, etc.). However, the roughness coefficients of the main channel and the floodplain still have large uncertainties and significantly influence water level predictions (e.g. Van der Klis, 2003; Warmink et al., 2007; Paarlberg, 2007).

The flow resistance of the main channel is largely determined by form drag due to river dunes and due to groynes (if present). River dunes typically develop in sand-bed rivers, if the bed shear stress exceeds the threshold of sediment motion. The dunes that form in the river Rhine in the Netherlands (Fig. 1.2) have heights in the order of $10-30 \%$ of the flow depth in the main channel. Both dune height and length, and the dune migration rates vary during the passage of a flood wave. Generally, the dune length increases with flow depth, and the migration rate is inversely proportional to the dune height (Paarlberg et al., subm.; Chapter 3).

Figure 1.5b shows measured dune heights during the 1998 flood in the river Rhine near the Pannerdensche Kop (Fig. 1.2) as a function of the discharge. A clear hysteresis in dune height is observed, which occurs because it requires time for the dunes to adapt to the changing flow conditions by means of sediment transport. After the discharge peak, the dunes continue to grow about $20 \%$ in height. It is expected that this hysteresis effect in dune evolution also has its impacts on water levels. Unfortunately, we lack simultaneous measurements of both dunes and water levels. However, Figure 1.5a shows a significant hysteresis effect in water levels in the river Meuse in the Netherlands. This effect can be attributed to $(i)$ accelerations and decelerations during the passage of a flood wave (conform the Jones formula, see e.g. Jansen et al., 1979; Perumal et al., 2004) and ( $i$ ) dunes forming on the bed during the passage of a flood wave.

In some hydraulic simulation models, form drag due to dunes is included by using (semi-)empirical relationships that predict dune dimensions and the associated form drag (e.g. Warmink et al., 2007; Giri et al., 2008). Most empirical relationships to predict dune dimensions are valid for steady flows only and are based on a range of parameters like flow strength, flow depth or sediment size (e.g. Yalin, 1964; Allen, 1968b; Van Rijn, 1984; Julien \& Klaassen, 1995; Coleman et al., 2005). The flow resistance due to dunes is mainly determined by the dune shape (i.e. dune height and length, or aspect ratio). Therefore, a range of relationships exist that link a roughness coefficient to dune geometry (e.g. Vanoni \& Hwang, 1967; Yalin, 1972; Van Rijn, 1984; Karim, 1995). Wilbers (2004) proposed a method to take hysteresis effects (time-lags) in dune evolution into account in roughness predictions, following the approach of Allen (1976). This approach requires using a calibrated adaptation constant, limiting the general applicability of the model. Giri et al. (2008) based the adaptation constant on the local sediment transport rate, resulting in a variable adaptation constant, which enabled the simulation of dune evolution during floods on a semi-empirical basis. Giri et al. (2007) developed a morphodynamic simulation code which was able to predict stage-discharge relationships under flume conditions. However, the detailed and complicated flow model results in extremely 
large computational times and makes the model infeasible for operational water management purposes.

Therefore, in current practice the roughness coefficients of hydraulic models are often calibrated to match observed and computed water levels and discharge (distributions) (e.g. Wasantha Lal, 1995; Werner, 2004; Van den Brink et al., 2006). Often, a time-independent constant roughness value is applied over the full time scale of a flood wave, meaning that only parts of a flood wave can be reproduced accurately. Recently, the main channel roughness coefficients in the 1-D hydraulic simulation model SOBEK were calibrated as a function of the discharge, to obtain better results for complete flood waves (Udo et al., 2007). However, this still implies that there is one unique value for the roughness coefficient for every discharge. This means that the calibration is specific for the conditions (e.g. the peak discharge, flood wave shape) for which the model was calibrated. Effectively, the effects of dune evolution in the main channel, and the associated hysteresis effect in dune height, are incorporated into the calibrated roughness coefficient of the main channel.

This paper investigates (1) whether dune evolution during floods varies significantly for different flood wave shapes, and (2) whether the hysteresis effect in dune evolution yields significant changes to water level predictions during the rising and falling stages of a flood wave. To this end, the 1-D hydraulic simulation model SOBEK is extended with a dynamic roughness model. This dynamic roughness model consists of an idealized process-based dune evolution model (Paarlberg et al., subm.; Chapter 3) and a roughness predictor, translating dune geometry to a roughness coefficient. During a flood wave, dune dimensions are computed, which are translated to a roughness coefficient of the main channel. In this way, the hysteresis effects of dune evolution are explicitly taken into account. Moreover, since the dune evolution model is set-up to minimize the required computational effort, the new simulation model can be applied at flood wave time scales.

In Section 4.2, the extended SobEK model is introduced, by discussing the various submodels. In this paper we set-up a representative SoBEK model of the river Waal as case study (Section 4.3). In the same section, also the analyzed flood wave shapes and the method to analyze the differences in water level predictions between the original and the new SOBEK model are discussed. The model results are presented in Section 4.4. First, we focus on simulated dune dynamics for both types of flood waves; then, we discuss to what extent water level predictions over the entire range of the flood waves change, compared to a SOBEK model which employs calibrated roughness coefficients. The paper ends with a discussion and conclusions, in Sections 4.5 and 4.6, respectively.

\subsection{Hydraulic simulation model including dynamic rough- ness due to dune evolution}

The simulation model presented in this paper extends the existing hydraulic simulation model SOBEK with two submodels to describe the dynamic roughness 


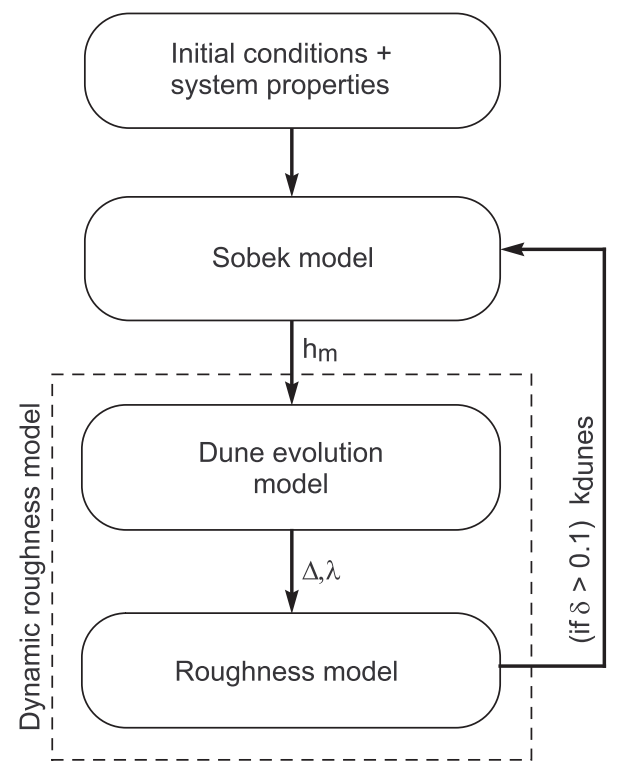

Figure 4.1: Overview of the simulation model presented in this paper, which consists of the existing hydraulic simulation model SOBEK and a dynamic roughness model. A simulation is initialized by specification of a discharge wave, system properties (such as grain size) and initial dune height. The water depth in the main channel $\left(h_{\mathrm{m}}\right)$ computed by SOBEK is used as input for the dune evolution model to compute dune height $\Delta$ and dune length $\lambda$. The roughness model translates these dune dimensions into a Nikuradse roughness height $k_{\text {dunes. }}$. If the relative change in roughness height $(\delta)$ is larger than $10 \%$, a new SOBEK computation is performed.

due to dune evolution during flood waves (Fig. 4.1). Roughly, the procedure to simulate a flood wave in the new extended SOBEK model is as follows. During a flood wave, dune dimensions are computed by solving an idealized morphodynamic model (Sec. 4.2.2) that runs separately from SobEK (Sec. 4.2.1). The dune evolution model uses the average water depth $h_{\mathrm{m}}$ as computed by SoBEK as input. Computed dune dimensions are translated into a Nikuradse roughness height by using an empirical roughness height model (Sec. 4.2.3). For steady flow, a $10 \%$ change in roughness height results in a change of water depth of $1-2 \%$. Therefore, water levels are updated by SOBEK only if the relative change in roughness height during a simulation is $10 \%$ or more (Fig. 4.1). The approach to determine the dune length in our simulation model is explained in Section 4.2.4.

\subsubsection{Hydraulic model Sobek}

In the Netherlands, the hydraulic model SOBEK is used to make water level predictions for the rivers Rhine and Meuse (Fig. 1.2). SOBEK solves the 1-D cross-sectional integrated shallow water equations. The river is divided into 
trajectories of a certain length, and cross sections are defined roughly every $500 \mathrm{~m}$, to take large-scale variations in bed levels and river non-uniformity in stream direction into account. This introduces local water level differences and different conveyance capacities of floodplains along the river, enabling to simulate natural river settings. The specific SOBEK schematization of the river Waal, that is used in this paper, along with required boundary conditions and roughness coefficients, will be discussed in Section 4.3.

\subsubsection{Dune evolution model}

Dune dimensions are calculated with the dune evolution model of Paarlberg et al. (subm.) (Chapter 3), using the reach-averaged channel slope, the average water depth in the main channel (as computed by SOBEK) and the bed material (represented as $D_{50}$ ) as inputs (Fig. 4.1). This morphodynamic simulation model is based on the two-dimensional vertical (2-DV) shallow water equations with hydrostatic pressure assumption. As basic turbulence closure, a constant eddy viscosity over the water depth and a partial slip condition at the bed are employed. Two coefficients of the turbulence model which determine the values of the eddy viscosity and the resistance at the bed were calibrated on the basis of flume experiments (see chapter 3; Paarlberg et al., subm.). In this paper, the model is applied with the same calibrated coefficients (see Section 4.5).

Flow separation is included in a parameterized way. In the region of flow separation, the separation streamline forms an artificial bed (Paarlberg et al., 2007), enabling to compute the hydrostatic flow over the dunes. An empirical sediment transport relationship including gravitational bed-slope effects is applied to determine bed evolution. In the flow separation zone, bed shear stresses and sediment transport rates are set to zero. Sediment passing the crest of a dune deposits on the lee face at the angle of repose.

\subsubsection{Roughness model}

In this paper we determine the roughness coefficient of the main channel as a Nikuradse roughness height. This roughness height is translated into a Chézy coefficient for use in SOBEK by using a Colebrook-White type formula (ASCE Task Force on Friction Factors in Open Channels, 1963; Van Rijn, 1984):

$$
C_{\mathrm{m}}=18 \log \left(\frac{12 h_{\mathrm{m}}}{k_{\mathrm{m}}}\right),
$$

in which $C_{\mathrm{m}}$ is the Chézy coefficient of the main channel and $k_{\mathrm{m}}$ is the Nikuradse roughness height of the main channel. Following Van Rijn (1984), the roughness height of the main channel $\left(k_{\mathrm{m}}\right)$ can be divided into a contribution of grains $\left(k_{\text {grains }}\right)$ and dunes $\left(k_{\text {dunes }}\right)^{1}$ :

$$
k_{\mathrm{m}}=k_{\text {grains }}+k_{\text {dunes }} .
$$

\footnotetext{
${ }^{1}$ if the roughness coefficients of a hydraulic model are calibrated to reproduce measured water levels, all uncertainties and (model) errors end up in the calibrated roughness coefficient; this will be further discussed in the discussion of this chapter.
} 
Generally, if dunes are present, form drag due to dunes is dominant over the grain roughness (e.g. Knighton, 1998; Julien et al., 2002; De Vriend, 2006). The grain roughness $k_{\text {grain }}$ is specified as $3 D_{90}$ (Van Rijn, 1993). To close our model, we need a relationship between computed dune dimensions and roughness height $k_{\text {dunes }}$ (Fig. 4.1). Although numerous relationships are proposed in literature, we chose to use the relationship of Van Rijn (1984). Van Rijn's relationship is based on an extensive database of both flume and field measurements, and is widely applied, particularly for field studies (e.g. Julien et al., 2002; Sieben, 2003). The empirical relationship of Van Rijn $(1984,1993)$ reads:

$$
k_{\text {dunes }}=1.1 \gamma \Delta\left(1-\exp \frac{-25 \Delta}{\lambda}\right),
$$

in which $\Delta$ is the dune height and $\lambda$ is the dune length. The shape factor $\gamma$ expresses the influence of the dune form on the roughness height. The shape factor $\gamma$ is 1 for dunes with angle-of-repose slip faces, since Van Rijn (1984) based his relationship on such dunes. However, in the field, the dune lee is often smaller than the angle of repose (Ogink, 1988; Van Rijn, 1993; Van der Mark et al., 2007). As a result, flow separation might be less pronounced (or in some cases even absent), reducing the form drag due to dunes. Since our dune evolution model assumes an angle-of-repose leeside, it is considered that the roughness is overestimated for field conditions. Therefore, we apply a value of $\gamma=0.7$ as was proposed by Van Rijn (1993), based on field measurements.

The dune evolution model used in this paper is 2-DV (Section 4.2.2) and thus explicitly assumes that dunes form uniformly over the complete main channel width, that all dunes have the same height, and that all available energy and bed load transport directly contribute to the formation of the dunes. In reality however, dunes might be of different size near the banks or part of the transported sediment passes the crest or is in suspension without contributing to dune formation. Therefore, it is anticipated that our dune evolution model predicts maximum dune dimensions in rivers, rather than average dune dimensions. Although not explicitly stated, it is likely that the original relationship of Van Rijn (1984) is based on the average (or: representative) dune height, rather than on maximum dune height. Van der Mark et al. (2007) analyzed flume data and found that the average dune height is more or less half the maximum dune height. In anticipation of the model results (Section 4.4), the dune aspect ratio $(\Delta / \lambda)$ is more or less constant, meaning that the dune roughness linearly depends on the dune height (Eq. 4.3). Therefore, we chose to half the dune shape factor, i.e. we use $\gamma=0.35$ as correction factor in Equation 4.3 to determine the Nikuradse roughness height. In the discussion, the sensitivity of computed roughness coefficients and water levels to this parameter is investigated.

\subsubsection{Method to determine dune length}

In this paper we study dune dynamics and water levels in a uniform channel (Section 4.3), which means that dunes will be distributed more or less uniform over the river reach, as well. Therefore, we simulate the dynamics of a single 


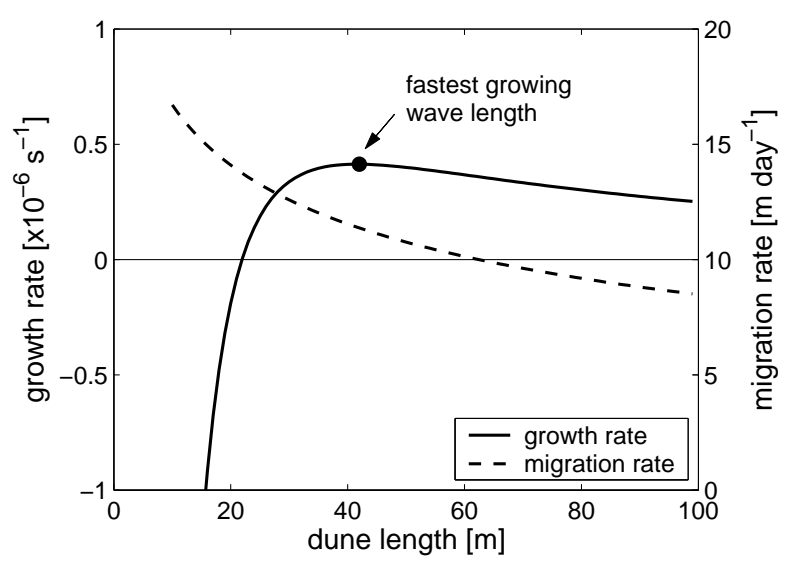

Figure 4.2: Results of a numerical linear stability analysis for a main channel water depth of $6 \mathrm{~m}$. Dunes with a length shorter than $20 \mathrm{~m}$ shrink because of negative growth rates. A dune with a wave length of $\sim 40 \mathrm{~m}$ has the largest growth rate, and is used as dune length in a simulation. The stability analysis is repeated if the water depth changes by $1 \%$ due to dune evolution.

dune in a computational domain with periodic boundary conditions in the horizontal direction. It is assumed that this dune, and associated form drag and resistance coefficient, is representative for the whole river reach.

Wilbers \& Ten Brinke (2003) observed that in the river Waal (near Druten), the dune length remains fairly constant during a flood, i.e. about $40 \mathrm{~m}$. They argue that this is caused by a combination of grain-size distribution over the river width and distance between groynes in the river Waal. However, for other river sections such as the Upper Rhine between Lobith and the Pannerdensche Kop (Fig. 1.2), the dune length may vary during floods. More specifically, Wilbers \& Ten Brinke (2003) observed that the dune length continues to grow, while the discharge is already falling after the discharge peak. Instead of decreasing dune lengths during the falling stage ${ }^{2}$, smaller secondary dunes form on the primary dunes at the end of a flood. Probably, this is related to the inability of the large primary dunes to diminish in length because this requires sediment transport, which decreases in magnitude because of decreasing flow strength during the falling stage of a flood wave.

To analyze the effects of a changing dune length on dune heights and water levels, simulations are performed using a constant and a variable dune length. Since we use periodic boundary conditions in the dune evolution model, the dune length does not automatically change. However, the dune length can be changed by changing the length of the domain. The dune length is determined

\footnotetext{
${ }^{2}$ during the falling stage of a flood, decreasing dunes lengths could be expected as a result of the decreasing water depth, since dune length primarily scales with the water depth
} 


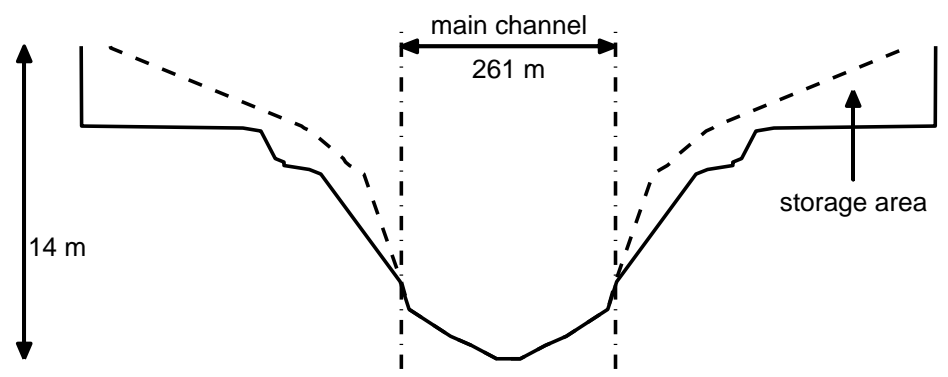

Figure 4.3: Cross section for the SOBEK model, based on relatively straight section in the river Waal (river $\mathrm{km}$ 895.34, Fig. 1.2b). The solid line represents the actual bathymetry, while the dashed line gives the part of the cross-section that actually contributes to the conveyance of the channel. The difference between those lines is the part of the cross-section used as storage area.

by the simulation model on the basis of a numerical linear stability analysis (Dodd et al., 2003), and is mainly controlled by the water depth in our model. If the water depth changes by $1 \%$, the simulation model performs a linear stability analysis using small amplitude sinusoidal disturbances with different wave lengths on a flat bottom as topography (see also Paarlberg et al., subm., chapter 3 ). Typically, a $1 \%$ change in water depth, results in a $1 \%$ change of dune length. It is assumed that the dune length found from the linear analysis is a good representation of the dune length in the nonlinear regime as well (e.g. Paarlberg et al., subm.; Chapter 3; Dodd et al., 2003; Németh et al., 2006).

An example result of the linear stability analysis is shown in Figure 4.2. From this analysis a fastest growing wave length is found and is used as domain length (effectuated by adapting the horizontal distance between grid-points in horizontal direction). Note that using this approach, the dune length becomes smaller during the falling stage of a flood wave, since it mainly scales with the flow depth. This is not in agreement with the observed behaviour of the dune length of primary dunes in the river Waal lined out above. However, it may represent the smaller secondary dunes forming on top of these large primary dunes during the falling stage of a flood wave.

\subsection{Model set-up and methodology for analysis}

\subsubsection{Representative river Waal schematization}

The SoBEK Rhine model covers the non-tidal part of the Dutch Rhine branches. This model contains two river bifurcations (Fig. 1.2b) and model results are sensitive to the assumed discharge distribution at these bifurcations. To avoid such effects we set-up a simple 60-km long straight channel with floodplains in SOBEK, having a uniform cross section that is representative for a relatively straight trajectory in the river Waal (river km 885.23-900.88) (Fig. 4.3).

Computed roughness coefficients are uniform over the entire reach and SoBEK 
computes the water level along the channel. At the downstream end of the model, a stage-discharge relationship is used. To minimize the influence of the downstream stage-discharge relationship on the results, the average flow depth $\left(h_{\mathrm{m}}\right)$ at the upstream boundary of the main channel is used as input for the dune evolution model ${ }^{3}$. The grain-size distribution and channel slope are uniform over the entire reach. Based on conditions in the river Waal we specify $D_{50}$ as $1 \mathrm{~mm}$ and $D_{90}$ as $10 \mathrm{~mm}$ (Wilbers \& Ten Brinke, 2003; Kleinhans et al., 2007) and the channel slope $i$ as $0.76 \times 10^{-4}$.

\subsubsection{Flood wave scenario's}

Flood waves in the river Rhine are variable in shape, with rapid or gradual changes in discharge over time (Fig. 4.4). For some waves the flood wave has a sharp peak (high discharge for a short period of time), while other waves are characterized by a longer period of high discharge. Note that the discharge in the river Waal is about $2 / 3$ of that of the river Rhine at Lobith, because of the bifurcation at the Pannerdensche Kop (Fig. 1.2).

Since we are interested in the effects of dunes on water levels for different flood wave shapes, we analyze two different flood wave shapes, as presented in Figure 4.5. The sharp-peaked (SP) flood wave (Fig. 4.5a) is based on the flood wave that occurred in the river Waal in October and November 1998 which had a maximum discharge of about $6,000 \mathrm{~m}^{3} \mathrm{~s}^{-1}$ in the river Waal. The wave is characterized by a sharp peak, i.e. the high discharge occurs for a small period of time. For the broad-peaked (BP) flood wave (Fig. 4.5b) we chose the same maximum discharge, but this discharge occurs for a longer period of time. These shape differences may influence dune dynamics, since for the broad wave the rising and falling stages are shorter, while the dunes have more time to adapt to the higher discharge since this lasts longer. Note that both flood waves have the same duration (i.e. 30 days).

Generally, dune dimensions at the start of a flood wave are not known, but in the simulation model initial dune dimensions have to be specified. We have chosen to start a simulation with an initial dune height of $2 \mathrm{~cm}$. A model simulation consists of two subsequent flood waves of identical shape with a period of 1 week of constant low discharge in between (Fig. 4.5). For the first wave (indicated by 'SP1' and 'BP1' in Fig. 4.5), dunes have to develop from very small sinusoidal waves, while for the second wave (indicated by 'SP2' and 'BP2' in Fig. 4.5), the dune height is more or less in equilibrium with flow conditions as the second wave starts.

\subsubsection{Comparison of Sobek models with different roughness formu- lations}

Hysteresis in water levels is caused by a combined effect of dune dynamics and accelerations and decelerations during the passage of a flood wave. In the SoBEK

\footnotetext{
${ }^{3}$ typically, the adaptation length scale of disturbance in the river Waal is some tens of kilometers
} 


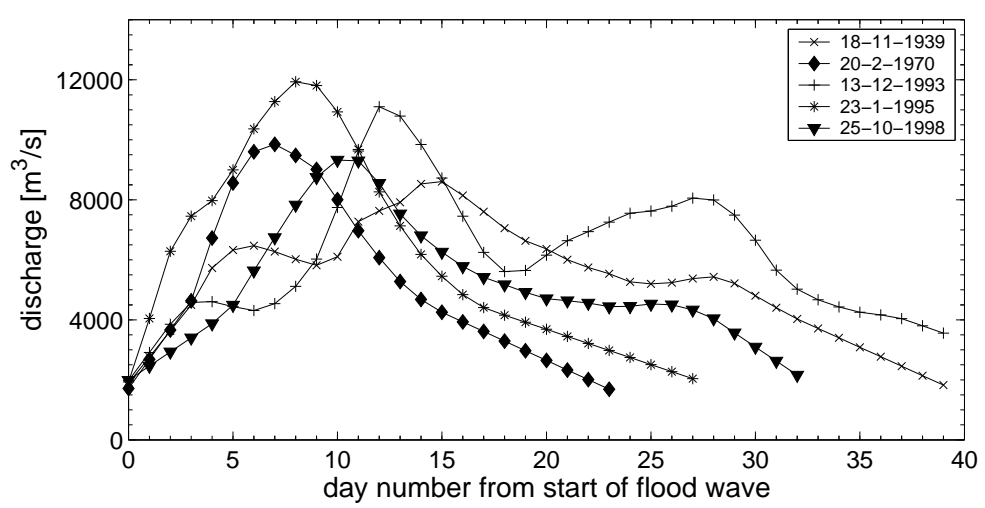

Figure 4.4: Some recorded flood waves in the river Rhine at Lobith.
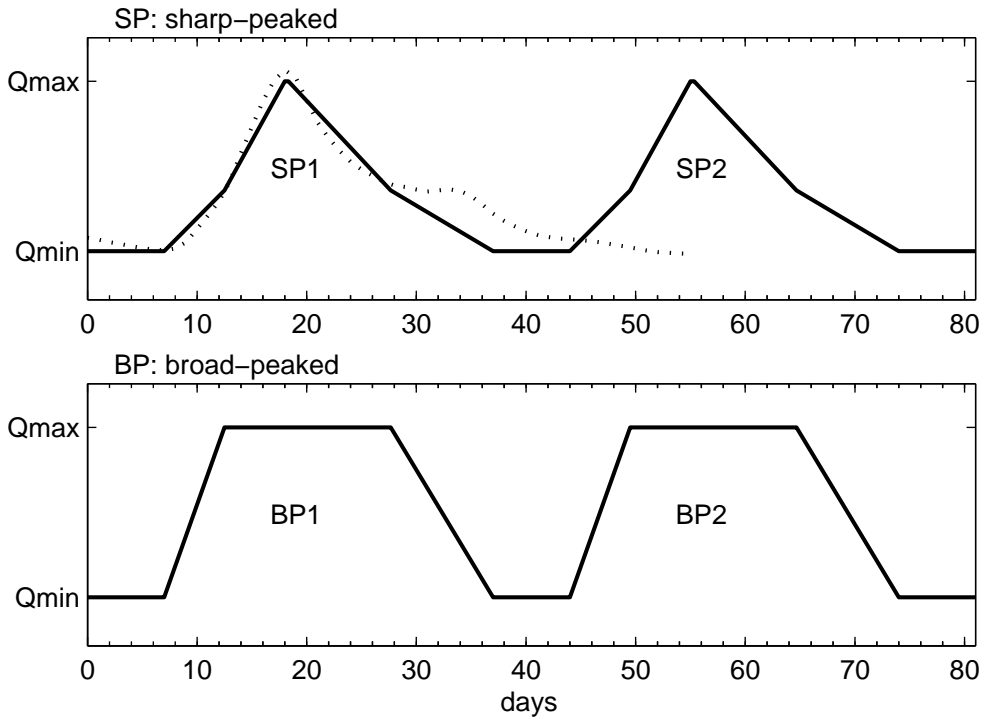

Figure 4.5: Two types of flood waves analyzed in this paper. Qmax $\left(=6,000 \mathrm{~m}^{3}\right.$ $\left.\mathrm{s}^{-1}\right)$ and $\operatorname{Qmin}\left(=1,333 \mathrm{~m}^{3} \mathrm{~s}^{-1}\right)$ are the maximum and minimum simulated discharges in the river Waal, respectively. The dotted line in the top plot gives the recorded hydrograph for the 1998 flood in the river Waal. In the simulations, two subsequent waves of identical shape are simulated, for which the numbering is indicated in the plots ('SP' is sharp-peaked, and 'BP' is broad-peaked). Note that the waves are not symmetrical with longer falling stages than rising stages, in line with observed flood waves (Fig. 4.4). 


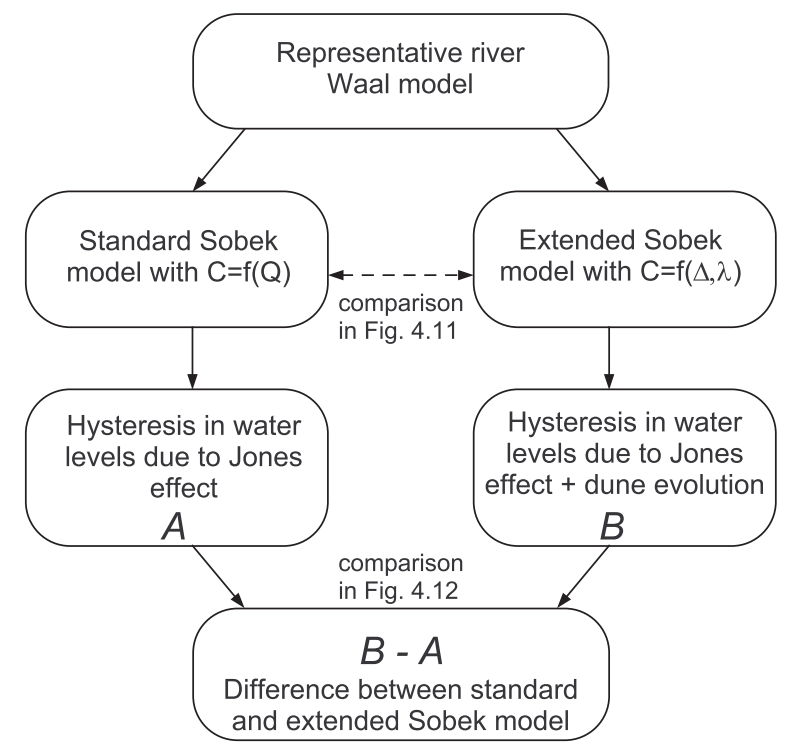

Figure 4.6: Illustration of the approach to analyze the differences between a SOBEK model using calibrated $(A)$ and computed $(B)$ roughness coefficients.

Rhine model of Udo et al. (2007), roughness coefficients for the main channel and floodplain are calibrated for a certain number of trajectories, as a function of the discharge. Thus for each discharge there is one unique value of the Chézy coefficient. The aim of the new extended SOBEK model is to analyze the effects of hysteresis in dune dimensions on water levels, for different flood wave shapes. Figure 4.6 illustrates the approach to analyze the differences between a SOBEK model using computed and calibrated roughness coefficients.

The calibrated roughness coefficients are used to compare the results of the extended model with original SoBEK model (Fig. 4.6). Figure 4.7 shows the calibrated Chézy coefficients for the river trajectory on which our SoBEK model is based (Fig. 4.3). For this calibration, recorded discharges (up to 7,000 $\mathrm{m}^{3}$ $\mathrm{s}^{-1}$ in the river Waal) and water levels of various flood waves were used. For discharges higher than about $7,000 \mathrm{~m}^{3} \mathrm{~s}^{-1}$, the SOBEK model is calibrated on the basis of simulation results of the 2-DH hydraulic model WAQUA of the river Rhine in the Netherlands (Van den Brink et al., 2006; Udo et al., 2007). In this paper, we focus on discharges $\leq 6,000 \mathrm{~m}^{3} \mathrm{~s}^{-1}$ in the river Waal, since this is the recorded maximum discharge for the 1998 flood. Since the roughness of the floodplain is not of central interest in this paper, we base the roughness coefficient of the floodplains on the calibrated coefficients. We chose to use a discharge-independent value of $38 \mathrm{~m}^{1 / 2} \mathrm{~s}^{-1}$ for the Chézy coefficient in the floodplains, since the variations of this coefficient are small in the calibration (Fig. 4.7).

To analyze the performance of the extended SOBEK model presented in this 


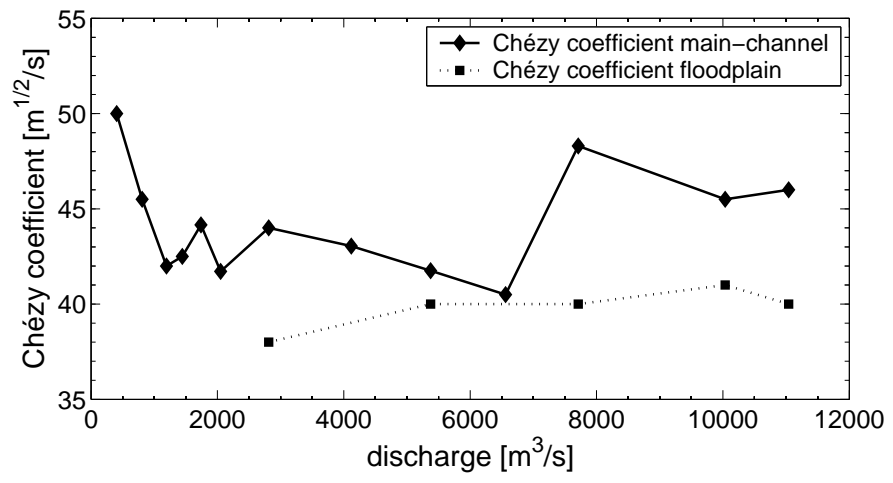

Figure 4.7: Calibrated Chézy coefficients of the main channel and the floodplain as a function of discharge in the Waal for trajectory with river $\mathrm{km} 885.23-900.88$ (data from Udo et al., 2007).

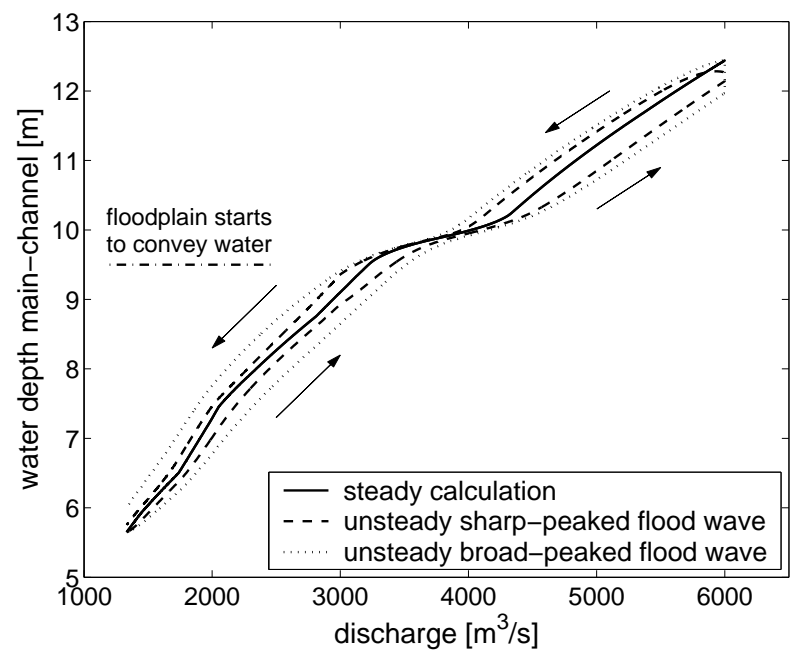

Figure 4.8: Stage-discharge relationships for a steady and unsteady SoBEK calculation using calibrated roughness coefficients for two types of flood waves (at the upstream model boundary). The arrows indicate the direction of the hysteresis. 
paper, computed water levels are compared to the results of the originally calibrated model in which the roughness coefficients are a function of discharge (Fig. 4.6). Figure 4.8 shows stage-discharge relationships for steady flow and for the two flood waves as computed with the SOBEK model, using calibrated roughness coefficients as a function of discharge (Fig. 4.7). In the steady calculation, for each discharge the SOBEK model iterates water levels along the $60-\mathrm{km}$ reach until steady flow conditions are obtained, yielding a stage-discharge relationship without hysteresis. For the unsteady calculations however, the effect of accelerations and decelerations due to the passage of a non-uniform flood wave (i.e. the water surface slope is different from the average channel slope) is included in SOBEK, since the unsteady terms are retained in the equation of motion. Compared to the steady computation, this results in lower water levels during the rising stage (i.e. the wave accelerates) and higher water levels during the falling stage, for both types of flood waves. The maximum water level difference between rising and falling stage is larger for the broad-peaked flood wave $(\simeq 1 \mathrm{~m})$ than for the sharp-peaked flood wave $(\simeq 0.7 \mathrm{~m})$. This is because the discharge variations during the rising and falling stage are more gradual for the sharp-peaked flood wave (Fig. 4.5), leading to smaller acceleration and deceleration effects.

\subsection{Results of the extended Sobek model}

This section presents the simulation results of the new SOBEK model, which includes the new dynamic roughness model (Fig. 4.1). First, simulated dune dynamics are discussed for the sharp-peaked flood wave. We focus on this type of flood wave, since it is based on a real flood in 1998 in the river Waal (Fig. 4.5a). Then, the hysteresis effect in dune height is discussed for both types of flood waves. The results section ends with an analysis of the effects of dune evolution on simulated water levels. To this end, simulated water levels are compared to a simulation with calibrated roughness coefficients (Fig. 4.6).

\subsubsection{Dune dynamics for sharp-peaked flood wave}

Figure 4.9 shows simulated dune dynamics for two subsequent sharp-peaked flood waves, with constant dune length and with variable dune length. For constant dune length, the simulated dune height reaches a value of about $2 \mathrm{~m}$ (Fig. 4.9b). Wilbers \& Ten Brinke (2003) report dune heights of $\sim 1-1.2 \mathrm{~m}$ for a reach in the river Waal at peak discharge, for a dune length of $40 \mathrm{~m}$. Thus our simulations compare quite well with measured dimensions, if we take into account that the dune evolution model predicts maximum dune dimensions rather than average dune dimensions (accounts for a factor 2 difference, Sec. 4.2.3). Simulations show small variations in dune height due to discharge variations (Fig. 4.9b), and the maximum dune height occurs about 3 days after the peak discharge, which is comparable to measurements in the river Rhine (Wilbers \& Ten Brinke, 2003). The hysteresis effects will be discussed in Section 4.4.2 in more detail. For a variable dune length, the model predicts increasing dune 

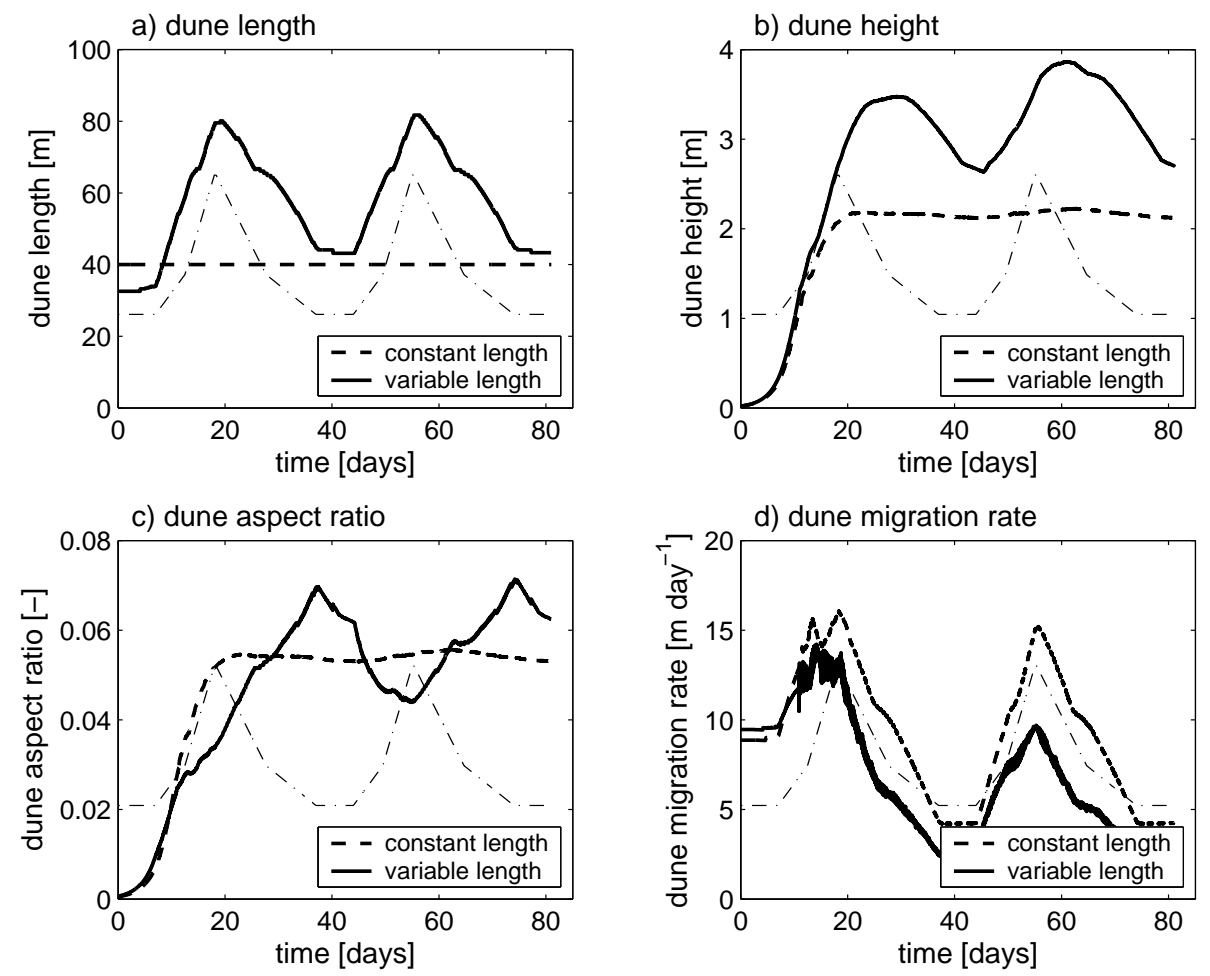

Figure 4.9: Result for sharp-peaked flood wave (Fig. 4.5a); the discharge variation is sketched in the subplots with dash-dotted lines. a) dune length; b) dune height; c) dune aspect ratio (ratio of dune height to dune length); d) dune migration rate. 
lengths during the rising stage due to an increasing water depth in the main channel (Fig. 4.9a). Elongating dunes have smaller bed slopes and grains can be transported up-slope easier, resulting in higher dunes (Fig. 4.9b). As a result, the dune height becomes up to $40 \%$ higher than for a constant dune length.

If the dune length is constant, a more or less constant aspect ratio of about 0.055 is obtained (Fig. 4.9c). For variable dune length, the simulated dune aspect ratio varies roughly between 0.05 and 0.07 (Fig. $4.9 \mathrm{c}$ ), which is well within the range of values from literature (e.g. Bennett \& Best, 1995; McLean et al., 1999; Carling et al., 2000a). In the river Rhine, also lower values around 0.04 are reported (Julien \& Klaassen, 1995; Wilbers \& Ten Brinke, 2003). However, as discussed in Section 4.2.3 the dune height may be overpredicted for natural river settings which may explain the slightly higher dune aspect ratios. At the second discharge peak, the dune height is higher than at low discharge (Fig. 4.9b), while the dune aspect ratio is lowest at the peak discharge (Fig. 4.9c). This is because the dune length is largest at the peak discharge and differs $\sim 100 \%$ between low and high discharge, while the dune height differs $\sim 40 \%$ between low and high discharge (Fig. 4.9). Since the dune aspect ratio is important for roughness predictions (Eq. 4.3), a proper modelling of this aspect ratio is very important for accurate modelling of dynamic roughness due to dunes.

Figure $4.9 \mathrm{~d}$ shows that the migration rate is highly variable and especially responds to a changing discharge. This is not surprising, since for increasing discharge and flow depth, the bed shear stress and thus the sediment transport increase. For constant dune length, the dune height becomes more or less constant in time, while the migration rate still varies significantly (Fig. 4.9d). Apparently, the flow depth (or bed shear stress) is the controlling parameter on the migration rate in case of constant dune length. Wilbers \& Ten Brinke (2003) assumed a relationship between dune length and migration rate with higher migration rates for longer dunes. If the dune length varies during the flood wave we find similar behaviour (Fig. 4.9a and d). However, the relationship is less strong than Wilbers \& Ten Brinke (2003) assumed, since longer dunes are also higher, reducing the migration rate if we assume that all sediment that passes the dune crest deposits evenly at the bedform lee (as is done in the dune evolution model).

\subsubsection{Hysteresis effect in dune height}

Figures 4.10a-b show the dune height as a function of discharge for constant dune length for the two different flood wave types. The simulated hysteresis effect is similar for both types of flood waves. The maximum dune height is about $2.25 \mathrm{~m}$ and the dune height varies roughly $10 \mathrm{~cm}$ between the rising and the falling stages. For the broad-peaked flood wave, the period of high discharge is relatively long, causing the dunes to become slightly higher at the moment the discharge starts falling, compared to the sharp-peaked flood wave. In contrast, during the broad-peaked flood wave, the dunes do not really respond to the changing discharge during the rising and the falling stage, since these periods are relatively short (Fig. $4.5 \mathrm{~b})$. 

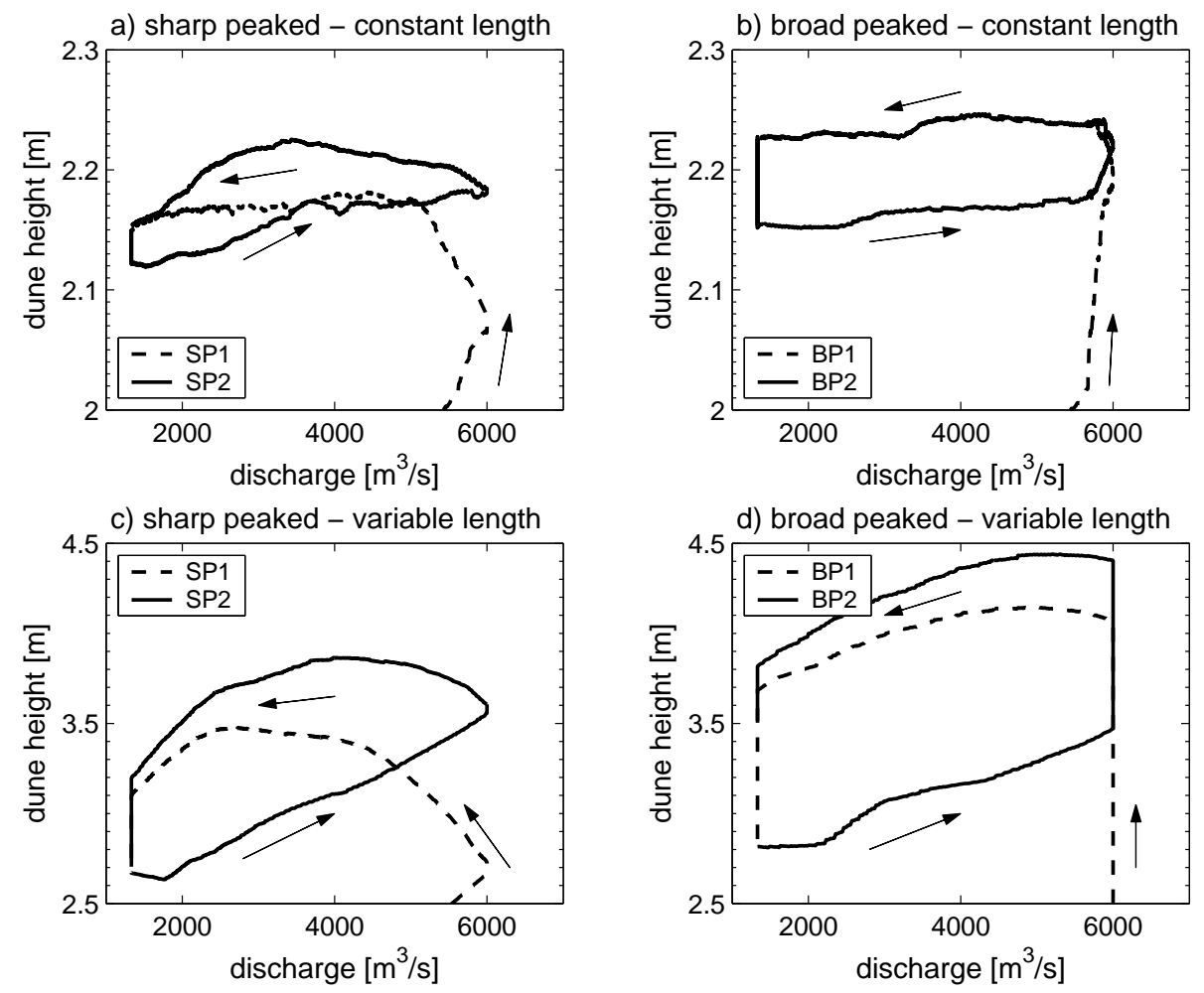

Figure 4.10: Hysteresis in dune height, for the two types of flood waves (Fig. 4.5). Results for both constant dune length (a-b) and variable dune length (c-d) are shown (note different scales on y-axis). In the figures, the two subsequent flood waves in each simulation are plotted separately (in the legends, 'BP' is broad-peaked and 'SP' is sharp-peaked, while ' 1 ' indicates the first, and '2' the second wave, Fig. 4.5). 
For variable dune length, the hysteresis effects in dune height are more pronounced for both flood wave shapes (Fig. 4.10c-d) compared to the case with constant dune length. This is a direct result of the observation that dunes change in height if the dune length changes. However, the dune length adapts immediately to changing flow conditions (because of the used approach to simulate dune length, Sec. 4.2.4), while it takes time for the dune height to change. Therefore, the dune aspect ratio varies during a flood wave if the dune length is variable.

For the second wave of the sharp-peaked flood wave, we clearly observe a hysteresis loop with a maximum dune height difference of $\sim 1.2 \mathrm{~m}$ between the rising and the falling stage. Also, the maximum dune height occurs if the discharge is already falling. For the broad-peaked flood wave, the dunes remain somewhat lower during the rising stage of the second wave than is the case for the sharp-peaked flood wave (i.e. $\sim 10 \mathrm{~cm}$, Fig. $4.10 \mathrm{c}-\mathrm{d}$ ). However, the relatively long period of high discharge for the broad-peaked flood wave yields dunes that are $\sim 80 \mathrm{~cm}$ higher at the start of the falling stage than for the sharp-peaked flood wave. Moveover, at the start of the falling stage, the dune height is almost adapted to the new dune length, meaning that the time-lag in dune height during the falling stage is very small and almost negligible. Note that after the floods the simulated dune heights differ between the two types of flood waves. At the end of the flood wave the relict dunes are higher for the broad-peaked flood wave than for the sharp-peaked flood wave. This is important information because these relict dunes may cause problems for e.g. navigation, and the dunes may diminish in height slowly at low discharge, because the transport rates are relatively low.

\subsubsection{Effects of dune evolution on hydraulics}

Changing dune dimensions in time and the hysteresis effect in dune height also yield temporal variations and hysteresis in roughness height, since the roughness coefficient of the main channel is directly linked to both dune height and dune length (Eq. 4.3). Figure 4.11 compares Chézy coefficients computed with the new dynamic roughness model and the values of the originally calibrated model (Fig. 4.6). Results are only shown for the second wave in a simulation.

The new dynamic roughness model yields lower Chézy coefficients (higher roughness), for both types of flood waves, especially in case of variable dune length, which is directly linked to the higher dunes for these cases (Fig. 4.10). For constant dune length, the roughness coefficient at the peak discharge is predicted quite well. The hysteresis effect in roughness is very small for constant dune length, which is due to the dune height being almost constant during the second discharge peak (Fig. 4.10a-b). On the other hand, for variable dune length, the Chézy coefficient is $5-10 \%$ (higher roughness) lower during the falling stage, compared to the rising stage. Furthermore, this effect is larger for the broad-peaked flood wave, with even lower Chézy coefficients in the early phase of the falling stage (i.e. when the discharge is still high), than during the falling stage of the sharp-peaked flood wave. This illustrates the dependence 

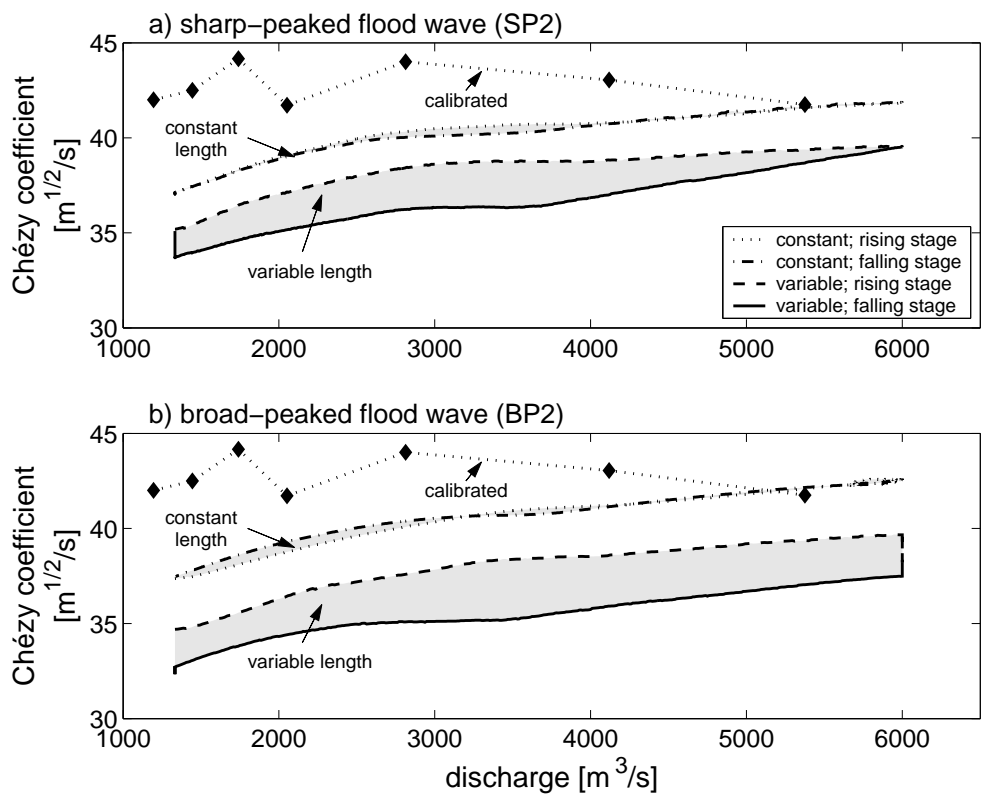

Figure 4.11: Chézy coefficients of the main channel computed by the dynamic roughness model, compared to the calibrated values (diamond symbols) for (a) sharp-peaked flood wave, and (b) broad-peaked flood wave. Results for both constant and variable dune length are shown, for the second flood wave of a simulation (Fig. 4.5). 

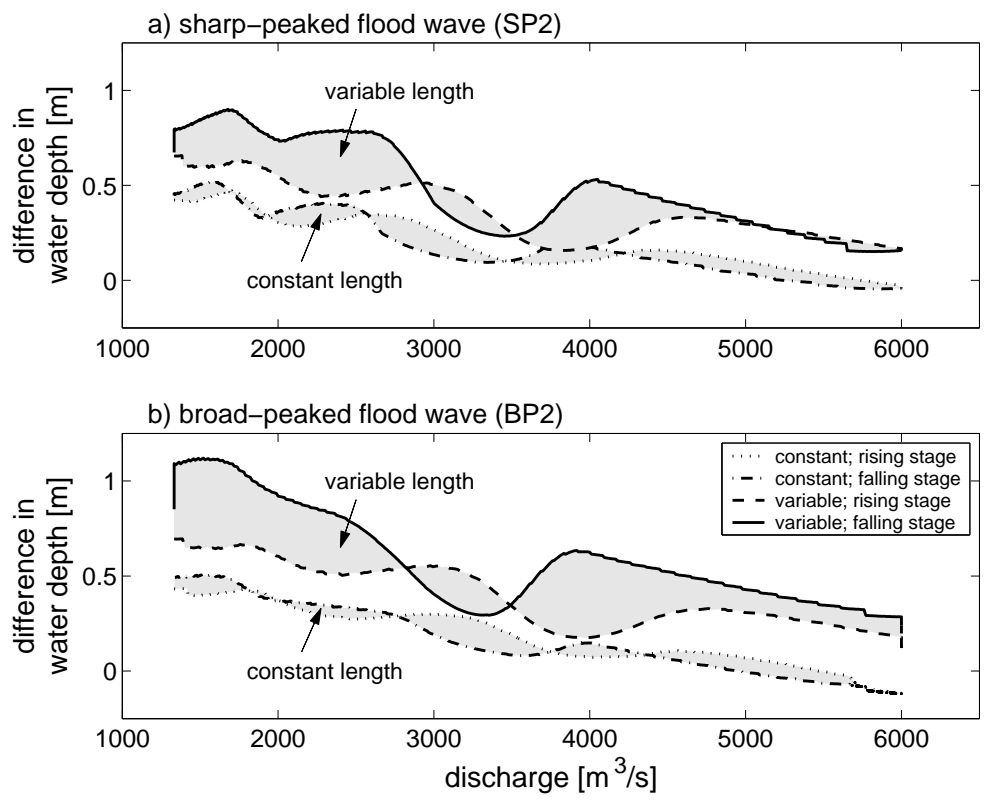

Figure 4.12: Differences in the stage-discharge relationships between the SoBEK model extended with a dynamic roughness model and the originally calibrated SOBEK model (Fig. 4.8) for (a) sharp-peaked flood wave, and (b) broad-peaked flood wave (for the second wave, conform Fig. 4.11). 
of roughness predictions on the shape of a flood wave. The differences between the new dynamic roughness model and the originally calibrated roughness coefficients are largest at low discharge. At low discharge, Chézy coefficients are about $13 \%$ lower for the constant dune length and about $22 \%$ for the variable dune length.

Figure 4.12 shows the difference between the water levels computed with the dynamic roughness model and the original stage-discharge relationship for both flood wave types (using the method presented in Fig. 4.6). Since the timeevolution of the main channel roughness differs between the dynamic roughness model and the calibrated model, water levels are different for a certain discharge. This implies that certain areas become flooded or dry at different discharges. This is the reason for the oscillations in Figure 4.12.

Generally, water levels are larger by using the new dynamic roughness model, as a result of lower Chézy coefficients. Water level differences between the extended SOBEK model and the originally calibrated model are largest at low discharge, if most water is conveyed through the main channel, and lowest at peak discharge. This is attributed to the aspects that $(i)$ in practice hydraulic models are calibrated on peak discharges, and $(i i)$ the relative influence of the main channel roughness decreases at higher water levels. Dunes reach their maximum dimensions after the peak discharge (Fig. 4.10) and decrease in dimensions slowly after they have reached their maximum dimensions. Therefore, for variable dune length, differences in flow depth are larger for the falling stage than for the rising stages. Differences in water depth can be up to $1 \mathrm{~m}$ for low discharge (Fig. 4.12), which is a difference in water depth of $\sim 15 \%$ between the new extended SOBEK model and the model adopting calibrated roughness coefficients. For the broad-peaked flood wave, effects are even larger than for the sharp-peaked flood wave, since dunes are higher for that case.

\subsection{Discussion}

The new dynamic roughness model provides more insight in the part of the main channel roughness coefficient, associated to time-evolution and hysteresis effects of dunes. The model is computationally efficient: typically, two flood waves in series, e.g. Fig. 4.5 a with a duration of 80 days, take about 8 hours to compute on a standard office PC.

Especially for variable dune length, hysteresis effects in dune height yield significant differences in roughness coefficients between the rising and falling stages. These hysteresis effects are not included in the model using calibrated roughness coefficients. This explains part of the differences in Chézy coefficients and water levels between the new dynamic roughness model and the model using calibrated Chézy coefficients. However, potentially there are three other possible causes for these differences: 1) the dune dimensions are predicted incorrectly, 2) the translation of dune dimensions into a roughness coefficient is incorrect, or 3) additional roughness component should be taken into account in the comparison between computed and calibrated roughness coefficients. We will address these issues here. 
In Section 4.2.3, it was argued that computed dune dimensions represented maximum dune heights, rather than average dune heights, giving rise to adaptation of the roughness correction factor. However, this overprediction could also be caused by physical processes that are currently not captured by the model, like suspended sediment transport, non-uniform sediment dynamics, or the aspect that part of the bed load transport passes the separation point, effectively not contributing to dune formation. These aspects remain for future research. It could also be due to parameter settings of the model. The dune evolution model employs periodic boundary conditions and the flow is forced by the channel slope and flow depth. The two required coefficients for the turbulence model, which determine the eddy viscosity and bed resistance, are calibrated on flume experiments (Paarlberg et al., subm.; Chapter 3). The flow depth, channel slope and these two coefficients determine the discharge that is 'forced' through the domain. For larger flow depths in field situations, this approach yields smaller simulated velocities (and thus discharges) in the dune evolution model compared to SOBEK. This might indicate that a recalibration of the parameters in the turbulence model is required. Figure 4.13 shows how the calibration coefficient $\beta_{1}$ (that determines the eddy viscosity, Chapter 3 ) depends on $\beta_{2}$ and the Chézy friction coefficient. For steady flow and increasing friction (i.e. lower Chézy coefficient), $\beta_{1}$ and thus the eddy viscosity increases (Eq. 3.21) due to increased turbulence. Figure 3.6 showed that both the eddy viscosity and the resistance parameter control the computed specific discharge in the dune evolution model. However, a variation of $\beta_{1}$ on the Chézy coefficient, is not incorporated in the presented simulation model (and will be subject of future research). Therefore, the dependence of $\beta_{1}$ on Chézy coefficients might explain the differences in simulated discharges. Interestingly, also the fastest growing wave length changes as a function of the Chézy coefficient, as is illustrated in Figure 4.13b for $\beta_{2}=0.5$. This means that taking dependencies on the Chézy coefficient into account could yield more variations in dune length over a flood wave as well. A related issue is that due to differences in roughness between the main channel and the floodplain, not only the water depth, but also the discharge distribution between main channel and floodplain changes due to dune evolution. Possibly, this might also be taken into account by allowing for a dependency of the calibration coefficients of the turbulence model on the Chézy coefficient.

Note that computed dune dimensions are different between the first and second flood wave in a simulation (Figs. 4.9 and 4.10). This also results in differences in roughness coefficients and water depths for the two waves. The hysteresis effects in dune height and associated effects on water depths were analyzed for the second flood wave, i.e. for a situation in which the dunes were almost in equilibrium with flow conditions at the start of the wave. Keeping this in mind, the differences between the new extended SoBEK model and the SOBEK model that adopts calibrated roughness coefficients, would probably be smaller due to smaller dune heights for the first flood wave. This illustrates the importance of having simultaneous measurements of water levels and dune dimensions during floods, which could improve model calibrations. 

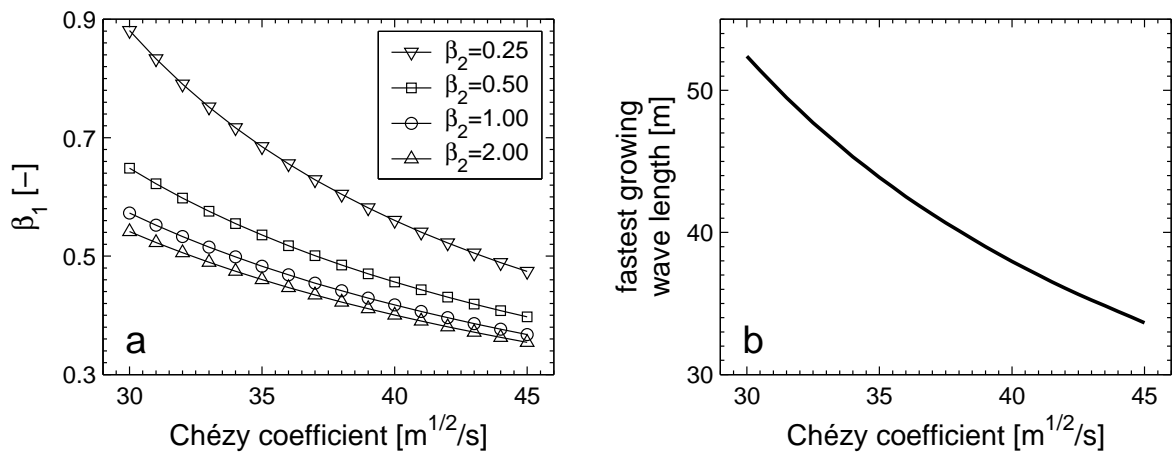

Figure 4.13: (a) Dependency of calibration coefficient $\beta_{1}$ on $\beta_{2}$ and the Chézy friction coefficient. (b) Linear stability analysis showing the fastest growing wave length as a function of the Chézy coefficient for $\beta_{2}=0.5$.

Table 4.1: Sensitivity analysis for roughness correction factor $\gamma$ for sharp-peaked flood wave and variable dune length. $C_{\mathrm{m}}$ is the main channel Chézy coefficient, and $h_{\text {diff }}$ represents the difference in flow depth between the extended SOBEK model and the SoBEK model adopting calibrated roughness coefficients (conform Fig. 4.12). The overbar indicates that a certain parameter is averaged over the second flood wave of a simulation (SP2 in Fig. 4.5).

\begin{tabular}{|c|c|c|c|c|c|c|c|}
\hline case & $\begin{array}{c}\gamma \\
{[-]}\end{array}$ & $\begin{array}{c}\Delta_{\max } \\
{[\mathrm{m}]}\end{array}$ & $\begin{array}{c}\bar{\Delta} \\
{[\mathrm{m}]}\end{array}$ & $\begin{array}{c}\bar{\lambda} \\
{[\mathrm{m}]}\end{array}$ & $\begin{array}{c}\overline{(\Delta / \lambda)} \\
{[-]}\end{array}$ & $\begin{array}{c}\overline{C_{\mathrm{m}}} \\
{\left[\mathrm{m}^{1 / 2} s^{-1}\right]}\end{array}$ & $\begin{array}{c}h_{\text {diff }} \\
{[\mathrm{m}]}\end{array}$ \\
\hline calibrated model & & & & & & 42.7 & \\
\hline$\gamma-50 \%$ & 0.175 & 3.72 & 3.15 & 57.5 & 0.055 & 41.7 & 0.09 \\
\hline$\gamma$ reference & 0.35 & 3.86 & 3.32 & 60.3 & 0.055 & 36.6 & 0.53 \\
\hline$\gamma+50 \%$ & 0.525 & 3.96 & 3.42 & 62.2 & 0.055 & 33.5 & 0.82 \\
\hline
\end{tabular}

Issue (2) deals with the new dynamic roughness model. A roughness correction coefficient $\gamma=0.35$ was introduced into Equation (4.3) to correct for the effects of the shape of the dune leeface and a translation to representative average dune dimensions (Section 4.2.3). A sensitivity analysis shows that varying this parameter has marginal influence on dune characteristics (Tab. 4.1). However, the influence on Chézy coefficients and water depths is significant, since the Nikuradse roughness height of the main channel linearly depends on $\gamma$. Effectively, the stage-discharge relationships shift upwards or downwards depending on $\gamma$. Apparently, changes in roughness coefficients and water depths do not change the flow significantly, leading to similar dune characteristics.

This indicates that future research is required on the relationship between dune dimensions and roughness coefficients. This could either mean to change the roughness formulation (i.e. Eq. 4.3) or to focus, e.g. on how irregularity in dunes can be taken into account in the dynamic roughness model. More insights 
into these aspects might be obtained by calibrating the model for situations where also dune dimensions are known. To this end, the new extended SoBEK model could be applied to flume experiments, preferably with floodplains.

Issue (3) relates to the way the roughness coefficient of the main channel is represented: we assume that it only consists of a contribution due to grains and dunes. However, in model calibrations, also uncertainties originating from (model) errors are incorporated in roughness coefficients:

$$
k_{\mathrm{m}}=k_{\text {grains }}+k_{\text {dunes }}+k_{\text {uncertain }},
$$

in which the term $k_{\text {uncertain }}$ represents uncertainties and model errors contributing to the roughness coefficient of the main channel. This term is not taken into account for the comparisons made in this paper, since it is not known for the SOBEK model that uses calibrated roughness coefficients. It is likely that the water level measurements that were used in the original SoBEK calibration, included effects due to dunes, however, to what extent is not known. Future work should aim on further reducing the uncertainties in this roughness coefficient of the main channel. This can be done by including the dynamic roughness caused by dunes using the approach presented in this paper and then recalibrating main channel roughness coefficients against historic flows by varying the term $k_{\text {uncertain }}$.

\subsection{Conclusions}

This paper presents a coupling between the existing hydraulic simulation model SOBEK, and a dynamic roughness model that explicitly takes drag due to dunes into account. The dynamic roughness model consists of a process-based dune evolution model and the roughness predictor of Van Rijn (1984). By computing dune dimensions during a flood wave, the main channel roughness coefficient in SOBEK is dynamically changed, and hysteresis effects are taken into account. The dynamic roughness model is computationally efficient, since it runs with only one dune in the domain.

Model application to two types of flood waves (i.e. a sharp-peaked and a broad-peaked flood wave) shows significant deviations from calibrated roughness coefficients due to dune evolution during floods. For variable dune length, the Chézy coefficient is $5-10 \%$ lower during the falling stage, compared to the rising stage. Model results show that differences in duration of the rising and falling stage between the sharp-peaked and the broad-peaked flood wave have some effect on dune dimensions. However, the relatively long duration of the maximum discharge for the broad-peaked flood wave is more important, since dunes can grow further in height during this period. This emphasizes the dependence of roughness predictions on the shape of the flood wave, a factor that is not taken into account if hydraulic simulation models are calibrated on recorded water levels. In the extended SoBEK model, this effect is automatically accounted for, since dune dynamics are explicitly simulated.

Differences in simulated roughness coefficients and water levels between the extended SoBEK model and the originally calibrated model are significant, espe- 
cially at low discharge. At low discharge, Chézy coefficients are 13-22\% lower (higher roughness) as computed with the dynamic roughness model, compared to the originally calibrated Chézy coefficients. Due to the hysteresis effect in dune roughness, caused by the hysteresis effect in dune height, water depths are significantly different between the rising and the falling stages of a flood wave. A broad-peaked flood wave with variable dune length leads to an increase in water depth of up to $1 \mathrm{~m}$, compared to a case with calibrated roughness coefficients. This is because the dunes have ample time to adapt to the high discharge. We found that the water level differences are sensitive to the value of the roughness correction factor $\gamma$. Therefore, future research should primarily focus on the part of the new dynamic roughness model that translates computed dune dimensions into a roughness coefficient. To this end, the extended SoBEK model should be recalibrated using measurements of both dune dimensions and water levels. 


\section{Chapter 5}

\section{Discussion}

In this thesis, a process-based dynamic roughness model is developed which is applicable at a flood wave time scale, by limiting the required computational effort. The modelling approach, followed to develop the dynamic roughness model, is justified in Section 5.1 by arguing that the dune evolution model contains the most essential physical processes to realistically simulate dune evolution and dynamic roughness. Section 5.2 discusses which complex dune dynamics cannot be simulated with the dune evolution model, due to assumptions that limit the required computational effort. Some possible model applications, other than presented in the preceding chapters, are discussed in Section 5.3.

\subsection{Justification of the modelling approach}

\subsubsection{Flow and sediment transport model}

The dune evolution model presented in this thesis predicts the initial dune length as fastest growing wave length from a linear stability analysis. To enable correct prediction of this fastest growing wave length, the flow model should reproduce circulation cells in the time-independent residual velocity field, yielding sediment transport from troughs to crests. This is captured by solving the flow field in a vertical plane using the 2-DV hydrostatic shallow water equations with appropriate boundary conditions. Using depth-averaged flow equations would reduce computational effort, but would not reproduce the circulation cells in the vertical plane without any parameterizations of acceleration and deceleration effects (e.g. Onda \& Hosoda, 2004). Flow models that are linearized with respect to the dune amplitude (as is often the case with aeolian dune modelling), could possibly reproduce the circulation cells. However, the presence of a free surface in the case of river dunes limits the validity of linearized flow equations in case of equilibrium dunes.

In the dune evolution model, it is assumed that bed load sediment transport drives dune formation, via convergences and divergences in the sediment flux distribution over a dune. In principle, bed load sediment transport is related to instantaneous turbulent fluctuations in the velocity field (e.g. Nelson et al., 1995). However, the model of this thesis shows that the general pattern of dune formation can also be captured using a Meyer-Peter Müller type of sediment transport equation, which uses the turbulence-averaged bed shear stress as input. Moreover, this sediment transport equation allows for including grav- 
itational bed-slope effects in a simple manner. These bed-slope effects play a crucial role in dune stabilization and are a prerequisite in our model to obtain stable short wave lengths in the linear regime. Moreover, the bed-slope effects are essential to obtain saturation to an equilibrium dune height in case of flow separation (Chapter 3).

In the dune evolution model, the dune length is initially determined using a numerical linear stability analysis, and remains constant during a simulation ${ }^{1}$. In the linear analysis, dune aspect ratios are very small and dunes are sinusoidal, meaning that it is not necessary to account for flow separation. One might expect that flow separation influences the dune length, since the transport processes change once flow separation sets in. However, it is widely accepted that the dune length scales with the flow depth, as also follows from our linear analysis. Moreover, a comparison between dune lengths predicted by our model and observed dune lengths of finite-amplitude dunes shows good agreement. Therefore, we assume in the dune evolution model that the fastest growing wave length found from a linear analysis is also representative for the dune length in the nonlinear regime.

\subsubsection{Turbulence model and partial slip condition}

The dune evolution model employs a zero-equation turbulence model (i.e. the eddy viscosity is constant over the flow depth), strongly reducing the required computational effort and allowing for an analytical solution to the flow equations in case of a flat bed (Eq. 3.21). A combination of a depth-independent viscosity and a no-slip condition at the bed results in an overestimation of the bed shear stress. To represent the bed shear stress better, a partial slip condition is adopted at the bed.

Both the value of the eddy viscosity and the bed resistance parameter are, apart from two calibration coefficients, based on physical principles. The basis eddy viscosity (i.e. before calibration) is derived by assuming a parabolic viscosity profile which is generally observed for turbulent river flow (e.g. Jansen et al., 1979). The resistance parameter is related to the shear velocity. The water depth is an important scaling length in the system, since both the eddy viscosity and the bed resistance parameter have this parameter as only length scale. Modelled velocities deviate from measured velocities, especially in the region very close to the bed. However, the (turbulence-averaged) bed shear stress, which is the driving force behind sediment transport and dune evolution in our model, is represented approximately correct. The values of the eddy viscosity and resistance parameter are found to be important for correct representation of the (specific) discharge, and initial wave length and migration rate. Using the values proposed in Chapter 3 (i.e. $\beta_{1}=\beta_{2}=0.5$ ) yields the most realistic flow and morphological behaviour, considering that model simulations using these

\footnotetext{
${ }^{1}$ In a dynamic roughness computation (chapter 4 ), the dune length can vary during a simulation, by repeating the stability analysis if the water depth changes by more than $1 \%$
} 
coefficients yield realistic results for various experimental conditions.

More detailed - and potentially more accurate - turbulence closures are possible. The eddy viscosity profile over the flow depth could be approximated with a parabolic profile (e.g. Soulsby, 1990; Besio et al., 2006) or using the mixing length concept (e.g. Prandtl, 1925; Colombini, 2004). However, it is considered more important to use a depth-constant eddy viscosity with the correct value, rather than modelling the exact profile of the eddy viscosity over the water depth (also the more detailed turbulence approximations need some parameter settings). Moreover, in line with Engelund (1970), we do not expect that a more sophisticated turbulence model would yield fundamental changes to the results.

\subsubsection{Parameterization of flow separation}

In Chapter 3, it has been shown that flow separation plays a crucial role for dune morphodynamics, by including flow separation in a parameterized way. The advantage of using the parameterized separation streamline as virtual bed in the region of flow separation is twofold: (1) we avoid the necessity of computing the complex flow behaviour in the flow separation zone, and (2) it allows for the flow field to be assumed hydrostatic over the full computational domain.

The morphodynamic simulation model of Giri \& Shimizu (2006) obtains realistic dune shapes and migration patterns by solving not only the mean flow, but also the associated statistics, resulting in large computational times. We have shown that using the parameterization of flow separation and assuming that the sediment that passes the flow separation point avalanches down the leeface at the angle of repose, realistically simulates dune shapes, migration rates, and time scales involved for flume conditions. Thus, flow separation is included without increasing the required computational effort. This is vital for using the dune evolution model in a dynamic roughness model. In flume experiments, the sediment is transported predominantly as bed load. However, in the field part of the sediment might be transported in suspension or part of the bed load might pass the separation point, effectively not contributing to dune formation. These aspects remain for future research.

To derive the parameterization we used experimental data of turbulent flow over fixed subaqueous bedforms (Chapter 2). Measurements of flow velocities over fixed bedforms have proven to be very accurate (although the flow near the bed over the steep leeside is difficult to measure accurately). Using a numerical model to study how the shape of the separation streamline depends on bedform properties, would allow to study various bedform types, and possibly dune fields. However, solutions of the flow field obtained from numerical simulation models always depend on the chosen turbulence closure model and boundary conditions. This is not the case for the experimental data. The proposed parameterization of the separation streamline is based upon bedform properties. Thus, at each computational time step in the dune evolution model, the shape of the flow separation zone is independent of the chosen turbulence model. Flow separation zone characteristics might be influenced by the fact that the dunes are actually 
migrating when they consist of erodible sediment. However, since the flow adapts almost instantaneously to bathymetric changes, this is not considered to play an important role.

In the dune evolution model, turbulence and mixing patterns inside the flow separation zone are not explicitly modelled and as such they do not influence the flow field. Still, we are able to realistically simulate dune evolution, by parameterizing important flow dynamics related to flow separation directly into the bed shear distribution over dunes, i.e. zero stress inside the flow separation zone and a shear stress gradient at the flow reattachment point.

\subsubsection{Dynamic roughness model}

In the dynamic roughness model, the dune evolution model is coupled with an empirical relationship to determine the form drag due to dunes. Thus, we assume that the dune geometry mainly determines form drag, which is confirmed by other research (e.g. Vanoni \& Hwang, 1967; Ogink, 1988; Julien et al., 2002). However, as discussed in Section 4.2.3, a roughness correction factor $\gamma$ was required to correctly represent flow resistance for field conditions with complex dune shapes (see also Section 5.2). Although the value of the correction factor $(\gamma=0.35$, Chapter 4$)$ is based on physical arguments, it needs further research, since the correction factor has a significant influence on the model results.

The dune evolution model employs periodic boundary conditions and one dune of constant length is simulated in the domain. For unsteady flow conditions in the field, the dune length is observed to change as a response to the changing water depth (e.g. Wilbers \& Ten Brinke, 2003). Since we aim to simulate dynamic roughness over the time scale of flood waves, it is essential to keep the required computational effort as low as possible. An approach could be to assume that the dune length remains constant for unsteady flow. However, since dune height is generally linked to dune length, this implies that the dune aspect ratio (which is important for roughness predictions, Eq. 4.3) becomes constant. Therefore, for unsteady flow conditions, the dune length is changed during a simulation by repeating a linear stability analysis if the water depth changes by a certain amount. Using this approach, both the evolution of dune length and dune height is included in roughness predictions.

A problem that might arise to apply the dynamic roughness model for operational water management purposes to unsteady river flows is that dune dimensions are often not known at the start of a flood wave. The dune length found from a linear analysis for the prevailing hydraulic conditions might not be representative for the pattern present on the bed, due to relict bedforms. This pattern is usually unknown, since in general no continuous measurements of the bed are performed, neither is the bed measured just prior to the arrival of a flood wave. Therefore, model results have to be treated with care. Simulations should start well before the actual period of interest, preferably at the most recent flood wave to calculate which relict bedforms are be present. 


\subsection{Model limitations for complex dune dynamics}

\subsubsection{3-D flow and dune structures}

In rivers, dune fields often show 3-dimensional (3-D) structures, such as amplitude variations or crestline curvature (e.g. Allen, 1968b; Best, 2005 and references therein). Another $3-\mathrm{D}$ phenomenon is that dunes do not necessarily cover the full main channel width, due to lateral grain-size differences, horizontal flow patterns and sediment diffusion processes. The dune evolution model does not take lateral variations in dune dimensions into account, since it is a 2dimensional vertical model. Although 3-D dune shapes are observed in nature, the general pattern of dune formation is often aligned with the main flow direction (e.g. Fig. 1.2c), if the river is not too wide ${ }^{2}$. Thus, if a river is relatively narrow, and the flow is confined between groynes aligning the flow more or less in one direction, a 2-DV dune evolution model is thought to be representative.

Allen (1968b) illustrated flow patterns over 3-D dunes revealing complex flow separation zone dynamics due to generated vorticity and convergence and divergence of flow. Recent studies by Maddux et al. (2003a,b) and Venditti (2007) showed that the flow field over simple regular 3-D dunes is significantly different from that over their 2-D counterparts. Secondary currents and flow convergence and divergence over the 3 -D shapes significantly influence the separation zone dynamics, and thus flow resistance. Since our dune evolution model is 2-DV, these complex 3-D effects could not be captured.

To give a complete description of natural irregular 3-D dune fields, the 2-DV dune evolution model could be extended with a lateral component to a $3-\mathrm{D}$ morphodynamic model, such as the model of Hulscher (1996). This approach increases the required computational effort, but allows to investigate how the dunes and the shape of the separation zone depend on 2-DH dune-structures, e.g. by following streamlines and allowing for convergence and divergence of the parameterized separation zone. Moreover, it may give insight in the role of the roughness correction factor, since this factor relates to the presence of dunes distributed non-uniformly over the main channel width. Another possibility to include a lateral component could be to use an approach similar to Hersen (2004) or Jerolmack \& Mohrig (2005) where 1-D computational slices are coupled using horizontal diffusion processes for the sediment. However, such a 'diffusion' approach strongly affects required computational effort and diffusion parameters are difficult to estimate correctly.

\subsubsection{Non-uniform sediment dynamics}

Grain-size sorting within bedforms influences dune formation and the grains present on the surface of dunes (e.g. Miwa et al., 2001; Blom et al., 2003; Kleinhans, 2004). Miwa et al. (2001) argues that the presence of relatively coarse sediment restrains the development and growth of bedforms, while fine sedi-

\footnotetext{
${ }^{2}$ generally, 3-D bed features are observed for width to depth ratios larger than 3 (Crickmore, 1970; Williams, 1970)
} 
ment promotes bedform growth and collapse of bedforms. Effectively, this may lead to more irregular bedform patterns than considering uniform sediment.

In the dune evolution model, the sediment transport rate is based on the median grain diameter, i.e. the $D_{50}$ of the sediment, and the bed material is assumed to be uniform. In chapter 3 it was shown that a different grain size does not influence equilibrium dune dimensions (Fig. 3.14), although it does influence time scales to equilibrium. Roos et al. (2007) have shown that a simulation model for offshore sand waves, taking multiple sediment fractions into account, resulted in coarser material at the bedform crests; however, it did not yield different sand wave dimensions.

A complication that may arise from the presence of non-uniform sediment is the formation of armour layers on the river bed. Carling et al. (2000a,b) observed barchan-shaped supply-limited bedforms, which are migrating over an armour layer. Sediment (transport) dynamics can change significantly due to the formation and destruction of armour layers (Blom et al., 2003) and due to sorting processes within bedforms (Blom et al., 2003; Kleinhans, 2004; Kleinhans et al., 2007). If an armour layer is broken up, more fine sediment becomes available that can contribute to dune evolution. A related issue is the transport of sediment as suspended load which is more likely for the finer sediment. Relatively high concentrations of suspended load are sometimes related to dunes planing-out (Sec. 1.3.1), the presence of low-angle dunes (Best, 2005) or the stabilization of anti-dunes (Colombini, 2004). It might also change the shape of dunes, as pointed out by Tjerry \& Fredsøe (2005). At present, non-uniform grain-size dynamics are not taken into account in the dune evolution model. The effects could be explored by taking multiple sediment fractions into account (e.g. Roos et al., 2007).

\subsubsection{Bedforms at different scales}

Observations show that dune fields are characterized by bedforms of different spatial scales (e.g. Julien et al., 2002; Wilbers \& Ten Brinke, 2003; Jerolmack $\&$ Mohrig, 2005). During unsteady flow events in the river Rhine it is observed that during the falling stage of a flood wave, secondary dunes form on the primary dunes, because the primary dunes cannot instantaneously adapt to the changing flow conditions (Wilbers \& Ten Brinke, 2003). According to Wilbers (2004) it is important to distinguish between primary and secondary dunes for roughness predictions. Additionally, Fernandez et al. (2006) showed that the effects of amalgating dunes of different scales on turbulence structures in the flow field, also influence the total flow resistance caused by dunes.

This behaviour cannot be captured by the dynamic roughness model, since there is no mechanism present that allows for the formation of these secondary dunes (see also Sec. 5.2.4). However, knowledge on the exact influence of secondary dunes on flow resistance is still limited (Best, 2005). Numerical simulations of the turbulent flow over trains of irregular bedforms could give insight into the controlling dune dimensions on the total flow resistance. In the dynamic roughness model, during the falling stage of a flood wave, the water depth and 
dune length decrease. In reality this reduction in dune length manifests via the formation of secondary dunes, while in the dune evolution model the domain length is shortened, also leading to shorter (and lower) dunes.

\subsubsection{Dune initiation from flat bed and dune splitting}

Figure 5.1 presents observed bed profiles from a flume experiment, showing the evolution of dunes from an initially flattened bed under steady flow (see Friedrich et al., 2007 for details of the experiment). Initially, small dunes develop on the bed with a typical preferred spacing (Coleman \& Melville, 1996) and there is evolution towards a dynamic equilibrium where the average dune height and length remain approximately constant, with continuous splitting and merging of dunes at different scales.

The dune evolution model predicts a different initial behaviour for dunes developing from flat bed, if the initial bed topography consists of a spectrum of disturbances (Fig. 5.2c). This is due to reasons explained in Section 3.5.3. Small dunes are stable due to bed-slope effects in the sediment transport equation. The most unstable mode (i.e. dune length) has the largest growth rate and becomes visible after $\sim 10$ minutes of evolution (Fig. $5.2 \mathrm{c}$ ). Dunes of different heights and lengths have different migration velocities, and smaller fast migrating dunes generally catch-up larger slower migrating dunes. This behaviour is also observed in our simulations (Fig. 5.2a-b), yielding dunes to get longer. Model simulations in Chapter 3 (i.e. Fig. 3.13) have shown that the equilibrium dune height is linked to dune length. Therefore, if dunes continue to merge until one dune exists in the computational domain, the dune height becomes related to the length of the domain, which has questionable physical relevance.

The dune evolution model does not allow for dune splitting and gaining crests in the domain. In the dune evolution model, all sediment passing the flow separation point avalanches down the leeface. One could imagine that sediment can also pass the flow separation zone and deposits downstream of the flow separation zone, creating heaps of sediment that could develop into superimposed bedforms. Including this effect would require an adaptation of the parameterized bed shear stress distribution over the stoss-side of a dune in case of flow separation (because this 'smooth' distribution does not allow for disturbances to grow once they form).

In the simulations presented in Chapter 3, the problem lined out above does not play a role, since only one dune exists in the computational domain. The dune length is estimated as the fastest growing wave length from a numerical linear analysis (Sec. 5.1.1). Then, initially the dunes are longer than observed in the experiments, yielding a migration rate which stays constant during the initial stage of dune evolution. However, in equilibrium the dunes attain the correct dune height and also the migration rate is predicted correctly (Fig. 3.10). Therefore, it is considered that this initial phase of dune evolution is not crucial for modelling dune evolution in rivers. Moreover, in the field the bed may hardly be flat due to the presence of relict bedforms.

Adaptations to the turbulence closure model, and incorporating turbulent 


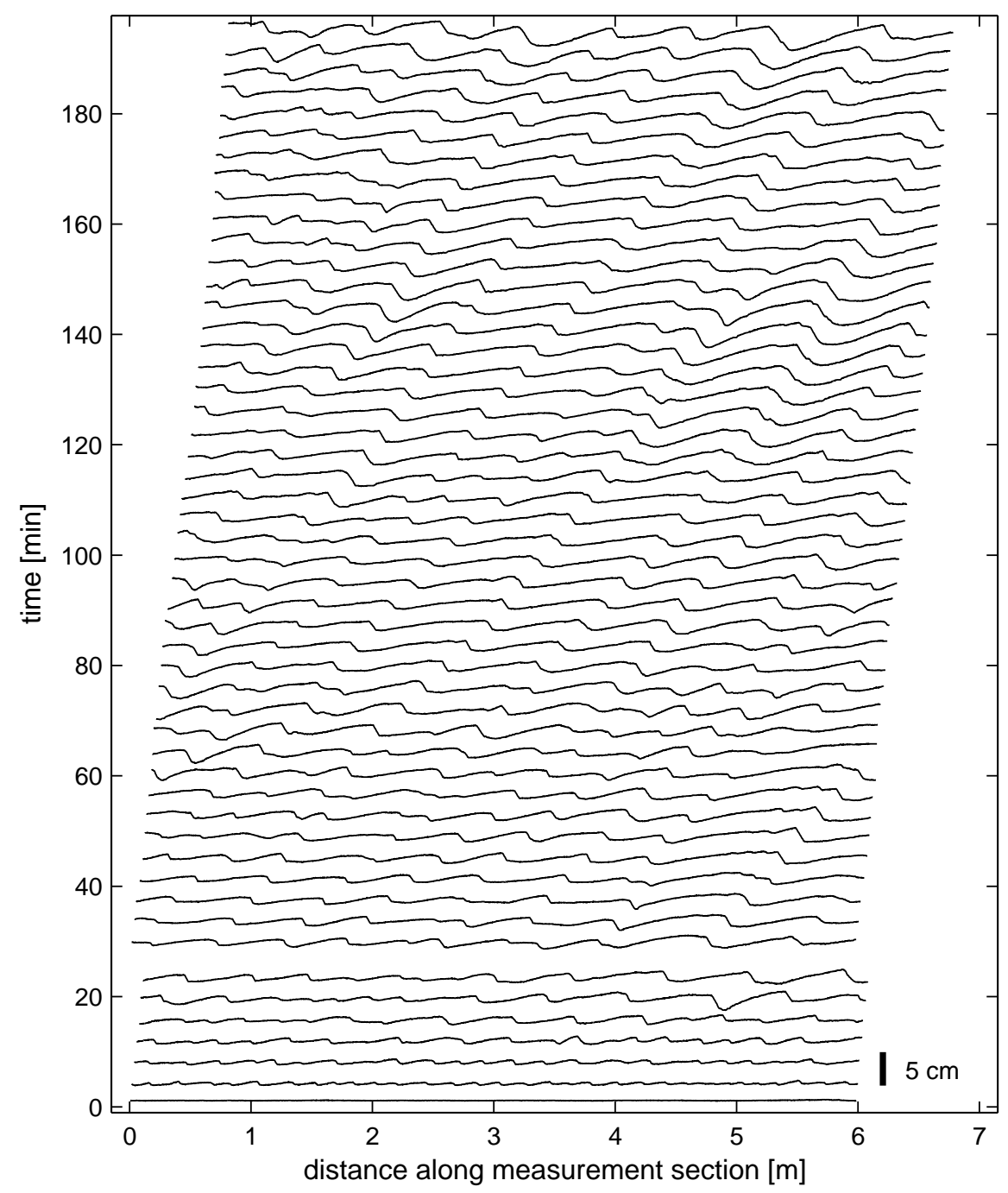

Figure 5.1: Dunes formed in a laboratory channel at the University of Auckland (experiment T23, Friedrich et al., 2007). The vertical scale is indicated by a vertical bar on the bottom right. Each line represents a bed profile with a time interval of 4 minutes. 

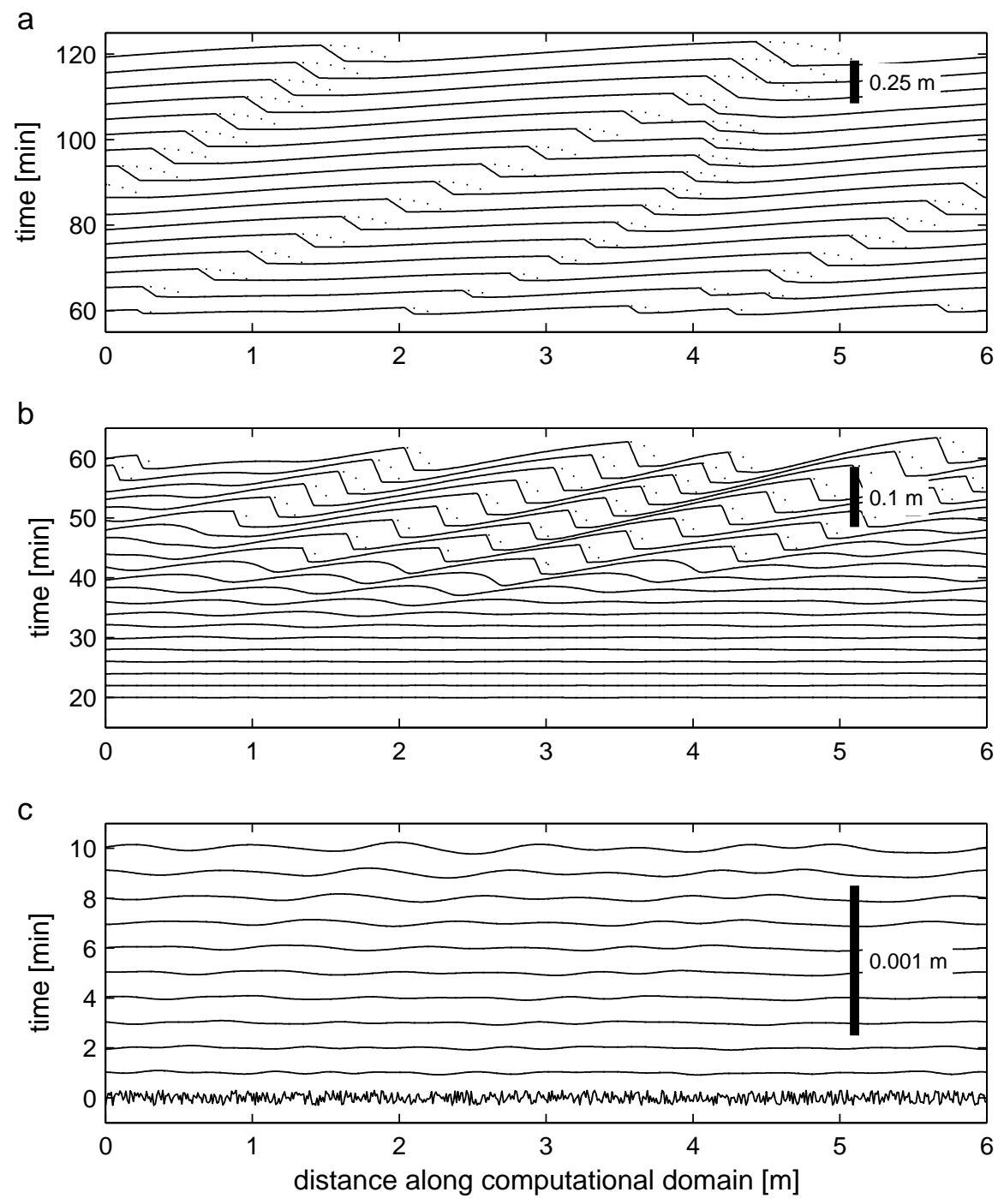

Figure 5.2: Simulation with the dune evolution model for the same conditions as in the experiment shown in Figure 5.1 on the facing page. (a) close to 'equilibrium'; (b) merging dunes with dashed lines indicating flow separation zones; (c) initial phase of dune evolution with a spectrum of disturbances as initial condition. Time reads from bottom to top. 
fluctuations on the bed shear stress into the sediment transport model (e.g. Giri \& Shimizu, 2006), could also yield bedform evolution with continuous splitting and merging of bedforms at different scales. However, this involves unacceptable additional computational effort, limiting application possibilities to flood waves. Another, perhaps simpler, option is to use the approach of DohmenJanssen et al. (2008) who argue that relatively long dunes with almost flat stoss-sides act as a flat bed where small dunes can initiate due to the regrowing internal boundary layer. Dohmen-Janssen et al. (2008) implemented this effect by artificially splitting a stoss-side that exceeds a certain critical length.

\subsection{Model application to natural river systems and other water systems}

\subsubsection{Deltaic low-land rivers with natural configurations}

The dynamic roughness model developed in this thesis is coupled with the hydraulic simulation model SoBEK that includes the effects of e.g. floodplains, groynes and variable streamwise cross-sectional shapes. This allows to represent natural river configuration with the model, since realistic parameters of the main channel can be used to determine dune evolution. In turn, dune evolution in the main channel influences the flow over the entire cross-section since the roughness coefficient of the main channel changes.

In Appendix A of chapter 3 it was shown that it is allowed to introduce some simplifications into the flow equations for small (squared) Froude numbers, limiting the required computational effort (as is done in this thesis). A quasisteady approach decoupling the flow and sediment transport and a rigid lid approximation at the free water surface are valid. Froude numbers in deltaic low-land rivers, such as the river Rhine are generally low, i.e. 0.1-0.35 (Van Vuren et al., 2005). Therefore, the model is applicable to mildly sloping low-land rivers such as the river Rhine or the Mississippi river. For flume experiments generally (squared) Froude numbers are $\leq 0.5$; this means that application of the dune evolution model to flume conditions should be done with care. The model is not applicable to predict the formation of anti-dunes, since these are associated with Froude number close to or exceeding 1.

At high discharge and flow strength, suspended sediment transport might become relevant. However, Engelund (1970) showed that suspended sediment transport is especially important in supercritical flow regimes with Froude numbers close to or exceeding 1 . In mildly sloping rivers the total suspended load is generally much less than the bed load and the suspended load that is transported does nearly contribute to the dune evolution process. Therefore, it is believed that suspended load is not crucial to model river dune formation and migration, in rivers with relatively low Froude numbers.

\subsubsection{Low flows}

The Dutch river Rhine branches are part of an important shipping route between the North Sea and Germany, which may suffer from local shallows due to the 
presence of river dunes at low flows. The model presented in this thesis includes a critical bed shear stress which is important for model application to such low flows. The critical bed shear stress depends on the size of the sediment. According to Equation (3.12) (thus neglecting bed-slope effects), the critical bed shear stress varies linearly between between 0.8 and $3.8 \mathrm{~N} \mathrm{~m}^{-2}$ if the median grain size varies between 1 and $5 \mathrm{~mm}$. In case of low flows, the bed shear stress for a typical river Waal situation (i.e. steady flow with a flow depth of $5 \mathrm{~m}$ with channel slope $0.76 \times 10^{-4}$ results in a bed shear stress of $\sim 3.7 \mathrm{~N} \mathrm{~m}^{-2}$ ) which is of the same order as the critical bed shear stress. Thus, also at low flows, the bed shear stress can exceed the critical bed shear stress leading to dune formation, depending on the grain size of the considered river reach. Note that for rivers with weirs (such as the rivers Nederrijn or Meuse) this might be different because the presence of weirs reduces the water surface slope and thus bed shear stress at low flows.

Another issue is that dunes slowly diminish in height when the water level drops at the falling stage of a flood wave (Chapter 4). This is important information for shipping activities since at low discharge, flow energy is relatively low and the dunes may exist on the bed for quite some time. The bed shear stress might even fall below the critical bed shear stress, meaning that the dunes do not decrease in amplitude at all, at low flows. These dunes might not be expected for the specific flow conditions if one applies a steady flow equilibrium dune predictor or stability diagram. Moreover, dunes are not taken into account in currently applied hydraulic model calibrations (because hydraulic models are calibrated on water levels and discharge distributions). This means that for a specific situation such a predictor might indicate that no dunes are present, while relict dunes from a past flood wave are present. Application of the extended SOBEK model as presented in this thesis does not only predict water levels, but also dune dimensions at the end of a flood wave.

\subsubsection{Offshore and estuarine systems}

The flow model used in this thesis is based on a simulation model to predict offshore sand wave dynamics, which was successfully applied to various sand wave areas (Németh et al., 2007; Van den Berg, 2007; Van der Meer et al., 2007). In a sand wave area in the Gulf of Cadiz (Spain) predominant unidirectional currents are observed, accompanied by asymmetric sand waves possibly associated with flow separation (Németh et al., 2007). The original flow model could not be applied there, since flow separation is not captured by that model. The dune evolution model of this thesis could be used for this purpose, although very little information on flow separation dynamics for offshore sand waves is known.

Also in estuarine systems, dune-like features are observed (e.g. Kostaschuk, 2000; Kostaschuk \& Best, 2004; Francken et al., 2004). Estuarine dunes are often quite symmetrically shaped, due to the oscillatory tidal flow in estuarine environments. However, the degree of symmetry depends on the relative flow strength in each direction. If one of the directions is dominant, then the estuarine dunes might develop an angle-of-repose leeside like dunes in a uni- 
directional flow. In such cases, the dune evolution model of this thesis can be used to include flow separation in the lee of the dune. However, a problem occurs if the flow reverses, and the estuarine dune still has an angle-of-repose leeside, that becomes exposed to the flow. To apply the model in this case, we need a description of the roughness of this leeside that blocks the flow and some model for the morphological adaptation of the leeside.

\subsubsection{Opportunities to improve hydraulic simulation models}

The dynamic roughness model presented in this thesis offers various application possibilities for operational water management purposes. Interviews with model experts in the Netherlands (Paarlberg, 2007) have indicated that processes/parameters related to flow resistance, i.e. vegetation and dune dimensions, have large uncertainties and significantly influence water levels predictions.

This research improved the insight into the behaviour of the main channel roughness during floods. Dune dynamics and associated hysteresis effects can be excluded from calibrated roughness coefficients, by using the dynamic roughness model of this thesis. A starting point for future model calibrations should be to use the dynamic model presented in this thesis to predict the main channel roughness, and calibrate the term $k_{\text {uncertain }}$ in Equation (4.4) or other model parameters to take model uncertainties into account. Preferably, simultaneous dune and water levels measurements should be available for this calibration. In this way, hydraulic models depend less on the shape of a flood wave and differences between the rising and falling stages of a flood wave, at least for the part that is caused by the hysteresis in dune evolution. Interviews with water managers and model experts in the Netherlands, have indicated that this would be an important improvement for hydraulic simulation models (Paarlberg, 2007).

Empirical models or hydraulic models with calibrated roughness coefficients are limited in application to the conditions for which they are calibrated. Although some calibration was required for the dune evolution model, these calibrations are based on physical arguments (i.e. the calibration coefficients for the eddy viscosity and bed resistance parameter and the roughness correction factor). Under the assumption that the physical processes involved in dune formation do not change under extreme conditions, the dynamic roughness model can be applied to higher discharges than measured so far, or even to design discharges conditions.

In nature, flood waves often come in series, meaning that relict dunes might still be present if the discharge increases again at the start of a new flood wave. Because the models presented in this thesis require minimal computational effort, a series of flood waves of various shape can be simulated to investigate the role of this history effect. 


\section{Chapter 6}

\section{Conclusions and recommendations}

The objective of this thesis was:

To develop a process-based simulation model of dynamic roughness due to river dune evolution, which is applicable at a river-reach spatial scale and flood wave time scale, and that requires limited computational time.

In this concluding chapter, first the research questions that were formulated to fulfill this objective, are answered. After that, we reflect on the objective and suggestions for future research are given.

\subsection{Answers to the research questions}

Q1: How can we represent flow separation over subaqueous river dunes, such that it can be included in a morphodynamic simulation model of river dune evolution?

The analysis of experimental data of turbulent flow over straight-crested 2-D dunes and backward facing steps in Chapter 2 has shown that the separation streamline, which forms the upper boundary of the flow separation zone, can be approximated by a third-order polynomial. The length of the flow separation zone is generally independent of flow conditions. However, we found this length to be related to the bedform height and the bed slope at the flow separation point. If the bedform shape is known, the four coefficients of the third-order polynomial can be determined based on 1) the bedform shape at the flow separation point, and 2) a fixed angle of the separation streamline at the flow reattachment point.

The parameterization captures the shape of the separation streamline quite well (the mean deviation between the parameterized and the measured separation streamline is $2 \%$ ) for dunes with various heights and various height to length ratios and for a wide range of flow conditions. The proposed parameterization of the separation streamline is based upon bedform properties. Thus, at each computational time step in the dune evolution model (Chapter 3), the shape of the flow separation zone can be determined. 
Q2: To what extent is it possible to simulate the time-evolution of river dunes realistically with an idealized mathematical morphodynamic model by using this representation of flow separation?

Chapter 3 presents a new river dune evolution model, by extending a processbased morphodynamic model with the parameterization of flow separation. In the dune evolution model, flow separation is taken into account without increasing the required computational effort by using the parameterized separation streamline as virtual bed in the region of flow separation. This allows for the flow field to be considered hydrostatic over the full computational domain and avoids modelling the complex flow in the flow separation zone. Inside the flow separation zone, sediment that passes the dune crest is assumed to avalanche down the slip face.

Dunes evolving from a flat bed in steady flows quickly attain a certain dune length. In the dune evolution model, we find this length as fastest growing wave length from a linear stability analysis at the start of a simulation. The existence of a fastest growing wave length is due to two essential processes in the model: 1) transport of sediment from troughs to crests due to the typical 2-DV flow field structure, and 2) gravitational bed-slope effects causing sediment to move more difficult up-slope than down-slope counteracting the first process. The 2-DV flow field is treated as hydrostatic by relating the depth-averaged eddy viscosity and a bed resistance parameter to physical quantities (i.e. shear velocity and average flow depth). We find the fastest growing wave length $\left(\lambda_{\mathrm{fgm}}\right)$ to scale with the average water depth of the main channel $\left(h_{\mathrm{m}}\right)$ as $\lambda_{\mathrm{fgm}} \simeq 7 h_{\mathrm{m}}$, which is well in range with values from literature.

Model results show that the dune length and dune height in equilibrium compare reasonably well to various data sets from flume experiments, with most model results within the $25 \%$ accuracy band. This shows that the dune length found from a linear analysis is a reasonable estimate for the dune length in equilibrium and that this length is probably not influenced by the occurrence of flow separation. In equilibrium, the dune aspect ratio is predicted more or less constant at $\sim 0.045$, implying that dune height and dune length are linked. The model predicts two other important characteristics of dunes also reasonably well, namely their migration rate and the time it takes for dunes to evolve to equilibrium configurations.

Q3: To what extent is flow separation crucial for modelling river dune evolution and time scales involved?

During their evolution, initial small-amplitude dunes with the dune length found from a linear stability analysis, grow in amplitude and get asymmetrically shaped with steeper leesides. We found the process of flow separation as key element to model realistic finite-amplitude dune shapes. Without employing the parameterization of flow separation, dune leesides do not obtain a slope at the angle of repose. Instead, a maximum leeside slope of $\sim-18^{\circ}$ is obtained, causing the dunes to reach an equilibrium amplitude in a too early stage of dune 
evolution.

In the dune evolution model, it is assumed that flow separation sets in when the leeside obtains a slope of $-10^{\circ}$. By assuming that the sediment that passes the dune crest avalanches down the leeface at the angle of repose, realistic dune shapes are obtained with the model with steep angle-of-repose leeside and more gentle stoss sides. Moreover, dunes grow in amplitude after flow separation sets in and an equilibrium dune amplitude is obtained. The local bed slope at the dune crest plays a crucial role in the saturation to an equilibrium dune height, since it determines the shape of the separation streamline and the bed shear stress and sediment flux distributions over a dune.

Q4: How can we extend a hydraulic simulation model with the dune evolution model to predict dynamic roughness due to developing dunes in rivers?

To incorporate dynamic roughness due to dune evolution in the 1-D hydraulic model SoBEK, we developed a dynamic roughness model. This dynamic roughness model consists of the new river dune evolution model and the empirical form drag relationship of Van Rijn (1984). This dynamic roughness model is used to adapt the main channel roughness coefficient of SOBEK during a simulation. The dune evolution model uses the average flow depth computed with SoBEK, the channel slope and the grain size as inputs. Computed dune dimensions are translated into a Nikuradse roughness height using the empirical relationship of Van Rijn (1984). If the computed roughness coefficient changes by more than $10 \%$, SoBEK determines updated water levels, yielding new input data for the dune evolution model. The dune evolution model predicts maximum, rather than average dimensions, and dune shapes in the field are different from those used to calibrate the relationship of Van Rijn. Therefore, a roughness correction factor is required to obtain realistic roughness estimates (see also section 4.2.3).

The dynamic roughness model is computationally efficient, since it runs with only one dune in the domain. Typically, two identical subsequent flood waves (e.g. Fig. 4.5 a with a total duration of 80 days), take about 8 hours to compute on a standard office PC. The dune length can vary during a simulation, based on a numerical linear stability analysis. Due to the coupling between the 1-D hydraulic model, in which arbitrary cross sections can be used, and the 2-DV dune evolution model, water levels in natural river settings can be simulated with the extended SoBEK model. Importantly, the dynamic roughness model is linked to SoBEK without changing the SoBEK code, making it easy to apply the model also in other hydraulic models.

Q5: What is the effect of river dune evolution, and particularly the hysteresis effect in dune height, on water levels during flood waves?

The extended SoBEK model is applied to two flood waves of different shape, in an idealized SOBEK model of the river Waal in the Netherlands (one of the Dutch branches of the river Rhine, Fig. 1.2b). The two tested flood wave shapes (i.e. sharp-peaked and broad-peaked) extend over a time period of 30 days, with 
a maximum discharge in the river Waal of $6,000 \mathrm{~m}^{3} \mathrm{~s}^{-1}$. The dune length is either constant, or varies based on a linear stability analysis for the prevailing flow conditions (i.e. no hysteresis effect occurs for dune length).

Model results show a clear hysteresis effect in dune height, with dunes still growing in height when the discharge already falls after the peak discharge. The time-lag is several days on a flood wave period of 30 days for constant dune length, which is comparable to measurements in the river Rhine. Predicted dune aspect ratios are well within range of other research and dunes appear to develop a more or less constant aspect ratio (i.e. $~ 0.055$ ), which causes the dune height to become approximately constant if the dune length is constant. Generally, a variable dune length yields higher dunes and a dune aspect ratio that varies between $\sim 0.045$ at low discharge and $\sim 0.07$ at peak discharge for the sharp-peaked flood wave. For variable dune length the time-lag is about 10 days and thus relatively long. This is because the dunes are larger and more sediment has to be transported before the dunes diminish significantly in height. The hysteresis in dune height for the broad-peaked flood wave is larger than for the sharp-peaked flood wave, because the relatively long period of high river discharge gives the dunes ample time to increase in height.

The effects of dune evolution and hysteresis in dune height on flow depths are assessed by comparing flow depths between a model in which the main channel roughness coefficients 1) are calibrated as a function of the discharge, and 2) are determined using the dynamic roughness model. Differences are largest at low discharge, if most water is conveyed through the main channel, and lowest at peak discharge. This is attributed to the aspects that $(i)$ in practice hydraulic models are mainly calibrated on peak discharges, and (ii) the relative influence of the main channel roughness decreases at higher water levels. Varying the roughness correction factor $\gamma$ by $50 \%$ shows significant effects on the results. Although dune characteristics are marginally influenced, the overall Chézy coefficients can reduce by more than $10 \%$ (averaged over a flood wave).

The hysteresis in dune height clearly results in a hysteresis in flow resistance (and thus flow depths) as well with lower Chézy coefficients (i.e. higher roughness) and larger flow depths during the falling stage of the flood wave than during the rising stage. Furthermore, model results show that effects of dune evolution on flow depths are most pronounced if the dune length varies during a simulation and for a broad-peaked flood wave. This emphasizes the importance of the shape of a flood wave for dune evolution and thus roughness predictions. This aspect is not taken into account if roughness coefficients are calibrated as a function of discharge, as is done in current practice.

\section{Reflection on research objective}

We have developed a process-based dynamic roughness model, which can be applied at a river-reach spatial scale and to flood wave time scales. Dune dynamics and associated hysteresis effects can be included in hydraulic simulation models by using the dynamic roughness model of this thesis. In this way, the simulation models become less dependent on the flood wave shape. 


\subsection{Recommendations}

Extending the dune evolution model in lateral direction gives a 3-D simulation model which is more representative for field conditions. It would allow for more complex separation zone dynamics and for complex dune shapes. This could not only lead to a more realistic representation of dune fields, but also to more realistic predictions of dune roughness (possibly avoiding the necessity of using a roughness correction factor). Possible approaches to include the lateral flow component would be to follow Hulscher (1996), or to use the approach of Hersen (2004) or Jerolmack \& Mohrig (2005) by coupling several longitudinal 'dune slices' with a horizontal sediment diffusion process.

Also non-uniform sediment dynamics are important to consider as possible model improvement. The presence of non-uniform sediment, which is often the case in the field, can lead to the formation of armour layers preventing part of the sediment to be transported (e.g. Blom et al., 2003; Kleinhans et al., 2007). If these layers are broken up, a lot of fine material can become exposed to the flow. This sediment can either promote dune formation via bed load transport, or suspended sediment transport can gain in importance, possibly leading to planing-out of dunes. The influence of non-uniform sediment can be explored by taking multiple sediment fractions into account as done by Roos et al. (2007). Suspended sediment transport dynamics can be included by using a suspended sediment transport model as used by Van der Meer et al. (2007) in a sand wave model that also employs a constant eddy viscosity over the water depth.

The parameterization of flow separation is an important part of the dune evolution model. The separation streamline was determined from experiments with dunes of simple shapes. Since in nature, dune fields often have more complex shapes, it should be investigated how the flow separation zone shape changes for such complex dune shapes. To this end, flume experiments could be used (e.g. Maddux et al., 2003a,b; Venditti, 2007), or numerical studies can be used since this allows for more complex shapes and variations of topography.

In section 5.2.4 it was argued that if simulations start with a random initial bed disturbance, incorrect finite dune dimensions are obtained. DohmenJanssen et al. (2008) presented a promising approach to include dune splitting in the dune evolution model as presented in this thesis, which should be investigated further. The experiments performed at the University of Auckland (see Friedrich et al., 2007 and Dohmen-Janssen et al., 2008) offer possibilities to study the processes responsible for dune splitting, since the measurements were done with a very high resolution. Additional flume experiments should focus on unsteady flows, if possible with real flood waves (i.e. gradually varying steps in discharge); this allows to test the dynamic roughness model, using simultaneous measurements of bedforms and water levels. This might increase the insight into the role of the correction coefficient for roughness predictions.

The dune evolution and dynamic roughness models should be calibrated more extensively for field conditions. This requires simultaneous measurements of dunes and water levels during floods. Also sediment transport measurements could be useful, since this might give insight in the role of suspended sediment 
transport and the aspect that a part of the bed load transport might pass the separation point, effectively not contributing to dune formation. 


\section{Bibliography}

Allen, J. R. L. (1968a). The nature and origin of bed form hierarchies. Sedimentology, 10, pp. 161-182.

Allen, J. R. L. (1968b). Current ripples: their relation to patterns of water and sediment motion. North Holland Publishing Company, Amsterdam, the Netherlands.

Allen, J. R. L. (1976). Computational models for dune time-lag: general ideas, difficulties and early results. Sedimentary Geology, 15, pp. 1-53.

Anderson, A. G. (1953). The characteristics of sediment waves formed by flow in open channels. In: Proceedings of the Third Midwestern Conference of fluid mechanics, pp. 379-395.

Anderson, R. S. (1990). Eolian ripples as examples of self-organization in geomorphological systems. Earth-Science Reviews, 29, pp. 77-96.

ASCE Task Force on Friction Factors in Open Channels (1963). Friction factors in open channels. Journal of Hydraulic Engineering, 89 (HY2), pp. 97-143.

Ashworth, P. J., J. L. Best, J. E. Roden, C. S. Bristow, and G. J. Klaassen (2000). Morphological evolution and dynamics of a large, sand braid-bar, Jamuna River, Bangladesh. Sedimentology, 47, pp. 533-555.

Azad, R. S. (1996). Turbulent flow in a conical diffuser: A review. Experimental Thermal and Fluid Science, 13, pp. 318-337.

Bennett, S. J. and J. L. Best (1995). Mean flow and turbulence structure over fixed, two-dimensional dunes: implications for sediment transport and bedform stability. Sedimentology, 42 (3), pp. 491-513.

Bennett, S. J., J. S. Bridge, and J. L. Best (1998). Fluid and sediment dynamics of upper stage plane beds. Journal of Geophysical Research, 103 (C1), pp. $1239-1274$.

Besio, G., P. Blondeaux, M. Brocchini, and G. Vittori (2004). On the modeling of sand wave migration. Journal of Geophysical Research, 109 (C04018), pp. 1-13, doi:10.1029/2002JC001622.

Besio, G., P. Blondeaux, and G. Vittori (2006). On the formation of sand waves and sand banks. Journal of Fluid Mechanics, 557 (C04018), pp. 1-27, doi:10.1017/S0022112006009256. 
Best, J. (2005). The fluid dynamics of river dunes: A review and some future research directions. Journal of Geophysical Research, 110 (F04S01), doi:10.1029/2004JF000218.

Best, J. and R. Kostaschuk (2002). An experimental study of turbulent flow over a low-angle dune. Journal of Geophysical Research, 107 (C9, 3135), pp. 1118-1129, doi:10.1029/2000JC000294.

Bezuyen, M. J., M. J. van Duin, and U. Rosenthal (1995). Watersnood 1995. Blad bestuurskunde, Jaargang 4, nummer 8, pp. 353-360 (in Dutch, www.bestuurskunde.nl/publicaties/).

Blom, A., J. S. Ribberink, and H. J. de Vriend (2003). Vertical sorting in bed forms: Flume experiments with a natural and a trimodal sediment mixture. Water Resources Research, 39 (2), doi:10.1029/2001WR001088.

Buckles, J., T. J. Hanratty, and R. J. Adrian (1984). Turbulent flow over largeamplitude wavy surfaces. Journal of Fluid Mechanics, 140, pp. 27-44.

Carling, P. A., E. Gölz, H. G. Orr, and A. Radecki-Pawlik (2000a). The morphodynamics of fluvial sand dunes in the River Rhine, near Mainz, Germany. I. Sedimentology and morphology. Sedimentology, 47, pp. 227-252, doi:10.1046/j.1365-3091.2000.00290.x.

Carling, P. A., J. J. Williams, E. Gölz, and A. D. Kelsey (2000b). The morphodynamics of fluvial sand dunes in the River Rhine, near Mainz, Germany. II. Hydrodynamics and sediment transport. Sedimentology, 47, pp. 253-278, doi:10.1046/j.1365-3091.2000.00291.x.

Casas, A., G. Benito, V. R. Thorndycraft, and M. Rico (2006). The topographic data source of digital terrain models as a key element in the accuracy of hydraulic flood modelling. Earth Surf. Process. Landforms, 31, pp. 444-456, doi:10.1002/esp.1278.

Chang, P. K. (1970). Separation of flow. Pergamon Press, Oxford.

Charru, F. (2006). Selection of the ripple length on a granular bed sheared by a liquid flow. Physics of Fluids, 18 (121508), pp. 1-9, doi:10.1063/1.2397005.

Coleman, S. E. (1991). The mechanics of alluvial stream bed forms. PhD thesis, University of Auckland, Auckland, New Zealand.

Coleman, S. E. and B. W. Melville (1996). Initiation of bed forms on a flat sand bed. Journal of Hydraulic Engineering, 122 (6), pp. 301-310.

Coleman, S. E., M. H. Zhang, and T. M. Clunie (2005). Sediment-wave development in subcritical water flow. Journal of Hydraulic Engineering, 131 (2), pp. 106-111, doi:10.1061/(ASCE)0733-9429(2005)131:2(106). 
Coleman, S. E., V. I. Nikora, S. R. McLean, T. M. Clunie, T. Schlicke, and B. W. Melville (2006). Equilibrium hydrodynamics concept for developing dunes. Physics of Fluids, 18 (105104), doi:10.1063/1.2358332.

Colombini, M. (2004). Revisiting the linear theory of sand dune formation. Journal of Fluid Mechanics, 502, pp. 1-16, doi:10.1017/S0022112003007201.

Crickmore, M. J. (1970). Effects of flume width on bed form characteristics. Journal of the Hydraulics Division, ASCE, 96 (HY2, paper 7077), pp. 473496.

De Vriend, H. J. (2006). Flood management research needs. In: J. Van Alphen, E. Van Beek, and M. Taal (Eds.), Floods, from Defence to Management, Third International Symposium on Flood Defence, pp. 49-61.

Dodd, N., P. Blondeaux, D. Calvete, H. E. de Swart, A. Falques, S. J. M. H. Hulscher, G. Rozynski, and G. Vittori (2003). Understanding coastal morphodynamics using stability methods. Journal of Coastal Research, 19 (4), pp. 849-865.

Dohmen-Janssen, C. M., J. Lansink, A. J. Paarlberg, S. J. M. H. Hulscher, and A. P. P. Termes (2008). Modelling river dune splitting. In: D. R. Parsons, T. Garlan, and J. L. Best (Eds.), Proc. of the $3^{\text {rd }}$ workshop on Marine Sandwave and River Dune Dynamics (MARID), 1-3 April 2008, Leeds, UK, pp. $79-86$.

Driegen, J. (1986). Flume experiments on dunes under steady flow conditions (uniform sand, $d_{\mathrm{m}}=0.77 \mathrm{~mm}$ ); description of bed forms. TOW rivers $\mathrm{R} 567$ - XXVII / M 1314 part XV, WL | Delft Hydraulics, Delft, the Netherlands.

Einstein, H. A. (1950). The bed-load function for sediment transportation in open channel flows. Technical Bulletin No. 1026, U.S. Department of Agriculture, Soil Conservation Service, Washington, DC.

Einstein, H. A. and N. L. Barbarossa (1952). River channel roughness. Transaction ASCE, 117, pp. 1121-1146.

Engel, P. (1981). Length of flow separation over dunes. Journal of the Hydraulics Division, ASCE, 107 (HY10), pp. 1133-1143.

Engelund, F. (1966). Hydraulic resistance of alluvial streams. Journal of the Hydraulics Division, ASCE, 92 (2), pp. 315-327.

Engelund, F. (1970). Instability of erodible beds. Journal of Fluid Mechanics, 42 (2), pp. 225-244.

Engelund, F. (1977). Hydraulic resistance for flow over dunes. Progress report 44, Institute for Hydrodynamic and Hydraulic Engineering, Tech. Univ. Denmark. 
Etheridge, D. W. and P. H. Kemp (1978). Measurements of turbulent flow downstream of a rearward-facing step. Journal of Fluid Mechanics, 86 (3), pp. 545-566.

Exner, F. M. (1920). Zur Physik der Dünen. Sitzungsbericht der Akademie der Wissenschaften in Wien, Abteilung IIa, Band 129 (in German).

Fernandez, R., J. Best, and F. López (2006). Mean flow, turbulence structure, and bed form superimposition across the ripple-dune transition. Water Resources Research, 42 (W05406), doi:10.1029/2005WR004330.

Fox, R. W., A. T. McDonald, and P. J. Pritchard (2003). Introduction to Fluid Mechanics. John Wiley \& Sons, 6 ed.

Francken, F., S. Wartel, R. Parker, and E. Taverniers (2004). Factors influencing subaqueous dunes in the Scheldt Estuary. Geo-Marine Letters, 24 (1), pp. 14-21, doi:10.1007/s00367-003-0154-x.

Fredsøe, J. (1974). On the development of dunes in erodible channels. Journal of Fluid Mechanics, 64 (1), pp. 1-16.

Fredsøe, J. (1979). Unsteady flow in straight alluvial streams: modification of individual dunes. Journal of Fluid Mechanics, 91, part 3, pp. 497-512.

Fredsøe, J. (1982). Shape and dimensions of stationairy dunes in rivers. Journal of the Hydraulics Division, Proceedings of the American Society of Civil Engineers, 108 (HY8), pp. 932-947.

Fredsøe, J. and R. Deigaard (1992). Mechanics of coastal sediment transport. Advanced Series on Ocean Engineering, Vol. 3, 368 pp. World Scientific, Singapore, ISBN: 9-8102-0840-5.

Friedrich, H., A. J. Paarlberg, and J. Lansink (2007). Evaluation of statistical properties of dune profiles. In: Dohmen-Janssen and Hulscher (Eds.), Proc. of the $5^{\text {th }}$ IAHR symposium on River, Coastal and Estuarine Morphodynamics, Enschede, the Netherlands, Vol. 2, pp. 913-921. Taylor \& Francis Group, London.

Gallagher, E. L. (2007). Computer simulations of megaripples in the nearshore. In: Dohmen-Janssen and Hulscher (Eds.), Proc. of the $5^{\text {th }}$ IAHR symposium on River, Coastal and Estuarine Morphodynamics, Enschede, the Netherlands, Vol. 2, pp. 1001-1006. Taylor \& Francis Group, London.

Giri, S. and Y. Shimizu (2006). Numerical computation of sand dune migration with free surface flow. Water Resources Research, 42 (W10422), doi:10.1029/2005WR004588.

Giri, S., S. Yamaguchi, Y. Shimizu, and J. Nelson (2007). Simulating temporal response of bedform characteristics to varying flows. In: Dohmen-Janssen and Hulscher (Eds.), Proc. of the $5^{\text {th }}$ IAHR symposium on River, Coastal 
and Estuarine Morphodynamics, Enschede, the Netherlands, Vol. 2, pp. 939947. Taylor \& Francis Group, London.

Giri, S., W. Van Vuren, Ottevanger, K. Sloff, and A. Sieben (2008). A preliminary analysis of bedform evolution in the Waal during 2002-2003 flood event using Delft3D. In: D. R. Parsons, T. Garlan, and J. L. Best (Eds.), Proc. of the $3^{\text {rd }}$ workshop on Marine Sandwave and River Dune Dynamics (MARID), 1-3 April 2008, Leeds, UK, pp. 141-148.

Haque, M. I. and K. Mahmood (1983). Analytical determination of form friction factor. Journal of Hydraulic Engineering, 109 (4), pp. 590-610.

Hersen, P. (2004). On the crescentic shape of barchan dunes. European Physical Journal B, 37, pp. 507-514.

Hulscher, S. J. M. H. (1996). Tidal-induced large-scale regular bed form patterns in a three-dimensional shallow water model. Journal of Geophysical Research, 101, pp. 20,727-20,744.

Hulscher, S. J. M. H. and C. M. Dohmen-Janssen (2005). Introduction to special section on Marine Sand Wave and River Dune Dynamics. Journal of Geophysical Research, 110 (F04S01), doi:10.1029/2005JF000404.

Hulscher, S. J. M. H. and G. M. Van Den Brink (2001). Comparison between predicted and observed sand waves and sand banks in the North Sea. Journal of Geophysical Research, 106 (C5), pp. 9,327-9,338.

Huthoff, F. (2007). Modeling hydraulic resistance of floodplain vegetation. PhD thesis, University of Twente, Enschede, the Netherlands.

Huthoff, F., D. C. M. Augustijn, and S. J. M. H. Hulscher (2007). Analytical solution of the depth-averaged flow velocity in case of submerged rigid cylindrical vegetation. Water Resources Research, 43 (W06413).

Jansen, P. P., L. van Bendegom, J. van den Berg, M. de Vries, and A. Zanen (1979). Principles of river engineering: the non-tidal alluvial river. Delfste Uitgevers Maatschappij, Delft, the Netherlands.

Jerolmack, D. J. and D. C. Mohrig (2005). A unified model for subaqueous bed form dynamics. Water Resources Research, 41 (W12421), doi:10.1029/2005WR004329.

Ji, Z.-G. and C. Mendoza (1997). Weakly nonlinear stability analysis for dune formation. Journal of Hydraulic Engineering, 123 (11), pp. 979-985.

Julien, P. Y. and G. J. Klaassen (1995). Sand-dune geometry of large rivers during floods. Journal of Hydraulic Engineering, 121 (9), pp. 657-663.

Julien, P. Y., G. J. Klaassen, W. B. M. Ten Brinke, and A. W. E. Wilbers (2002). Case Study: Bed resistance of Rhine River during 1998 flood. Journal of Hydraulic Engineering, 128 (12), pp. 1042-1050. 
Karim, F. (1995). Bed configuration and hydraulic resistance in alluvial-channel flows. Journal of Hydraulic Engineering, 121 (1), pp. 15-25.

Karim, F. (1999). Bed-form geometry in sand-bed flows. Journal of Hydraulic Engineering, 125 (12), pp. 1253-1261.

Kennedy, J. F. (1963). The mechanics of dunes and antidunes in erodible-bed channels. Journal of Fluid Mechanics, 16, pp. 521-544.

Kennedy, J. F. (1969). The formation of sediment ripples, dunes and antidunes. Ann. Rev. Fluid Mech., 1, pp. 147-168.

Kleinhans, M. G. (2004). Sorting in grain flow at the lee side of dunes. EarthScience Reviews, 65, pp. 75-102, doi:10.1016/S0012-8252(03)00081-3.

Kleinhans, M. G., A. W. E. Wilbers, and W. B. M. Ten Brinke (2007). Opposite hysteresis of sand and gravel transport upstream and downstream of a bifurcation during a flood in the River Rhine, the Netherlands. Netherlands Journal of Geosciences - Geologie en Mijnbouw, 86 (3), pp. 273-285.

Knighton, D. (1998). Fluvial forms and processes. Arnold, London, England.

Kornman, B. A. (1995). The effect of changes in the lee shape of dunes on the flow field, turbulence and hydraulic roughness. Report on measurements R 95-1, University of Utrecht, Utrecht, the Netherlands.

Kostaschuk, R. (2000). A field study of turbulence and sediment dynamics over subaqueous dunes with flow separation. Sedimentology, 47, pp. 519-531, doi:10.1046/j.1365-3091.2000.00303.x.

Kostaschuk, R. and J. Best (2004). The response of sand dunes to variations in tidal flow and sediment transport: Fraser Estuary, Canada. In: S. J. M. H. Hulscher, T. Garlan, and D. Idier (Eds.), Proc. of the $2^{\text {nd }}$ international workshop on Marine Sandwave and River Dune Dynamics, 1-2 April, 2004, pp. 849-863, University of Twente and SHOM, Enschede, the Netherlands.

Kostaschuk, R. and P. Villard (1996). Flow and sediment transport over large subaqueous dunes: Fraser River, Canada. Sedimentology, 43, pp. 849-863.

Kroy, K., G. Sauermann, and H. J. Herrmann (2002). Minimal model for aeolian sand dunes. Physical Review E, 66 (3), doi:10.1103/PhysRevE.66.031302.

Leliavsky, S. (1955). An Introduction to fluvial hydraulics. Constable, London.

Maas, L. R. M. and J. J. M. Van Haren (1987). Observations on the vertical structure of tidal and internal currents in the central North Sea. Journal of Marine Research, 45, pp. 293-318.

Maddux, T. B., J. M. Nelson, and S. R. McLean (2003a). Turbulent flow over three-dimensional dunes: 1. Free surface and flow response. Journal of Geophysical Research, 108 (F1, 6009), doi:10.1029/2003JF000017. 
Maddux, T. B., J. M. Nelson, and S. R. McLean (2003b). Turbulent flow over three-dimensional dunes: 2. Fluid and bed stresses. Journal of Geophysical Research, 108 (F1, 6010), doi:10.1029/2003JF000018.

McLean, S. R., J. M. Nelson, and S. R. Wolfe (1994). Turbulence structure over two-dimensional bed forms: Implications for sediment transport. Journal of Geophysical Research, 99 (C6), pp. 12,729-12,747.

McLean, S. R., S. R. Wolfe, and J. M. Nelson (1999). Spatially averaged flow over a wavy boundary revisited. Journal of Geophysical Research, 104 (C7), pp. $15,743-15,753$.

Meyer-Peter, E. and R. Müller (1948). Formulas for bed-load transport. In: Proceedings of the $2^{\text {nd }}$ IAHR congress, Vol. 2, pp. 39-64, Stockholm, Sweden.

Ministerie van Verkeer en Waterstaat (2007). Hydraulische Randvoorwaarden 2006: voor het toetsen van primaire waterkeringen (in Ducth). Ministerie van Verkeer en Waterstaat, Directoraat-Generaal Water, Den-Haag, the Netherlands. ISBN: 978-90-369-5761-8.

Miwa, H., A. Daido, and I. Kato (1999a). Transformation of sand waves under unsteady conditions in alluvial streams. In: A. W. Jayawardena, J. H. W. Lee, and Z. Y. Wang (Eds.), Proc. of the rth International Symposium on River Sedimentation, Theory and Applications, pp. 211-216, Hong Kong, China. Balkema, Rotterdam, the Netherlands.

Miwa, H., A. Daido, and I. Kato (1999b). Sand wave transformation due to change of water discharge in graded and uniform sediment beds. In: Proceedings of IAHR Symposium on River, Coastal and Estuarine Morphodynamics, Genova, Italy, pp. 293-302.

Miwa, H., A. Daido, and I. Kato (2001). Sand wave transformation with sediment sorting. In: Proceedings of the 8th International Symposium on River Sedimentation, Cairo, Egypt.

Momiji, H. and S. R. Bishop (2002). Estimating the windward slope profile of a barchan dune. Sedimentology, 49, pp. 467-481.

Morvan, H., D. Knight, N. Wright, X. Tang, and A. Crossley (2008). The concept of roughness in fluvial hydraulics and its formulation in 1D, 2D and 3D numerical simulation models. Journal of Hydraulic Research, 46 (2), pp. $191-208$.

Nakagawa, H. and I. Nezu (1987). Experimental investigation on turbulent structure of backward-facing step flow in an open channel. Journal of Hydraulic Research, 25, pp. 67-88.

Nelson, J. M., S. R. McLean, and S. R. Wolfe (1993). Mean flow and turbulence fields over 2-dimensional bed forms. Water Resources Research, 29 (12), pp. 3935-3953. 
Nelson, J. M., R. L. Schreve, S. R. McLean, and T. Drake (1995). Role of near-bed turbulence structure in bedload transport and bedform mechanics. Water Resources Research, 31 (8), pp. 2071-2086.

Nelson, J. M., A. R. Burman, Y. Shimizu, S. R. McLean, R. L. Shreve, and M. Schmeeckle (2005). Computing flow and sediment transport over bedforms. In: G. Parker and M. H. Garcia (Eds.), Proceedings of the $4^{\text {th }}$ IAHR Symposium on River, Coastal and Estuarine Morphodynamics, Urbana, Illinois, USA, Vol. 2, pp. 861-872. Taylor \& Francis Group, London.

Németh, A. A., S. J. M. H. Hulscher, and R. M. J. Van Damme (2006). Simulating offshore sand waves. Coastal Engineering, 53, pp. 265-275, doi:10.1016/j.coastaleng.2005.10.014.

Németh, A. A., S. J. M. H. Hulscher, and R. M. J. Van Damme (2007). Modelling offshore sand wave evolution. Continental Shelf Research, 27 (5), pp. 713-728, doi:10.1016/j.csr.2006.11.010.

Niño, Y., A. Atala, M. Barahona, and D. Aracena (2002). Discrete particle model for analyzing bedform development. Journal of Hydraulic Engineering, 128 (4), pp. 381-389, doi:10.1061/(ASCE)0733-9429(2002)128:4(381).

Noordam, D. (2006). Hydraulic resistance in rivers and related uncertainties. Civil Engineering \& Management research report 2006R-005/WEM-006 (ISSN: 1568-4652), University of Twente, Enschede, the Netherlands.

Ogink, H. J. M. (1988). Hydraulic roughness of bedforms. Rep. M2017, Delft Hydraulics Laboratory, Delft, the Netherlands.

Onda, S. and T. Hosoda (2004). Numerical simulation on development process of dunes and flow resistance. In: M. Greco, A. Carravetta, and R. Della Morte (Eds.), Proc. of River Flow 2004, Napoli, Italy, Vol. 1, pp. 245-252. Balkema, Leiden, the Netherlands.

Paarlberg, A. J. (2007). Modelnauwkeurigheid en -onzekerheden van in Nederland toegepaste hydraulische modellen; Verslag van interviews met waterbeheerders en modelexperts (in Dutch). Civil Engineering \& Management research report 2007R-001/WEM-001 (ISSN 1568-4652), University of Twente, Enschede, the Netherlands.

Paarlberg, A. J., C. M. Dohmen-Janssen, S. J. M. H. Hulscher, and A. P. P. Termes (2005). A parameterization for flow separation in a river dune development model. In: Parker and Garcia (Eds.), Proc. of the $4^{\text {th }}$ IAHR symposium on River, Coastal and Estuarine Morphodynamics, Urbana, Illinois, USA, Vol. 2, pp. 883-895. Taylor \& Francis Group, London.

Paarlberg, A. J., C. M. Dohmen-Janssen, S. J. M. H. Hulscher, J. Van den Berg, and A. P. P. Termes (2006). Modelling morphodynamic evolution of river dunes. In: Ferreira, Alves, Leal, and Corsado (Eds.), Proceedings of the 
River flow 2006 conference, Lisbon, Portugal, pp. 969-978. Taylor \& Francis Group, London.

Paarlberg, A. J., C. M. Dohmen-Janssen, S. J. M. H. Hulscher, and P. Termes (2007). A parameterization of flow separation over subaqueous dunes. Water Resources Research, 43 (W12417), doi:10.1029/2006WR005425.

Paarlberg, A. J., C. M. Dohmen-Janssen, S. J. M. H. Hulscher, and A. P. P. Termes (subm.). Modelling river dune evolution using a parameterization of flow separation. Submitted to Journal of Geophysical Research - Earth Surface.

Parsons, D. R., J. L. Best, O. Orfeo, R. J. Hardy, R. Kostaschuk, and S. N. Lane (2005). Morphology and flow fields of three-dimensional dunes, Rio Paraná, Argentina: Results from simultaneous multibeam echo sounding and acoustic Doppler current profiling. Journal of Geophysical Research, 110 (F04S03), doi:10.1029/2004JF000231.

Perumal, M., K. B. Shrestha, and U. C. Chaube (2004). Reproduction of hysteresis in rating curves. Journal of Hydraulic Engineering, 130 (9), pp. 870878, doi:10.1061/(ASCE)0733-9429(2004)130:9(870).

Prandle, D. (1982). The vertical structure of tidal currents and other oscillatory flows. Continental Shelf Research, 1 (2), pp. 191-207.

Prandtl, L. (1925). Bericht über Untersuchungen zur ausgebildeten Turbulenz. Angew. Math, Meth., 5, pp. 136-139.

Prent, M. T. H. and E. J. Hickin (2001). Annual regime of bedforms, roughness and flow resistance, Lillooet River, British Columbia, BC. Geomorphology, 41, pp. 369-390, doi:10.1016/S0169-555X(01)00068-X.

Raudkivi, A. J. (1963). Study of sediment ripple formation. Journal of the Hydraulics Division, ASCE, 89 (6), pp. 15-33.

Reynolds, A. J. (1965). Waves on the erodible bed of an open channel. Journal of Fluid Mechanics, 22, pp. 113-133.

Richards, K. J. (1980). The formation of ripples and dunes on an erobible bed. Journal of Fluid Mechanics, 99, pp. 597-618.

Roden, J. E. (1998). The Sedimentology and Dynamics of Mega-Dunes, Jamuna River, Bangladesh. Unpublished PhD thesis, Department of Earth Sciences and School of Geography, University of Leeds, 310 pp.

Roos, P. C., S. J. M. H. Hulscher, F. M. van der Meer, T. A. G. P. van Dijk, I. G. M. Wientjes, and J. van den Berg (2007). Grain size soring over offshore sandwaves: observations and modelling. In: Dohmen-Janssen and Hulscher (Eds.), Proc. of the $5^{\text {th }}$ IAHR symposium on River, Coastal and Estuarine Morphodynamics, Enschede, the Netherlands, Vol. 1, pp. 649-656. Taylor \& Francis Group, London. 
Sauermann, G., P. Rognon, A. Poliakov, and H. J. Herrmann (2000). The shape of the barchan dunes of southern morocco. Geomorphology, 36, pp. 47-62.

Sauermann, G., J. S. Andrade Jr, L. P. Maia, U. M. S. Costa, A. D. Araújo, and H. J. Herrmann (2003). Wind velocity and sand transport on a barchan dune. Geomorphology, 54, pp. 245-255.

Schatz, V. and H. J. Herrmann (2006). Flow separation in the lee side of transverse dunes: A numerical investigation. Geomorphology, 81, pp. 207216, doi:10.1016/j.geomorph.2006.04.009.

Schramkowski, G. P. and H. E. de Swart (2002). Morphodynamic equilibrium in straight tidal channels: Combined effects of Coriolis force and external overtides. Journal of Geophysical Research, 107 (C12, 3227), doi:10.1029/2000JC000693.

Schwämmle, V. and H. J. Herrmann (2004). Modelling transverse dunes. Earth Surface Processes and Landforms, 29, pp. 769-784.

Sekine, M. and G. Parker (1992). Bed-load transport on transverse slope. Journal of Hydraulic Engineering, 118 (4), pp. 513-535.

Sharp, R. P. (1963). Wind ripples. Journal of Geology, 71, pp. 617-636.

Sieben, J. (2003). Estimation of effective hydraulic roughness on non-uniform flow. In: J. Ganoulis and P. Prinos (Eds.), Proceedings $30^{\text {th }}$ IAHR-congres, Thessaloniki, Greece, Vol. II, Theme C, pp. 17-24.

Simons, D. B. and E. V. Richardson (1963). Forms of bed roughness in alluvial channels. Trans. Am. Soc. Civ. Eng., 128 (1), pp. 284-323.

Simons, D. B. and E. V. Richardson (1966). Resistance to flow in alluvial channels. Geological survey professional paper 422-J, U.S. Department of the Interior, Washington, D.C., 61 pp.

Smith, J. D. (1970). Stability of a sand bed subjected to a shear flow of low Froude number. Journal of Geophysical Research, 75, pp. 5928-5940.

Smith, J. D. and S. R. McLean (1977). Spatially-averaged flow over a wavy surface. Journal of Geophysical Research, 82, pp. 1735-1746.

Soulsby, R. L. (1990). Tidal-current boundary layers. In: B. Le Mehaute and D. Hanes (Eds.), The Sea, Volume 9, Ocean Engineering Science, pp. 523566, New York. Wiley.

Stansby, P. K. and J. G. Zhou (1998). Shallow water flow solver with nonhydrostatic pressure: 2D vertical plane problems. International Journal of Numerical Methods in Fluids, 28, pp. 541-563. 
Sumer, B. M., L. H. C. Chua, N. S. Cheng, and J. Fredsøe (2003). Influence of turbulence on bed load sediment transport. Journal of Hydraulic Engineering, 129 (8), pp. 585-596, doi:10.1061/(ASCE)0733-9429(2003)129:8(585).

Ten Brinke, W. B. M., A. W. E. Wilbers, and C. Wesseling (1999). Dune growth, decay and migration rates during a large-magnitude flood at a sand and mixed sand-gravel bed in the Dutch Rhine river system. Spec. Pub., Int. Assoc. Sediment., 28, pp. 15-32.

Termes, A. P. P. (1984). Water movement over a horizontal bed and solitary sand dune. Rep. No. R/1984/H/8, Delft Univ. Tech., Delft, the Netherlands.

Termes, A. P. P. (2004). Herziening Qh-relaties Venlo en Megen en afleiding Qh-relaties Belfeld-beneden en Lith-boven. Tech. Rep. PR902 (in Dutch), HKV Consultants, Lelystad, the Netherlands.

Tjerry, S. and J. Fredsøe (2005). Calculation of dune morphology. Journal of Geophysical Research, 110 (F04013), doi:10.1029/2004JF000171.

Udo, J., M. Bakker, and P. Termes (2007). SOBEK-model Rijn; hydraulische calibratie. Report PR1158 (in Dutch), HKV Lijn in water, Lelystad, the Netherlands.

Van den Berg, J. (2007). Non-linear sand wave evolution. PhD thesis, University of Twente, the Netherlands.

Van den Berg, J. and R. Van Damme (2005). Sand wave simulation on large domains. In: Parker and Garcia (Eds.), Proc. of the $4^{\text {th }}$ IAHR symposium on River, Coastal and Estuarine Morphodynamics, Urbana, Illinois, USA, Vol. 2, pp. 991-997. Taylor \& Francis Group, London.

Van den Brink, N. G. M., D. Beyer, M. J. M. Scholten, and E. H. van Velzen (2006). Onderbouwing hydraulische randvoorwaarden 2001 van de Rijn en zijn takken. RIZA report 2002.015 (in Dutch), RIZA, the Netherlands.

Van der Klis, H. (2003). Uncertainty Analysis applied to Numerical Models or River Bed Morphology. PhD thesis, University of Delft, Delft, the Netherlands.

Van der Mark, C. F., A. Blom, and S. J. M. H. Hulscher (2007). Variability in bedform characteristics using flume and river data. In: Dohmen-Janssen and Hulscher (Eds.), Proc. of the $5^{\text {th }}$ IAHR symposium on River, Coastal and Estuarine Morphodynamics, Urbana, Illinois, USA, Vol. 2, pp. 923-930. Taylor \& Francis Group, London.

Van der Meer, F., S. J. M. H. Hulscher, and J. Van den Berg (2007). On the influence of suspended sdiment transport on the generation of offshore sand waves. In: B. J. Geurts, H. Clercx, and W. Uijttewaal (Eds.), ParticleLaden Flow - From Geophysical to Kolmogorov Scales, Vol. 11 of ERCOFTAC Series, pp. 29-41. Springer. Dordrecht, the Netherlands. 
Van der Veen, R., U. Pakes, and L. Schutte (2002a). Bouw en calibratie SOBEKMaas. versie 2000.1 t/m 2000.3. RIZA Rapport 2002.031 (in Dutch).

Van der Veen, R., U. Pakes, and L. Schutte (2002b). Bouw en calibratie SOBEKRijn. versie 2000.1 t/m 2000.3. RIZA Rapport 2002.039 (in Dutch).

Van Mierlo, M. C. L. M. and J. C. C. De Ruiter (1988). Turbulence measurements above artificial dunes; Report on measurements. Report Q789, WL | Delft Hydraulics, Delft, the Netherlands.

Van Rijn, L. C. (1984). Sediment transport, part III: Bed forms and alluvial roughness. Journal of Hydraulic Engineering, 110 (12), pp. 1733-1754.

Van Rijn, L. C. (1993). Principles of sediment transport in rivers, estuaries and coastal seas. AQUA Publications, Amsterdam, 335 pp.

Van Velzen, E. H., P. Jesse, P. Cornelissen, and H. Coops (2003). Stromingsweerstand vegetatie in uiterwaarden; handboek versie 1-2003. RIZA Report 2003.028/029 (in Dutch), RIZA, Arnhem, the Netherlands.

Van Vuren, S., H. J. de Vriend, S. Ouwekerk, and M. Kok (2005). Stochastic modelling of the impact of flood protection measures along the River Waal in the Netherlands. Natural Hazards, 36, pp. 81-102.

Vanoni, V. A. and L. S. Hwang (1967). Relation between bed forms and friction in streams. Journal of the Hydraulic Division, ASCE, 93, pp. 121-144.

Venditti, J. G. (2003). Initiation and development of sand dunes in river channels. PhD thesis, University of Britisch Columbia, Canada.

Venditti, J. G. (2007). Turbulent flow and drag over fixed two- and threedimensional dunes. Journal of Geophysical Research, 112 (F04008), pp. 1-21, doi:10.1029/2006JF000650.

Venditti, J. G., M. A. Church, and S. J. Bennett (2005). Bed form initiation from a flat sand bed. Journal of Geophysical Research, 110 (F01009), doi:10.1029/2004JF000149.

Vidal, J.-P., S. Moisan, J.-B. Faure, and D. Dartus (2007). River model calibration, from guidelines to operational support tools. Environmental Modelling Es Software, 22, pp. 1628-1640, doi:10.1016/j.envsoft.2006.12.003.

Vittal, N. (1972). Flow over triangular roughnesses in open channels. PhD thesis, University of Roorkee, India.

Walker, I. J. and W. G. Nickling (2002). Dynamics of secondary airflow and sediment transport over and in the lee of transverse dunes. Progress in Physical Geography, 26 (1), pp. 47-75, doi:10.1191/0309133302pp325ra. 
Warmink, J. J., M. J. Booij, H. van der Klis, and S. J. M. H. Hulscher (2007). Uncertainty in water level predictions due to various calibrations. In: C. PahlWostl (Ed.), Proc. CAIWA 2007, 12-15 November 200\%, Basel, Switserland, pp. $1-18$.

Wasantha Lal, A. M. (1995). Calibration of riverbed roughness. Journal of Hydraulic Engineering, 121 (9), pp. 664-671.

Werner, B. T. (1995). Eolian dunes: computer simulations and attractor interpretation. Geology, 23, pp. 1107-1110.

Werner, M. (2004). Spatial flood extent modelling; A performance-based comparison. PhD thesis, Delft University of Technology, Delft, the Netherlands.

Wijbenga, J. H. A. (1990). Flow resistance and bedform dimensions for varying flow conditions; a literature review (main text and annexes). TOW Rivers Report Q785, WL | Delft Hydraulics, Delft, the Netherlands.

Wijbenga, J. H. A. and G. J. Klaassen (1983). Changes in bed form dimensions under unsteady flow conditions in a straight flume. Spec. Publs. Int Ass. Sediment, 6, pp. 35-48.

Wijbenga, J. H. A. and A. R. Van Nes (1986). Flow resistance and bedform dimensions for varying flow conditions; results of flume experiments with flood waves. TOW rivers R 567 - XXV / M 1314 part XIII, WL | Delft Hydraulics, Delft, the Netherlands.

Wijbenga, J. H. A., M. T. Duits, and J. M. Van Noortwijk (1998). Parameter optimisation for two-dimensional flow modelling. In: V. Babovic and L. C. Larsen (Eds.), Proceedings of the Third International Conference on Hydroinformatics, Copenhagen, Denmark, pp. 1037-1042. Balkema, Rotterdam, the Netherlands.

Wilbers, A. W. E. (2004). The development and hydraulic roughness of subaqueous dunes. PhD thesis, University of Utrecht, the Netherlands.

Wilbers, A. W. E. and W. B. M. Ten Brinke (2003). The response of subaqueous dunes to floods in sand and gravel bed reaches of the Dutch Rhine. Sedimentology, 50, pp. 1013-1034, doi:10.1046/j.1365-3091.2003.00585.x.

Williams, P. G. (1970). Flume width and water depth effects in sediment transport experiments. Geological survey professional paper 562-H, U.S. Department of the Interior, Washington, D.C.

Wong, M. and G. Parker (2006). Reanalysis and correction of bed-load relation of Meyer-Peter and Müller using their own database. Journal of Hydraulic Engineering, 132 (11), pp. 1159-1168, doi:10.1061/(ASCE)07339429(2006)132:11(1159). 
Yalin, M. S. (1964). Geometrical properties of sand waves. Journal of the Hydraulics Division, ASCE, 90 (5), pp. 105-119.

Yalin, M. S. (1972). Mechanics of sediment transport. Pergamon Press, New York.

Yamaguchi, S. and N. Izumi (2002). Weakly nonlinear stability analysis of dune formation. In: D. Bousmar and Y. Zech (Eds.), Proc. of River Flow 2002, pp. 843-850. Swets and Zeitlinger, Lisse, the Netherlands.

Yizhaq, H., N. J. Balmforth, and A. Provenzale (2004). Blown by wind: nonlinear dynamics of aeolian sand ripples. Physica D: Nonlinear Phenomena, 195 (Issues 3-4), pp. 207-228, doi:10.1016/j.physd.2004.03.015.

Yoon, J. Y. and V. C. Patel (1996). Numerical model of turbulent flow over sand dune. Journal of Hydraulic Engineering, 122 (1), pp. 10-18.

Yossef, M. F. M. (2005). Morphodynamics of rivers with groynes. Isbn 90-4072606-x / delft university press / delft hydraulics select series 7 (isbn 90-4072607-8)., Delft University of Technology, the Netherlands.

Yue, W., C.-L. Lin, and V. C. Patel (2006). Large-eddy simulation of turbulent flow over a fixed two-dimensional dune. Journal of Hydraulic Engineering, 132 (7), pp. 643-651, doi:10.1061/(ASCE)0733-9429(2006)132:7(643).

Zeman, O. and N. O. Jensen (1987). Modification of turbulence characteristics in flow over hills. Quarterly Journal of the Royal Meteorological Society, 113 (475), pp. 55-80.

Zhou, D. and C. Mendoza (2005). Growth model for sand wavelets. Journal of Hydraulic Engineering, 131 (10), pp. 866-876, doi:10.1061/(ASCE)07339429(2005)131:10(866). 


\section{Nomenclature}

\section{General}

... $\quad$ unscaled quantity (used in appendix of Chapter 3)

.. transformed variable

.. $\quad$ parameter averaged over flood wave

$\therefore$ nondimensional parameter

\section{Roman}

$\begin{array}{lll}a_{0} \ldots a_{3} & \text { coefficients for parameterized shear stress distribution } & {[-]} \\ A_{\mathrm{v}} & \text { (vertical) eddy viscosity } & {\left[\mathrm{m}^{2} \mathrm{~s}^{-1}\right]} \\ b & \text { flume width } & {[\mathrm{m}]} \\ C_{\mathrm{m}} & \text { Chézy coefficient of main channel } & {\left[\mathrm{m}^{1 / 2} \mathrm{~s}^{-1}\right]} \\ \mathrm{dx} & \text { horizontal grid distance } & {[\mathrm{m}]} \\ \mathrm{dt} & \text { time step } & {[\mathrm{s}]} \\ D_{50} & \text { median grain size } & {[\mathrm{m}]} \\ D_{90} & \text { grain size for which } 90 \% \text { of the sand (by weight) is } & {[\mathrm{m}]} \\ & \text { smaller } & {[-]} \\ E_{\mathrm{p}} & \text { relative error of parameterized separation streamline } & {[-]} \\ \text { Fr } & \text { Froude number, } \frac{U}{\sqrt{g h}} & {\left[\mathrm{~m} \mathrm{~s}{ }^{-2}\right]} \\ g & \text { acceleration due to gravity } & {[\mathrm{m}]} \\ h & \text { average water depth } & {[\mathrm{m}]} \\ h_{\mathrm{i}} & \text { initial water depth } & {[\mathrm{m}]} \\ h_{\mathrm{diff}} & \text { difference in water depth between SoBEK model } & \\ & \text { using computed or calibrated roughness values } & {[\mathrm{m}]} \\ h_{\mathrm{e}} & \text { water depth in equilibrium } & {[\mathrm{m}]} \\ h_{\mathrm{m}} & \text { water depth in main channel } & \end{array}$


$H_{\mathrm{d}} \quad$ bedform height (measured from crest to trough) [m]

$H_{\mathrm{b}} \quad$ brinkpoint height (measured from brinkpoint to trough) [m]

$i \quad$ channel or flume slope $\quad[-]$

$k \quad$ turbulent kinetic energy $\quad\left[\mathrm{m}^{2} \mathrm{~s}^{-2}\right]$

$k_{\mathrm{m}} \quad$ Nikuradse roughness height of main channel $\quad[\mathrm{m}]$

$k_{\text {dunes }} \quad$ Nikuradse roughness height of dunes [m]

$k_{\text {grains }} \quad$ Nikuradse roughness height of grains $[\mathrm{m}]$

$k_{\text {uncertain }}$ uncertain part contributing to Nikuradse roughness [m]

height of main channel

$L \quad$ (arbitrary) flow length scale $[\mathrm{m}]$

$L_{\mathrm{d}} \quad$ bedform length (measured from crest to crest) [m]

$L_{\text {dom }} \quad$ length of periodic domain $[\mathrm{m}]$

$L_{\mathrm{s}} \quad$ length of flow separation zone $[\mathrm{m}]$

$L_{\mathrm{st}} \quad$ length of flow separation zone measured from $x_{\mathrm{s}}$ to $x_{\mathrm{rt}} \quad[\mathrm{m}]$

$L_{\mathrm{st}}^{\prime} \quad$ nondimensional length of flow separation zone, $\frac{L_{\mathrm{st}}}{H_{b}} \quad[-]$

$m \quad$ bed load efficiency parameter $\quad[-]$

$M_{\mathrm{e}} \quad$ migration rate in equilibrium $\quad\left[\mathrm{m} \mathrm{hr}^{-1}\right]$

$n \quad$ power in bed load transport equation [-]

$\mathbf{n}_{\mathrm{b}} \quad$ unit vector normal to bed $\quad[-]$

$\mathbf{n}_{\mathrm{s}} \quad$ unit vector normal to water surface $\quad[-]$

Npx number of grid-points in $x$-direction [-]

$\mathrm{Npz} \quad$ number of grid-points in $z$-direction $\quad[-]$

$N_{\mathrm{p}} \quad$ number of points on the separation streamline to determine regression (not including separation point)

$N_{\mathrm{s}} \quad$ number of observations in a slope-class $\quad[-]$

$p \quad$ pressure $\quad\left[\mathrm{N} \mathrm{m}^{-2}\right]$

$\begin{array}{lll}p_{\mathrm{a}} & \text { atmospheric pressure } & {\left[\mathrm{N} \mathrm{m}^{-2}\right]}\end{array}$

$q \quad$ specific discharge $\quad\left[\mathrm{m}^{2} \mathrm{~s}^{-1}\right]$

$q_{\mathrm{b}} \quad$ bed load transport rate per unit of width $\quad\left[\mathrm{m}^{2} \mathrm{~s}^{-1}\right]$

$q_{\text {comp }} \quad$ specific discharge in computation $\quad\left[\mathrm{m}^{2} \mathrm{~s}^{-1}\right]$

$q_{\text {expt }} \quad$ specific discharge in experiment $\quad\left[\mathrm{m}^{2} \mathrm{~s}^{-1}\right]$

$Q_{\mathrm{b}} \quad$ (arbitrary) bed load scale factor $\quad\left[\mathrm{m}^{2} \mathrm{~s}^{-1}\right]$

$Q_{\text {min }} \quad$ minimum discharge in a flood wave $\quad\left[\mathrm{m}^{3} \mathrm{~s}^{-1}\right]$

$Q_{\max } \quad$ maximum discharge in a flood wave $\quad\left[\mathrm{m}^{3} \mathrm{~s}^{-1}\right]$

$Q_{\text {sep }} \quad$ volumetric sediment transport passing flow separation $\quad\left[\mathrm{m}^{2} \mathrm{~s}^{-1}\right]$ 
point per unit of width

$R \quad$ coefficient of determination $[-]$

Re Reynolds number, $\frac{U h}{\nu} \quad[-]$

$s(x) \quad$ vertical position of separation streamline [m]

$\tilde{s}(\xi) \quad$ nondimensional separation streamline, $\frac{s}{H_{b}} \quad[-]$

$s_{0} \ldots s_{3} \quad$ coefficients for separation streamline $\quad[-]$

$S \quad$ resistance parameter $\quad\left[\mathrm{m} \mathrm{s}^{-1}\right]$

$t$ time [s]

$T_{\text {adv }} \quad$ advective time scale, $\frac{L}{U} \quad[\mathrm{~s}]$

$T_{\text {mor }} \quad$ morphological time scale, $\frac{L h}{Q_{\mathrm{b}}} \quad[\mathrm{s}]$

$T_{\mathrm{e}} \quad$ time to equilibrium [s]

T shear stress tensor $\left[\mathrm{m}^{2} \mathrm{~s}^{-2}\right]$

$u \quad$ flow velocity in $x$-direction $\quad\left[\mathrm{m} \mathrm{s}^{-1}\right]$

$u_{*} \quad$ shear velocity, $\sqrt{g h i} \quad\left[\mathrm{~m} \mathrm{~s}^{-1}\right]$

$U \quad$ average horizontal flow velocity $\left[\mathrm{m} \mathrm{s}^{-1}\right]$

$V \quad$ vorticity, $\frac{\partial u}{\partial z}-\frac{\partial w}{\partial x} \quad\left[\mathrm{~s}^{-1}\right]$

$w \quad$ flow velocity in $z$-direction $\quad\left[\mathrm{m} \mathrm{s}^{-1}\right]$

$x \quad$ horizontal streamwise coordinate [m]

$x_{\mathrm{b}} \quad x$-coordinate of brinkpoint $\quad[\mathrm{m}]$

$x_{\mathrm{d}} \quad x$-coordinate where leeside starts $\quad[\mathrm{m}]$

$x_{\mathrm{m}} \quad x$-coordinate of point of maximum bed shear stress $\quad[\mathrm{m}]$

$\begin{array}{lll}x_{\mathrm{r}} & x \text {-coordinate of flow reattachment point } & {[\mathrm{m}]}\end{array}$

$x_{\mathrm{rt}} \quad$ location where separation streamline would intersect a $\quad[\mathrm{m}]$

flat bed whose elevation is the same as trough elevation

$x_{\mathrm{s}} \quad x$-coordinate of the flow separation point $\quad[\mathrm{m}]$

$z \quad$ vertical coordinate $\quad[\mathrm{m}]$

$z_{\mathrm{b}} \quad$ bed elevation $[\mathrm{m}]$

$z_{\mathrm{p}} \quad$ parameterized bed topography [m]

$z_{\mathrm{par}} \quad$ vertical position of parameterized separation streamline $\quad[\mathrm{m}]$

$\begin{array}{lll}z_{\text {sep }} & \text { vertical position of fitted separation streamline }\end{array}$ 


\section{Greek}

$\alpha$

$\alpha_{\mathrm{s}}$

$\alpha_{\mathrm{rt}}$

$\beta_{1}$

$\beta_{2}$

$\gamma$

$\delta$

$\delta_{1}$

$\delta_{2}$

$\delta_{q}$

$\delta_{\tau}$

$\Delta$

$\Delta_{\mathrm{i}}$

$\Delta_{\mathrm{e}}$

$\Delta_{\max }$

$\epsilon_{\mathrm{p}}$

$\varepsilon$

$\zeta$

$\eta$

$\theta_{\mathrm{c} 0}$

$\kappa$

$\lambda$

$\lambda_{\mathrm{e}}$

$\lambda_{\text {fgm }}$

$\mu_{\mathrm{p}}$

$\nu$

$\xi$ bed load proportionality constant, $\frac{m}{\left(\rho_{\mathrm{s}} / \rho_{\mathrm{w}}-1\right) g}$

bed slope at $x_{\mathrm{s}}$

slope of the separation streamline at $x_{\mathrm{rt}}$

calibration parameter for eddy viscosity $A_{\mathrm{v}}$

calibration parameter for resistance parameter $S$

dune shape factor or roughness correction factor

threshold for roughness feedback, $10 \%$

aspect ratio, $\frac{h}{L}$

ratio of advective time scale to morphological

time scale, $\frac{T_{\mathrm{adv}}}{T_{\mathrm{mor}}}$

displacement between maximum flux and dune crest

displacement between maximum bed shear stress

and dune crest

dune height

initial dune height

dune height in equilibrium

maximum dune height

sediment porosity

turbulent diffusion

water surface elevation

bed slope correction factor, $\frac{1}{\tan \varphi}$

critical Shields parameter for flat bed

Von Kármán constant

dune length

dune length in equilibrium

length of fastest growing mode

mean value of $E_{\mathrm{p}}$

kinematic viscosity

nondimensional distance away from the

separation point, $\frac{x-x_{\mathrm{s}}}{H_{\mathrm{b}}}$ $[\mathrm{m}]$

[m]

[m]

[m]

$\left[\mathrm{s}^{2} \mathrm{~m}^{-1}\right]$

[-]

[-]

[-]

[-]

[-]

[-]

[m]

[m]

[-]

$\left[\mathrm{m}^{2} \mathrm{~s}^{-3}\right]$

[m]

[-]

[-]

[-]

[m]

[m]

[m]

[-]

$\left[\mathrm{m}^{2} \mathrm{~s}^{-1}\right]$

[-] 


$\begin{array}{lll}\rho_{\mathrm{w}} & \text { density of water } & {\left[\mathrm{kg} \mathrm{m}^{-3}\right]} \\ \rho_{\mathrm{s}} & \text { density of sediment } & {\left[\mathrm{kg} \mathrm{m}^{-3}\right]} \\ \sigma_{\mathrm{p}} & \text { standard deviation of } E_{\mathrm{p}} & {[-]} \\ \tau & \text { (volumetric) shear stress } & {\left[\mathrm{m}^{2} \mathrm{~s}^{-2}\right]} \\ \tau_{\mathrm{b}} & \text { (volumetric) shear stress at the bed } & {\left[\mathrm{m}^{2} \mathrm{~s}^{-2}\right]} \\ \tau_{\mathrm{A}} & \text { shear stress factor at flow reattachment point for } a_{1} & {[-]} \\ \tau_{\mathrm{c}} & \text { critical bed shear stress corrected for sloping bed } & {\left[\mathrm{m}^{2} \mathrm{~s}^{-2}\right]} \\ \tau_{\mathrm{c} 0} & \text { critical bed shear stress for flat bed } & {\left[\mathrm{m}^{2} \mathrm{~s}^{-2}\right]} \\ \tau_{\mathrm{m}} & \text { bed shear stress at } x_{\mathrm{m}} & {\left[\mathrm{m}^{2} \mathrm{~s}^{-2}\right]} \\ \tau_{\mathrm{p}} & \text { parameterized bed shear stress distribution in case of } & {\left[\mathrm{m}^{2} \mathrm{~s}^{-2}\right]} \\ & \text { flow separation } & \\ \varphi & \text { angle of repose of the sediment } & {\left[{ }^{\circ}\right]}\end{array}$

\section{Abbreviations}

1-D 1-dimensional

2-D 2-dimensional

2-DV 2-dimensional in vertical plane

2-DH 2-dimensional in horizontal plane

3-D 3-dimensional

BP broad peaked flood wave

FGM fastest growing mode (= fastest growing wave length)

FRP flow reattachment point

FSP flow separation point

FSZ flow separation zone

subm. submitted

SP sharp peaked flood wave 



\section{List of publications}

\section{Peer reviewed journal papers}

Paarlberg, A. J., C. M. Dohmen-Janssen, S. J. M. H. Hulscher, R. M. J. Schielen, and A. P. P. Termes (in preparation). Modelling dynamic roughness in rivers during floods.

Paarlberg, A. J., C. M. Dohmen-Janssen, S. J. M. H. Hulscher, and A. P. P. Termes (conditionally accepted). Modelling river dune evolution using a parameterization of flow separation. Journal of Geophysical Research.

Paarlberg, A. J., C. M. Dohmen-Janssen, S. J. M. H. Hulscher, and P. Termes (2007). A parameterization of flow separation over subaqueous dunes. Water Resources Research 43 (W12417).

Paarlberg, A. J., M. A. F. Knaapen, M. B. De Vries, S. J. M. H. Hulscher, and Z. B. Wang (2005). Biological influences on morphology and bed composition of an intertidal flat. Estuarine, Coastal and Shelf Science, (ISSN 0272-7714) 64(4), $577-590$

\section{Conference / Proceedings papers}

Paarlberg, A. J., C. M. Dohmen-Janssen, S. J. M. H. Hulscher, R. Schielen, and A. P. P. Termes (2008). Modelling dynamic roughness in rivers during floods. In D. R. Parsons, T. Garlan, and J. L. Best (Eds.), Proc. of the $3^{\text {rd }}$ workshop on Marine Sandwave and River Dune Dynamics (MARID), 1-3 April 2008, Leeds, $U K$, pp. 257-264.

Dohmen-Janssen, C. M., J. Lansink, A. J. Paarlberg, S. J. M. H. Hulscher, and A. P. P. Termes (2008). Modelling river dune splitting. In D. R. Parsons, T. Garlan, and J. L. Best (Eds.), Proc. of the $3^{\text {rd }}$ workshop on Marine Sandwave and River Dune Dynamics (MARID), 1-3 April 2008, Leeds, UK, pp. 79-86.

Friedrich, H., A. J. Paarlberg, and J. Lansink (2007). Evaluation of statistical properties of dune profiles. In Dohmen-Janssen and Hulscher (Eds.), Proc. of the $5^{\text {th }}$ IAHR symposium on River, Coastal and Estuarine Morphodynamics, Enschede, The Netherlands, Volume 2, pp. 913-921. Taylor \& Francis Group, London.

Paarlberg, A. J., C. M. Dohmen-Janssen, S. J. M. H. Hulscher, and A. P. P. Termes (2006). Modelling river dune development. In H. J. T. Weerts, I. L. Ritsema, and A. G. Van Os (Eds.), Proc. of NCR days 2005, Theme River and floodplain management, pp. 21-22. Delft: NCR.

Paarlberg, A. J., C. M. Dohmen-Janssen, S. J. M. H. Hulscher, J. Van den Berg, and A. P. P. Termes (2006). Modelling morphodynamic evolution of river dunes. In Ferreira, Alves, Leal, and Corsado (Eds.), Proc. of River flow 2006, Lisbon, Portugal, pp. 969-978. Taylor \& Francis Group, London. 
Paarlberg, A. J., C. M. Dohmen-Janssen, S. J. M. H. Hulscher, and A. P. P. Termes (2005). A parameterization for flow separation in a river dune development model. In Parker and Garcia (Eds.), Proc. of the $4^{\text {th }}$ IAHR symposium on River, Coastal and Estuarine Morphodynamics, Urbana, Illinois, USA, Volume 2, pp. 883-895. Taylor \& Francis Group, London.

Paarlberg, A. J., C. M. Dohmen-Janssen, S. J. M. H. Hulscher, and A. P. P. Termes (2004). Effect of main channel roughness on water levels. In B. Makaske and A. G. Van Os (Eds.), Proc. of NCR days 2004, (ISSN 1568-234X), Theme Sediments, Hydraulics and Morphology, pp. 106-107. NCR, Delft, the Netherlands.

De Vries, M. B., S. J. M. H. Hulscher, and A. J. Paarlberg (2004). Modelling biological influences on morphodynamics of intertidal areas. In Proc. of PECS 2004, Hydrodynamics and morphodynamics in estuaries and open seas, October 18-24, Mérida, Mexico.

\section{Scientific reports}

Paarlberg, A. J. (2007). Modelnauwkeurigheid en -onzekerheden van in Nederland toegepaste hydraulische modellen; Verslag van interviews met waterbeheerders en modelexperts (in Dutch). Civil Engineering \& Management research report 2007R-001/WEM-001 (ISSN 1568-4652), University of Twente.

Paarlberg, A. J., M. A. F. Knaapen, M. B. De Vries, S. J. M. H. Hulscher, and Z. B. Wang (2004). Biological influences on morphology and bed composition of an intertidal flat. WL Z2837 CE\&M res.rep. 2004W-005 / WEM 003, Delft: WL | Delft Hydraulics.

\section{Dutch magazines}

Dohmen-Janssen, C. M. and A. J. Paarlberg (2007a). Modelleren van rivierduinen. Concep Tueel 16(4), 6-9.

Dohmen-Janssen, C. M. and A. J. Paarlberg (2007b). Morfodynamisch model voor ontwikkeling van rivierduinen. Machazine (ISSN 1380-3476) 12(1), 24-25.

Hulscher, S. J. M. H., D. Noordam, and A. J. Paarlberg (2005). Onderzoekers buigen zich over bodemruwheid van rivieren. Land + Water 45(9), 24-25. 


\section{About the author}

Andries Jan Paarlberg was born on the $7^{\text {th }}$ of March 1980 in Alkmaar and grew up in Stroet, both in the Netherlands. He received his VWO diploma in 1998 from the Openbare Scholen Gemeenschap in Schagen. His interests for buildings and traffic lured him to the other side of the country to start with the study Civil Engineering \& Management at the University of Twente. Despite his interests for choosing this study, most of his masters courses focussed on the modelling of water systems. Andries performed his internship at the Università degli studi di Trento in Italy on modelling rainfall-runoff patterns and morphology of the river Noce in Northern Italy. His final Masters project was performed at WL | Delft Hydraulics on modelling biological influences on sediment stability and sediment redistribution on an intertidal flat in the Western Scheldt, the Netherlands.

After receiving his Master's degree, Andries conducted his $\mathrm{PhD}$ research at the Department of Water Engineering \& Management at the University of Twente, from November 2003 until April 2008. The research was performed in close cooperation with HKV consultants in Lelystad. At this moment, Andries is employed as advisor rivers and river management at $\mathrm{HKV}_{\text {CONSULTANTS }}$.

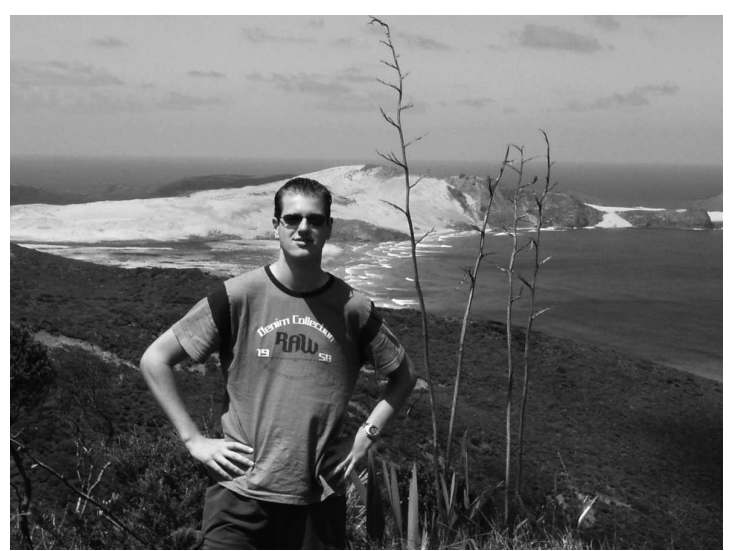

